NBER WORKING PAPER SERIES

\title{
COOPERATION IN THE COMMONS: \\ COMMUNITY-BASED RANGELAND MANAGEMENT IN NAMIBIA
}

\author{
D. Layne Coppock \\ Lucas Crowley \\ Susan L. Durham \\ Dylan Groves \\ Julian C. Jamison \\ Dean Karlan \\ Brien E. Norton \\ R. Douglas Ramsey \\ Working Paper 29469 \\ http://www.nber.org/papers/w29469 \\ NATIONAL BUREAU OF ECONOMIC RESEARCH \\ 1050 Massachusetts Avenue \\ Cambridge, MA 02138 \\ November 2021
}

The authors thank Nate Barker, Caton Brewster, Anais Dahmani, Pierre Durand, Alexander Fertig, Sam Hambira, Matthew Haufiku, Stephen Kulungu, Sayan Kundu, Peter Lugthart, Max Mauerman, Jared Otuke, Linda Papagallo, Amol Singh Raswan, Elvis Siyamba, Venoo Tjiseua, Delia Welsh, and Sandy Yuan for research assistance and project management; Leon Burger, Holly Dentz, and Cornelis van der Waal for their support implementing the cattle, qualitative, and rangeland data collection exercises, respectively; Helmke von Bach, Donald Green, John Huber, Indongo Indongo, Edmore Masaire, Colin Nott, Heinrich Pielok, and James Walsh for comments; and Johannes Beck, Algerlynn Gill, and Jack Molyneaux for feedback and support throughout the research process. This evaluation was made possible by funding from the Millennium Challenge Corporation. The opinions expressed herein are those of the authors and do not necessarily reflect the views of MCC or the U.S. government. The views expressed herein are those of the authors and do not necessarily reflect the views of the National Bureau of Economic Research.

NBER working papers are circulated for discussion and comment purposes. They have not been peer-reviewed or been subject to the review by the NBER Board of Directors that accompanies official NBER publications.

(C) 2021 by D. Layne Coppock, Lucas Crowley, Susan L. Durham, Dylan Groves, Julian C. Jamison, Dean Karlan, Brien E. Norton, and R. Douglas Ramsey. All rights reserved. Short sections of text, not to exceed two paragraphs, may be quoted without explicit permission provided that full credit, including $(\odot)$ notice, is given to the source. 
Cooperation in the Commons: Community-based Rangeland Management in Namibia D. Layne Coppock, Lucas Crowley, Susan L. Durham, Dylan Groves, Julian C. Jamison, Dean Karlan, Brien E. Norton, and R. Douglas Ramsey

NBER Working Paper No. 29469

November 2021

JEL No. O12,O13,P11,Q15,Q24

\section{ABSTRACT}

Classic theories suggest that common pool resources are subject to overexploitation. Communitybased resource management approaches may ameliorate "tragedy of the commons" effects. Using a randomized evaluation in Namibia's communal rangelands, we find that a comprehensive fouryear program to support community-based rangeland and cattle management led to persistent and large improvements for eight of thirteen indices of social and behavioral outcomes. Effects on rangeland health, cattle productivity and household economics, however, were either negative or nil. Positive impacts on community resource management may have been offset by communities' inability to control grazing by non-participating herds and inhibited by an unresponsive rangeland sub-system. This juxtaposition, in which measurable improvements in community resource management did not translate into better outcomes for households or rangeland health, demonstrates the fragility of the causal pathway from program implementation to intended socioeconomic and environmental outcomes. It also points to challenges for improving climate change-adaptation strategies.

D. Layne Coppock

Utah State University

Old Main Hill

Logan, UT 84322

layne.coppock@usu.edu

Lucas Crowley

228 Park Ave S, Suite 53674

Washington D.C. 20005

lukecrowley@gmail.com

Susan L. Durham

Utah State University

Old Main Hill

Logan, UT 84322

susan.durham@usu.edu

Dylan Groves

Columbia University

533 W. 218th St.

New York, NY 10034

dwg2115@columbia.edu
Julian C. Jamison

Department of Economics

University of Exeter Business School

Exeter EX4 4PU

United Kingdom

j.jamison@exeter.ac.uk

Dean Karlan

Kellogg Global Hub

Northwestern University

2211 Campus Drive

Evanston, IL 60208

and CEPR

and also NBER

dean.karlan@gmail.com

Brien E. Norton

Utah State University

Old Main Hill

Logan, UT 84322

brien_norton@comcast.net

R. Douglas Ramsey

Utah State University

Old Main Hill

Logan, UT 84322

doug.ramsey@usu.edu 
1 Title: Cooperation in the commons: Community-based rangeland

2 management in Namibia

D. Layne Coppock ${ }^{1}$, Lucas Crowley², Susan L. Durham ${ }^{3}$, Dylan Groves ${ }^{4}$, Julian C. Jamison ${ }^{5}$, Dean Karlan ${ }^{6 *}$, Brien E. Norton ${ }^{7}$, R. Douglas Ramsey ${ }^{7}$

$5 \quad{ }^{1}$ Department of Environment and Society, Utah State University, Logan, UT 84322-5215, USA.

${ }^{2}$ Innovations for Poverty Action, Washington D.C., 20005, USA.

${ }^{3}$ Ecology Center, Utah State University, Logan, UT 84322-5205, USA.

${ }^{4}$ Department of Political Science, Columbia University, New York City, NY, 10027, USA.

${ }^{5}$ Department of Economics, University of Exeter, Exeter EX44LZ, U.K.

${ }^{6}$ Kellogg School of Management, Northwestern University, Evanston, IL 60208, USA.

${ }^{7}$ Department of Wildland Resources, Utah State University, Logan, UT 84322-5230, USA.

*To whom correspondence should be addressed. E-mail: karlan@northwestern.edu 


\section{Main text}

In his seminal 1968 essay, "The Tragedy of the Commons," Garrett Hardin argued that poorly managed common resources are subject to overexploitation ${ }^{1}$. Hardin explained the tragedy of the commons using the metaphor of "a pasture open to all” in which each herd owner receives individual benefits from accumulating livestock while sharing the cost of overgrazing with other community members. This "natural" promotion of self-interest harms the common resource and ultimately brings ruin to all herders. Today, rangeland degradation is not only a textbook metaphor for the tragedy of the commons theory, but highly relevant globally: Drylands occupy $41 \%$ of the Earth's land area, support two billion people, and are experiencing rapid environmental degradation exacerbated by climate change, and in many cases attributable to overuse from livestock and crop agriculture ${ }^{2}$. Strategies for coping with impending climate change are critical for local and global policy.

Hardin concluded that the tragedy of the commons can be prevented only by coercive government regulation or resource privatization. However, Elinor Ostrom and other critics of Hardin's thesis have documented numerous communities that successfully developed local management systems to avoid overexploitation of commonly held resources, including rangelands $^{3-11}$. These findings have generated considerable enthusiasm for programs undertaken by governmental and non-governmental organizations that provide external support for holistic, community-based management of natural resources ${ }^{2,12,13}$.

But observing that some communities have developed successful systems of collective management does not mean that collective management instigated by outside organizations will succeed, and assessing the efficacy of such external interventions poses classic evaluation challenges. It is difficult to identify the impact of interventions because of external factors such as weather and macroeconomic conditions, and because of unobserved community or individual traits that drive both program participation and successful community management.

Measurement is difficult because impacts are expected across many domains of a socialecological system and at different points in time ${ }^{14}$. Related evidence from recent randomized evaluations suggests that community-driven programs can successfully deliver infrastructure and economic returns, but have less success sustainably affecting community governance and the creation of social capital ${ }^{15}$.

We evaluated an integrated program in Namibia's Northern Communal Areas (NCAs) that promoted improved rangeland and livestock management among cattle-owning households. To overcome attribution and measurement challenges, we conducted a large-scale, randomized evaluation and included multi-disciplinary measurement of behavioral, economic, livestock, and rangeland outcomes up to seven years after the program was initiated. The main questions posed were: (1) Can external support cause improvements in community resource management that persist two years after the support ends? (2) What is the effect of external support for community resource management on rangeland health, cattle productivity, and household well-being?

\section{Study context and design}

Namibia's NCAs have a population of about 1.2 million people, predominantly pastoralists and agro-pastoralists, who herd cattle and small ruminants using traditional methods and grow crops (i.e., millet, maize) under non-irrigated conditions ${ }^{16}$ Rangeland vegetation and soils have been degraded by pressure from growing populations and reduced herd mobility (see Supplementary Information section 2 for details). Low-input management results in uncoordinated livestock grazing and overuse of local resources. Resource management in the 
NCAs is further complicated by climate change ${ }^{17}$. For example, climate change may increase the prevalence of drought and bush encroachment, which are already destabilizing rangeland ecosystems in the NCAs ${ }^{2,18}$.

The economic and ecological challenges facing the NCAs are partially traceable to three established a veterinary cordon fence (VCF) separating the NCAs from southern Namibia to prevent the spread of livestock disease. Restrictions on movement and sale of livestock from northern to southern Namibia remain in place today, severely limiting the development of the formal livestock sector in the NCAs. Second, between 1897 and 1962, German and South African colonial authorities expropriated land from hundreds of thousands of black Namibians and relocated them to marginal communal lands known as "native reserves" on both sides of the VCF ${ }^{19,20}$. The native reserve policy restricted private land and capital accumulation by black Namibians and eroded customary land governance institutions in communal areas ${ }^{19,21}$. Finally, in 1962 the South African government, which took over the administration of Namibia from Germany following WWI, funded widespread borehole development in the NCAs to address growing political unrest. This dramatic expansion of water infrastructure, which was carried out with minimal concern for ecological consequences or investment in local resource governance, severed the link between grazing movements and the availability of natural water sources and catalyzed the growth of human and livestock populations, laying the groundwork for many of the ecological challenges that northern Namibia faces today ${ }^{16,22}$.

The Community Based Rangeland and Livestock Management program (CBRLM) was part of a four-year partnership between the Millennium Challenge Account-Namibia and the Government of Namibia to reduce rangeland degradation and promote economic development. From 2010 to 2014 the implementing partner, Gesellschaft für Organisation, Planung und Ausbildung (GOPA), worked with communities to jointly develop locally tailored rangeland grazing management, livestock management, and livestock marketing plans. GOPA then offered multi-faceted support to communities that established committees to coordinate and monitor these resource management plans. GOPA's support included water-infrastructure development, trainings on animal husbandry, livestock marketing, and rangeland management, livestock loans, matching grants, and technical assistance from trained field facilitators.

The rangeland management approach underlying CBRLM centered on combined herding and planned grazing. The program encouraged participating community members to combine household cattle herds into larger herds and rotate them among pre-planned sites within the grazing area. Planned rotation allows for vegetation rest and recovery and the establishment of dry-season fodder reserves, while combined herding improves grazing coordination and reduces the costs of herding. CBRLM field facilitators also encouraged enhanced livestock sales and flexible stocking rates to optimize grazing pressure. According to CBRLM's theory of change, improved management practices and enhanced cattle sales would improve communities' economic well-being while reducing the risk of rangeland degradation (see Methods). 


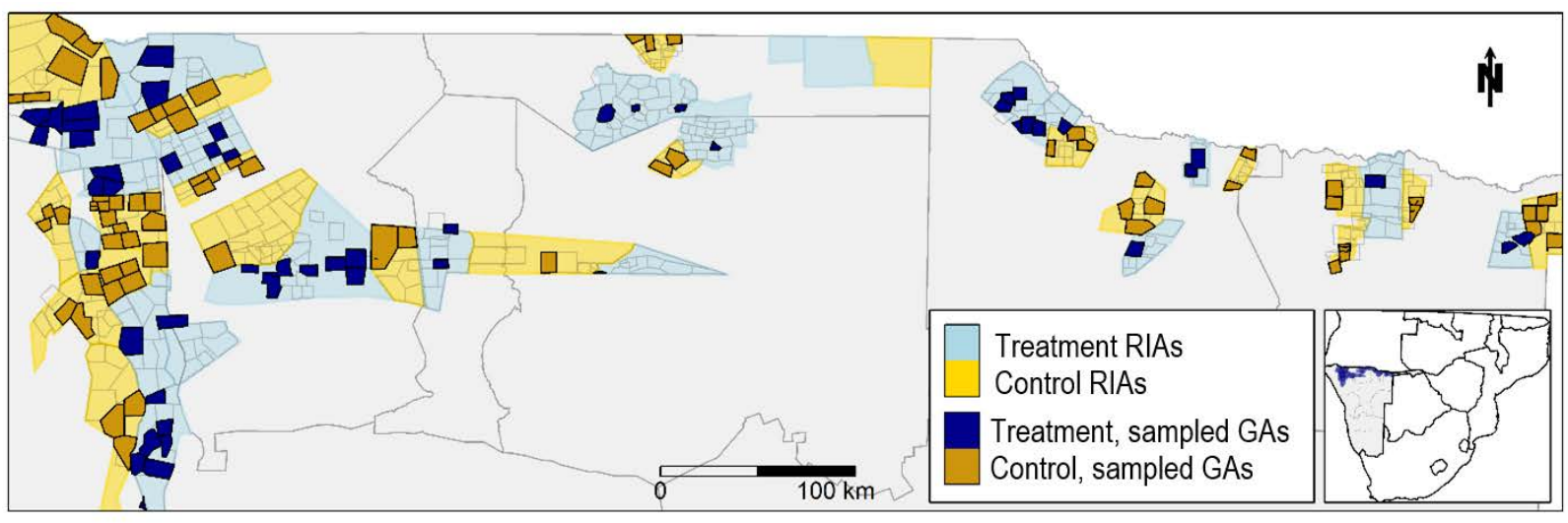

Fig. 1. Distribution of Rangeland Intervention Areas (RIAs) and Grazing Areas (GAs) for CBRLM in northern Namibia.

In order to select study areas, GOPA mapped 38 Rangeland Intervention Areas (RIAs), intervention zones with locally recognized boundaries and sufficiently low density of people, livestock, and bush cover to enable the implementation of new group-grazing plans Each RIA comprised 5-15 Grazing Areas (GAs), communal rangeland parcels shared by 5-35 households. We randomly assigned 19 RIAs to treatment and 19 RIAs to control, and measured program outcomes in 123 selected GAs (52 treatment and 71 control, see Methods). Figure 1 displays the GAs in treatment and control RIAs; darker shades identify the GAs sampled for measurement. Inference was computed using clustered standard errors and randomization inference, due to the 38-unit clustered design.

To measure resource management behaviors, we conducted 1,241 and 1,348 surveys of cattle herd managers at program end and two years later, respectively. We confirmed key practices with direct observation audits conducted after each survey. To assess impacts on rangeland condition two years after program end, we collected vegetation and soil data via randomly-sampled 1-ha sites during the wet (Apr-May) and dry (Sep-Oct) seasons. To assess impacts on cattle health and productivity two years after program end, we weighed, aged, and assessed body condition scores of 20,000 cattle in 730 herds during the dry season. Finally, to assess impacts on household economic outcomes three years after program end, we conducted 1,345 household surveys. We used ordinary least squares regression with standard errors clustered at the RIA level to estimate treatment effects.

\section{Treatment effects on social and behavioral outcomes}

Figure 2 illustrates impacts of CBRLM on standardized indices of social and behavioral outcomes (see Methods for details of the composition and construction of indices). At program end, we find large, statistically significant effects on eight of thirteen social indices: grazing planning $(+1.31 \mathrm{sd}, \mathrm{p}<0.001)$, grazing-plan adherence $(+0.35 \mathrm{sd}, \mathrm{p}<0.001)$, herding practices $(+0.37 \mathrm{sd}, \mathrm{p}=0.003)$, herder management $(+0.15 \mathrm{sd}, \mathrm{p}=0.07)$, cattle husbandry $(+0.36 \mathrm{sd}, \mathrm{p}=$ $0.002)$, community governance $(+0.75 \mathrm{sd}, \mathrm{p}<0.001)$, collective action $(+1.53 \mathrm{sd}, \mathrm{p}<0.001)$, and expertise $(+0.30 \mathrm{sd}, \mathrm{p}=0.005)$. We do not observe statistically significant improvements in herd restructuring $(+0.00 \mathrm{sd}, \mathrm{p}=0.95)$, cattle marketing $(-0.06 \mathrm{sd}, \mathrm{p}=0.37)$, community disputes 
$(+0.07 \mathrm{sd}, \mathrm{p}=0.34)$, trust $(-0.02 \mathrm{sd}, \mathrm{p}=0.73)$, or perceptions of self and community efficacy $(+0.04 \mathrm{sd}, \mathrm{p}=0.67)($ also see Extended Data Table 1$)$.

To illustrate program influences on collective action we highlight two key outcomes: At program end, planned grazing with peers increased by 28 percentage points (control mean $=$ $22 \%, \mathrm{p}<0.001$ ) while combining cattle with those of peers increased by 34 percentage points (control mean $=38 \%, \mathrm{p}<0.001)($ Extended Data Table 4). Patterns were validated via direct observation audits (Extended Data Table 10).

Two years after program end, improvements in all four indices of rangeland grazing management persisted: grazing planning (1.02sd, $\mathrm{p}<0.001)$, grazing-plan adherence $(0.32 \mathrm{sd}, \mathrm{p}<$ $0.001)$, herding practices (0.30sd, $\mathrm{p}=0.001)$, and herder management $(0.43 \mathrm{sd}, \mathrm{p}=0.004)$ ), as did positive effects on community governance ( $0.55 \mathrm{sd}, \mathrm{p}<0.001)$, collective action $(0.89 \mathrm{sd}$, $\mathrm{p}<$ 0.001 ), and expertise (0.35sd, $\mathrm{p}<0.001)$. Improvements in cattle husbandry were smaller and no longer statistically significant $(0.13 s d, p=0.19)$. Community disputes increased due to disagreements both within and between grazing communities over access to program-generated resources such as water developments and forage reserves $(-0.29 \mathrm{sd}, \mathrm{p}=0.002)$ (Extended Data Tables 1 and 4).

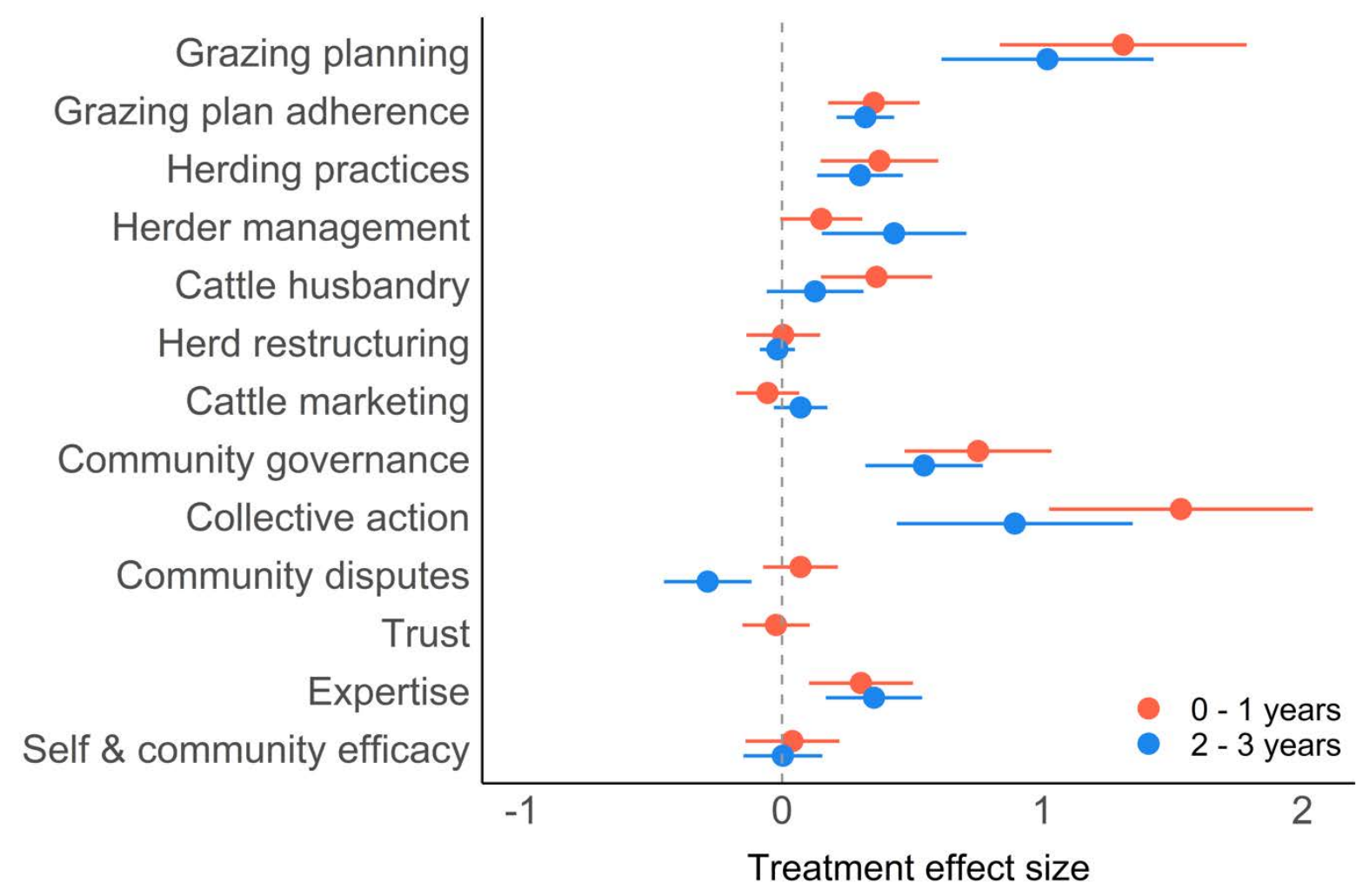

Fig. 2. Effects of CBRLM on 13 indices of social and behavioral outcomes at $0-1$ years after program end (2014) and 2 - 3 years after program end (2016). For each index the mid-point is the standardized treatment effect size, with a corresponding 95\% confidence interval. Supporting statistical results are shown in Extended Data Table 1. 


\section{Treatment effects on rangeland health, cattle productivity, and household economics}

Figure 3 illustrates results concerning our second research question, namely whether changes in resource management translated to improved rangeland health, cattle productivity, and household economics. No statistically significant effects were observed for herd productivity two years after program end or for household outcomes three years after program end. Of 10 rangeland outcomes measured two years after program end, four showed statistically significant but negative effects. We observed these adverse effects on key rangeland outcomes during the wet season, including 4 percentage points lower protected soil surface (control mean $=81 \%$ protected, $\mathrm{p}=0.05$ ), 3 percentage points lower plant litter cover (control mean $=55 \%, \mathrm{p}=0.04$ ), 8 percentage points lower herbaceous canopy cover (control mean $=45 \%, p=0.07$ ), and a $121 \mathrm{~kg} /$ ha decrease in fresh plant biomass (control mean $=459 \mathrm{~kg} / \mathrm{ha}, \mathrm{p}=0.10$ ). These are indicators of declining ecosystem health. We also observed a 5 percentage-point reduction in herbaceous canopy cover (control mean $=22 \%, \mathrm{p}=0.002$ ) and a $6 \mathrm{~kg} /$ ha reduction in fresh plant biomass during the dry season (control mean $=233 \mathrm{~kg} / \mathrm{ha} \mathrm{p}=0.004$ ), illustrating that the CBRLM failed to enhance fodder reserves for risk management purposes (see Extended Data Table 6).

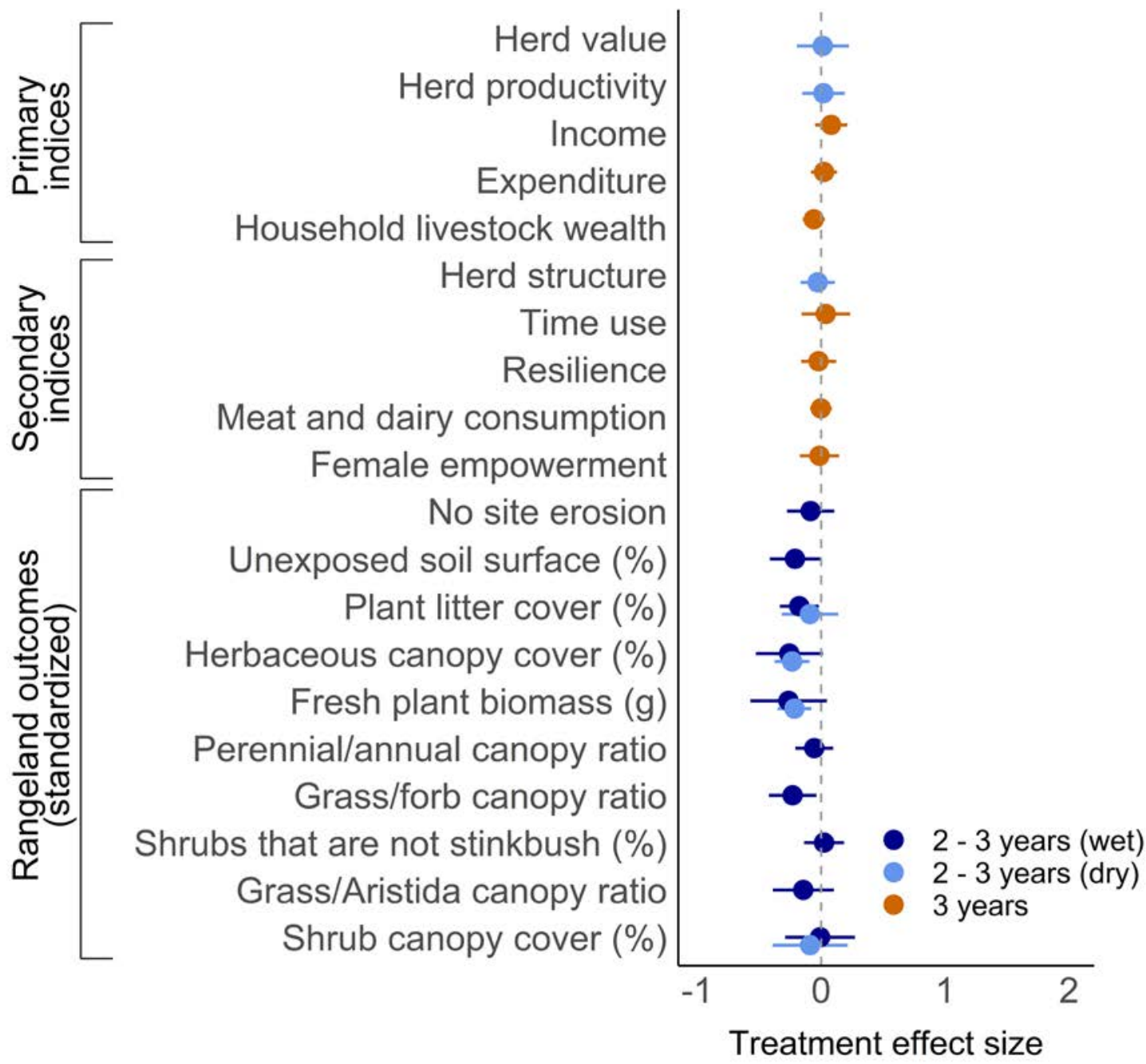


Fig. 3. Effect of CBRLM on 20 cattle, economic, and rangeland outcomes at 2 - 3 years or 3 years after program end (2016, 2017). For each outcome, the mid-point is the standardized treatment effect size with a corresponding 95\% confidence interval. Supporting statistical results are shown in Extended Data Table 2.

\section{Discussion}

We find that an external intervention to support community-based resource management generated substantial and persistent improvements in rangeland grazing management, community governance, and collective action. However, effects on rangeland, livestock, and household attributes were mostly nil, and in some cases negative.

The null to negative effects on rangeland condition are most likely the result of CBRLM increasing, rather than reducing, grazing intensity. For example, relative to control sites, sites in treatment areas were 12 percentage points more likely to be heavily grazed in the wet season (control mean $=13 \%, \mathrm{p}=0.003$ ) and 10 percentage points more likely to be heavily grazed in the dry season (control mean $=46 \%, \mathrm{p}=0.02$ ) of 2016 (see Extended Data Table 9). While we find no evidence that CBRLM increased the number of cattle herds or the number of cattle per herd in treatment areas, we did observe that non-CBRLM-participating herd owners from inside and outside treated areas exploited the treated GAs. Relative to herd owners in control areas, herd owners in treatment GAs were seven percentage points more likely to report observing "uninvited herds" in their GA in the previous year (control mean $=16 \%, p=0.005$ ). We speculate that the incentives for outsiders to "poach" forage in treated areas were strong in the dry season because of CBRLM investments in water infrastructure and encouragement of CBRLM herd owners to set aside un-grazed forage reserves. Thus, one consideration for future implementation and research is completeness of coverage: had implementation been able to cover all areas, then this would have reduced the risk of such incursions. These effects were compounded by the program's failure to stimulate opportunistic livestock off-take through livestock marketing.

Null effects on rangeland outcomes may also have resulted from an unresponsive rangeland sub-system. In this sense, our findings mirror the outcomes from other integrated, grazing management programs for commercial ranching in developed nations. Namely, ecologically based processes exhibit significant temporal inertia relative to management and social outcomes ${ }^{23-25}$. Temporal lags between primary and secondary productivity can be exacerbated by the precipitation variability that characterizes northern Namibia ${ }^{26}$. Even if the CBRLM grazing management schemes had been perfectly implemented with reduced stocking rates, adequate protection from grass poachers and favorable rainfall regimes, rangeland responsiveness to the treatment may have been limited by the nonequilibrium characteristics of forage_-dominated by annual grasses — and pervasive soil degradation (see Methods).

Nonetheless, further tracking of outcomes may be fruitful, and it is possible that positive economic or ecological outcomes will manifest over longer periods of time. While we do not observe early indicators of positive ecological or economic change, we also do not have a strong prediction based on outside literature as to whether impacts will improve, worsen or remain the same. We also recognize that improvements in social outcomes such as governance or collective action may offer intrinsic benefits to communities.

Hardin proposed that effective management of the commons under population pressure requires either coercive regulation or resource privatization ${ }^{1}$ (neither of which is politically 
realistic in many contexts in low-income countries). Inspired by Ostrom's theories of community resource management, CBRLM took a third path by investing in local institutions to arrest environmental degradation.

Our findings should temper overly optimistic views of what external interventions to promote community-based resource management can achieve in dryland situations to cope with climate change. Although it is important to note, as with any evaluation, our findings are particular to the specific program studied. Should our results temper enthusiasm for the theory of change, or are the results that did not match the aspirations more a consequence of specific programmatic decisions or imperfect implementation? The program studied took a holistic approach to CBRLM, whereas the broad concept of community-based resource management clearly could encompass a different set of components. For instance, water infrastructure development as implemented may have increased participation rates and provided direct benefits to the communities but at the cost of increased incursions by outside herds. On implementation, the process data do reveal high levels of participation and strong, positive feedback indicators, suggesting strong implementation fidelity (although a question remains whether the theory of change requires an even higher participation rate than achieved).

When designing future programs to support improved community-based responses to climate change and ecological degradation, policymakers should integrate complementary strengths, resources, and wisdom from local (e.g., traditional), regional and national authorities to address commons management challenges ${ }^{27,28}$. One focal area should be how to better design and enforce property rights for land, water, and grazing resources. The design of these rights should reflect the varied levels (e.g., household versus community) at which different resources are managed and utilized and incorporate historical perspectives about how social, economic, and ecological sub-systems have evolved and interacted over time $\mathrm{e}^{10,11,16,29-31}$. Innovative livestock marketing programs could be considered to better address structural constraints and incorporate cultural perspectives of producers. Finally, policymakers could explore well-tested alternative livelihood programs to achieve development goals in light of the long-time horizon and uncertain effects of programs to support new community-management systems ${ }^{32-34}$.

In addition to its theoretical and practical implications, this research demonstrates the value of providing experimental evidence on impacts of community-based development programs in a policy-relevant setting. Many experimental studies of resource management are conducted using tightly managed plots under direct researcher control, limiting their relevance for answering real-world policy questions ${ }^{25}$. On the other hand, field studies of community-based resource management programs typically rely on non-experimental evidence that may be biased due to self-selected participation or unobserved social, ecological, or economic factors. Given the importance of resource management, particularly with increasing issues from climate change, further research is needed to identify the contexts, approaches, and program components that yield strong and inclusive impacts ${ }^{12}$. 
Methods

\section{Intervention design}

\section{Theory of change}

At the heart of the of CBRLM's theory of change is the assumption that improvements in the ecological sub-system provide a sustainable resource base for increased livestock production and marketing ${ }^{35}$. The ecological sub-system, however, depends on a functioning economic sub-system because herd owners must be able to destock quickly in response to adverse ecological circumstances. The theory holds that the most important constraint on the economic sub-system is unproductive herds and low-quality cattle because farmers are unwilling to sell their cattle when they command low market prices. Therefore, improvements in rangeland grazing management need to be complemented by improvements in information and access to livestock markets, herd structures, and animal husbandry practices.

Crucially, changes to the ecological, economic, and livestock sub-systems rely on effective community governance and collective-action capacity in CBRLM communities. This is because rangeland grazing management practices can be easily undermined by non-participating herd owners inside or outside the GA. The theory therefore calls for investments at multiple levels of the social-ecological system to ensure that improvements in certain program areas are not undermined by failures in others ${ }^{35}$. The CBRLM implementers believed that previous rangeland development programs were undermined by a failure to account for the linkages among sub-systems, which motivated them to design a more holistic intervention ${ }^{35}$.

\section{Intervention components}

CBRLM was a multi-faceted package of administrative, educational, financial, and technical support. Implementation of the package was designed as an experimental treatment to assist in project assessment. To select study areas for evaluation, GOPA identified 38 RIAs with sufficiently low density of people, livestock, and bush cover to enable the implementation of new group-grazing plans, one of the core treatment components. The evaluation team randomly assigned 19 RIAs to treatment and 19 RIAs to control (see Randomization for details). GOPA implemented CBRLM in up to seven GAs within each treatment RIA.

Mobilization. GOPA conducted pre-mobilization meetings with TAs and other stakeholders in the second half of 2010 to identify GA communities most likely to participate in $\mathrm{CBRLM}^{35}$. Early mobilization efforts focused on soliciting community buy-in for the cornerstone principles of CBRLM, including community-planned grazing, combined herding of cattle, and efficient livestock management. There is also substantial evidence from qualitative surveys that some community members were motivated to participate in the CBRLM by prospects for water infrastructure development by GOPA ${ }^{35}$.

While almost 100 GAs were initially mobilized for the project, by 2014 GOPA was targeting resources and support towards 58 GAs based on community receptivity and the discretion of CBRLM management. In each GA, GOPA worked principally with households owning 10 or more cattle, although other community members benefitted from participation in a "Small Stock Pass-on Scheme" and a variety of training activities, which are described below.

Rangeland grazing management. The core aim of CBRLM was to shift how communities approached livestock grazing, forage conservation, and risk management by encouraging two key practices: planned grazing and combined herding. Planned grazing entails 
rotating a community's cattle to a new pasture on a regular basis in accordance with a written plan. The goal was to preserve grass for the dry season and allow grazed pastures more time to recover. Combined herding entails grouping many owners' cattle into one large herd and herding them in a tight bunch. This practice is meant to concentrate animal impact on rangeland, minimize cattle losses, and increase the likelihood that cows are exposed to bulls, thus increasing the pregnancy and calving rates of the entire herd. The scientific and practical rationale behind these practices is reviewed in Supplementary Information section 2.

GOPA staff developed grazing plans with each participating community and taught them planned grazing and combined herding via field-based training sessions. These followed a "training of trainers" approach in which GOPA recruited field facilitators from each community, taught them the principles of CBRLM, and tasked them with training their fellow participating pastoralists.

Livestock management. GOPA taught participants some best practices in animal husbandry, including structuring herds to maximize productivity (by increasing the proportion of bulls and reducing the proportion of oxen and cattle over the age of 10 years), providing vaccinations and supplements, and deworming ${ }^{35}$. Additionally, to support the introduction of more bulls into herds, the project implemented a "bull scheme" in which participating communities were given the opportunity to collectively buy certified breeding bulls at a subsidized price. Communities were meant to repay the cost of the bulls either with cash or inkind trades of goats. Goats collected in this repayment process fed into the small stock pass-on scheme under which participating community members nominated households to receive goats from GOPA. GOPA requested that communities nominate households that owned few or no livestock and were led by youth and/or women. When GOPA received goats as payment for loaned bulls, they would pass them on to nominated households. The recipients were then expected to pass on the offspring of the goats they received to other disadvantaged households.

Cattle marketing. CBRLM also sought to increase participants' marketing of cattle to generate revenue from livestock raising and encourage offtake of unproductive animals ${ }^{35}$. Community facilitators and project experts provided participating herd owners with information about market opportunities and ideal herd composition, and encouraged flexible offtake in response to forage shortages. In 2013, GOPA invested in the development of regional livestock cooperatives that held local auctions and helped farmers transport their animals to markets. Finally, GOPA invested in identifying international export opportunities for CBRLM farmers to Zimbabwe and Angola, although these were generally not successful ${ }^{32}$.

Community development. The project sought to institutionalize community-level governance to organize and enforce collective activities like planned grazing, water point maintenance, and financing of livestock inputs. The central management unit of each GA was a new Grazing Area Committee consisting of five to 10 elected community members. The project encouraged participating communities to collectively cover operational expenses in their GA through a GA fund managed by the committee. Among these expenses were the payments to herders, costs of diesel for water pumps and maintenance of water infrastructure, financing collective livestock vaccination campaigns, and any other collective expenses that would support operation of the GA. CBRLM supported every GA fund with a 1:1 matched subsidy. The matched subsidy was limited by a ceiling amount determined by the estimated number of cattle in a GA. GOPA also instructed committees to maintain "GA record books" to track grazing plans, record meeting minutes, and keep logs of community members’ participation and financial contributions. 
Water infrastructure. GOPA upgraded water infrastructure at a total of 84 sites throughout the NCAs to facilitate planned grazing and combined herding. Water infrastructure improvement included minor upgrades like water tanks and drinking troughs, and larger investments such as the installation of diesel and solar pump systems, the drilling and installation of boreholes, and the construction of pipelines, deep wells, and a large earthen dam $^{32}$.

\section{Intervention timeline}

The timeline for major components of the research process and CBRLM roll-out is illustrated in Supplementary Figure 1. The research team conducted the random assignments and the implementation team began community mobilization in early 2010. Formal enrollment in CBRLM began in early 2011. The program implementer conducted mobilization in two waves: they mobilized 11 of 19 RIAs in 2010 and the remaining 8 RIAs in 2011. The evaluation team conducted qualitative data collection to inform the design of social and cattle surveys prior to project end 2014; social surveys in 2014 and 2016; rangeland surveys in the wet and dry seasons of 2016; a cattle survey in 2016; and a household economic survey in 2017.

Cumulative GA-level implementation is illustrated in Supplementary Figure 2. The project implementer first formally reported enrollment and field visits in April 2011. The implementer achieved nearly full targeted enrollment (50 GAs) by November 11, although some grazing areas were added or subtracted thereafter. Mobilization exceeded enrollment because some grazing area communities chose not to participate in the program and some enrolled in the program and then dropped out. The program averaged between 25 and 50 field visits per month over the project period. A field visit consisted of a week-long community meeting about grazingplan development and implementation, animal husbandry and budget training, and marketing opportunities.

\section{Randomization}

The unit of randomization is the RIA, an intervention zone with a locally recognized boundary. Each RIA falls under the jurisdiction of a single local governing body, known as a Traditional Authority (TA). As noted above, RIAs contain five to 15 GAs where a community of producers share water and forage resources. Grazing areas do not have legally defined boundaries. A herd owner's ability to move among GAs is variable.

GOPA mapped 41 RIAs prior to randomization. Three contiguous RIAs in the northcentral region, composed of two treatment RIAs and one control RIA, were omitted from the study post-randomization because reexamination of baseline density of bushland vegetation deemed them unviable for CBRLM implementation. These are the three RIAs without sampled GAs in Fig 1. The other 38 RIAs were randomly assigned to either receive the CBRLM treatment (19 RIAs) or serve as controls (19 RIAs).

The randomization was stratified by TA to ensure that at least one RIA was assigned to the treatment in each TA. The research team then re-randomized the sample units until seven variables were balanced (a p-value of 0.33 or higher for an omnibus f-test of all seven variables) between treatment and control: (1) Presence of forest; (2) number of households; (3) number of cattle; (4) cattle density per unit area; (5) quality of water sources; (6) presence of communitybased organizations (CBOs); and (7) overlap with complementary interventions (see Supplementary Table 1). For future researchers, we recommend re-randomizing a set number of times and choosing the re-randomization with the highest balance ${ }^{36}$. These variables and indicator variables for TA are included as covariates in all analyses. 


\section{Sample selection}

In the original sampling strategy, the project implementer was asked to predict the GAs where they would implement the project if the RIA were assigned to treatment. However, there was limited overlap between the GAs that the implementer predicted and the GAs where CBRLM was ultimately implemented. Therefore, the evaluation team devised a revised sampling strategy in 2013, which proceeded in four steps:

(1) Map GAs in sampled RIAs. The evaluation team traveled to all 38 RIAs and worked with TAs and Namibian Agricultural Extension (AE) officers to map all the GAs in each RIA. The team mapped 171 GAs in control RIAs and 213 GAs in treatment RIAs.

(2) Collect pre-program data on GAs. The evaluation team collected information on preprogram characteristics of each GA from interviews with TAs and AE staff, the Namibian national census ${ }^{37}$, and the Namibian Atlas ${ }^{38}$. The latter has a georeferenced database on climate, ecology, and livestock for the nation.

(3) Predict CBRLM enrollment for treatment GAs. The researchers used these data in a logistic regression to predict the probability that each GA would enroll in CBRLM and would adopt the CBRLM interventions based on pre-program characteristics. For example, the model found that GAs with more existing water infrastructure, strong social cohesion, and adequate cell phone service were more likely to be enrolled in the program. The variables used to predict CBRLM adoption were: (1) Presence of water installations (yes/no); (2) carrying capacity of the land (above/below the regional median); (3) community’s readiness to change (high/very high); (4) community's social cohesion (high/very high); (5) spillover effects from neighbors; (6) quality of herders and herder turnover; (7) presence of members of the Himba ethnic group; (8) the TA's readiness to change; (9) cell phone coverage; and (10) primary housing material (mud, clay, or brick).

(4) Generate sample of GAs in treatment and control RIAs. The evaluation team applied the statistical model (above) to all GAs in the sample and set a cut-off point to separate GAs that were likely to adopt the CBRLM program versus those that were unlikely to do so. In treatment RIAs, the model predicted 52 GAs, of which 37 were formally enrolled in CBRLM and 15 were not. In control RIAs, 71 GAs met or exceeded the cutoff; they offer the best counter-factual estimate of which GAs would have enrolled in the program had their RIA received treatment.

\section{Data collection}

The names, survey questions, and variable constructions for all outcomes included in the analysis are available at the AEA RCT Registry (ID number: AEARCTR-0002723). See Supplementary Information section 1 for a list of definitions of variables depicted in Figure 2 and Figure 3.

\section{Social surveys}

Social surveys were intended to assess the effect of CBRLM on community behaviors, community dynamics, knowledge, and attitudes. All data were collected using electronic tablets with the SurveyCTO software ${ }^{39}$. 
The primary unit of analysis for household respondents is the manager of the cattle kraal (holding pen). Researchers conducted surveys with kraal managers, rather than heads of households, for three reasons. First, many kraals contain cattle owned by multiple households, and decisions about grazing practices, cattle treatment, and participation in grazing groups are generally made at the kraal level. Second, many cattle-owning households do not directly oversee the day-to-day activities of their cattle (many live outside the GA), and so would be unable to answer questions about key outcomes, such as livestock management behaviors and community dynamics $^{40}$. Finally, enrollment in CBRLM occurred at the kraal, rather than household, level.

In 2014, the research team worked with local headmen and other community members to generate a complete census of kraals in every sampled Grazing Area (GA) that contained 10 or more cattle at the start of the program (an eligibility requirement for enrollment in CBRLM). The research team randomly sampled up to 11 community members for participation in the 2014 kraal manager survey. Surveys were conducted in the manager's local language and lasted approximately 45 minutes. Alongside the 2014 survey, teams of two surveyors visited all grazing areas where at least one respondent reported participating in a community grazing group or community combined herd to corroborate reported behaviors through direct observation.

To assess the persistence of CBRLM's effects on behaviors, community dynamics, knowledge, and attitudes, the research team conducted a follow-up survey of kraal managers in 2016, two years after program end. The survey team randomly sampled two additional kraals in each grazing area to account for the possibility of attrition. The 2016 survey lasted approximately one hour on average, and included an expanded list of questions about governance, social conflict, and collective action as well as new survey modules on cattle marketing, cattle movement, and livestock management. In 2017, the research team randomly sampled three kraals in each grazing area to conduct direct observation audits of key rangeland grazing-management behaviors.

To assess the effects of CBRLM on economic outcomes, the research team conducted a household-level survey in 2017, three years after program end. The survey instrument asked detailed questions on topics that could not be answered by kraal managers, such as household consumption, income, food security, and savings. To select households for this survey, during the 2016 survey the research team asked kraal managers to list all households that owned cattle in the manager's kraal, then randomly selected one household from each kraal. Alongside the 2017 survey, the research team conducted an in-depth survey with the local headman of all 123 GAs in the sample. The headman survey focused on historical background about the grazing area, as well as the headman's perceptions of rangeland and livestock issues.

\section{Cattle data}

The cattle component was intended to assess effects of CBRLM on cattle numbers, body condition, and productivity. The variables of key interest involved the average liveweight and body condition, calving rates, and average market value of cattle, as well as overall herd structures.

The data collection protocols closely followed standards from livestock assessments elsewhere in Sub-Saharan Africa ${ }^{41}$. The research team randomly selected up to six kraals in each GA to participate in the cattle survey. The survey team mobilized selected herds during multiple community visits to ensure all herds were accounted for. Herd owners were compensated for the 
costs of rounding up animals and weighed cattle received anti-parasite treatment (“dipping”) ${ }^{42}$. A total of 19,875 cattle from 669 herds were weighed.

The data-collection process for each herd proceeded in six steps. First, surveyors worked with herd managers to round up all cattle that regularly stayed in the selected cattle kraal. Once cattle had been brought to the designated location for data collection, they were passed through a mobile crush pen and scale. As each animal passed through the crush pen, a survey team member recorded the animal type (i.e., bull, ox, cow, calf) and used a SurveyCTO randomizer to calculate whether the animal was randomly selected for assessment. The random number generator was set to randomly select approximately 30 cattle from each herd for weighing. If the animal was selected, the survey team kept the animal on the scale and recorded its weight and body condition. A semi-subjective 1-5 scale, commonly used by livestock buyers in the NCAs (see Supplementary Fig. 3), was adjusted to a 0-4 scale used to determine formal market pricing. The team then placed the animal in a neck clamp and estimated the animal's age by dentition (but extremely young calves were aged visually). Each animal was marked as it moved through the crush pen to ensure that it was assessed only once. In addition to assessing randomly selected animals, the survey team weighed and aged all bulls in the herd. The cattle survey yielded average cattle weight, age, and body condition for 19,875 animals across all treatment and control GAs, as well as estimates of calving rates, ratios of bulls to cows, and ratios of productive to unproductive animals.

\section{Rangeland data}

The rangeland ecology research was intended to assess treatment effects on vegetation and soil surface conditions. Full research details, including field technician training protocols, are available elsewhere ${ }^{43}$. The data collection approach followed methods commonly used in Africa $^{44,45}$. Extended definitions of variables depicted in Fig. 3 and Extended Data Table 2 are available in the Supplementary Information section 1.

The rationale for how the ecological variables presented in Fig. 3 translate into assessments of rangeland condition or health is based on forage and soil characteristics from a livestock production perspective ${ }^{26}$. The highest quality forages for cattle on rangelands are perennial grasses, since annual grasses are more ephemeral in terms of nutritive value and productivity. Herbaceous forbs often have the poorest forage quality for large grazers because of their low fiber content and risks of containing toxic chemicals. When rangelands are degraded by over-grazing, perennial grasses are reduced and replaced by annual grasses and forbs. This trend reflects animal diet selectivity that favors consumption of the perennial plants. Reversing such trends via management interventions can be difficult. The main option is to reduce grazing pressure and hope that perennial grasses can outcompete annuals and become reestablished over time. Another option is to implement a grazing rotation that allows perennial grasses to recover after a grazing period.

Increases in annual grasses are documented to occur as one outcome of chronic overgrazing in Namibia ${ }^{46,47}$. In 2016, annual grasses were 5-times more abundant than perennial grasses in our study area. When over-grazing occurs, most plant material is harvested and less is available for the pool of organic matter (OM) for the topsoil. Less OM (e.g., plant litter) on the soil surface means that more soil is also exposed to wind and rain, accelerating erosion. The GAs in our research occur on various soil types and landscapes, some of which are more susceptible to erosion than others. Silty soils on slopes are vulnerable to erosion, for example, while sandy soils on level sites are less vulnerable $e^{26}$. 
On-the-ground sampling was conducted in all 123 selected GAs along an 800-km zone running West to East. Elevations ranged from 750 to 1,700 masl (West) and 1,050 to 1,120 masl (East). Within each sampled GA, up to 12 1-ha (square) sampling sites were initially chosen using coordinates generated randomly from latitude and longitude coordinates in a satellite image of the $\mathrm{GA}^{\mathbf{4 8}}$. About $17 \%$ of sites were later removed from the sample based on their close proximity to landscape disturbances or inaccessibility by field technicians. Overall, 972 sites were analyzed in the wet season and 885 in the dry season of 2016, two years after the implementation phase of CBRLM had ended.

The geographic center-point for a sampling site was generated using a spatially constrained random distribution algorithm applied to the satellite image, and the field team navigated to the center-point coordinates using GPS technology. The team took photographs and recorded descriptive information including elevation, slope, aspect, other landscape features, vegetation type, dominant plant species, soil type, soil erosion, and degree of grazing or browsing pressure, and proximity to high impact areas such as trails, water points, and villages.

At the center point, the survey team then established two perpendicular transects, each $100 \mathrm{~m}$ in length and crossing at the middle. The resulting four, 50-m transect lines ran according to each cardinal direction (N, S, E, W) as determined with a compass. Technicians then placed 1$\mathrm{m}$ notched sampling sticks at randomized locations along each transect line and recorded what plants or other materials (i.e., stone, wood, leaf litter, animal dung, etc.) were located under or above the notches of the sampling sticks. These data points were tabulated to calculate percent cover for various categories of vegetation; there were $n=200$ data points per site based on 40 stick placements and 5 notches per stick. This method enabled precise calculation of cover values for herbaceous (i.e., grass, forb) and diminutive woody plants (i.e., small shrubs, seedlings, saplings, etc.). Tree cover was estimated from point data collected via a small adjustment in the approach ${ }^{43}$. Herbaceous species were identified in wet seasons but not in dry seasons due to senescence during the latter.

Quadrat sampling supplemented the notched stick approach. Random placements of a 1$\mathrm{m}^{2}$ quadrat frame within the sampling site allowed for 20 estimates of a soil surface condition score ranging from 1 (poor) to 2 (moderate) or 3 (good) ${ }^{43}$. Poor was indicated by smooth soil surfaces, absence of litter, having poor infiltration and signs of erosion such as rills, pedestals, or terracettes; Good was indicated by rough soil surfaces, abundant litter, seedlings evident, and lack of evidence of erosion. Herbaceous biomass was estimated in the quadrats and weighed to estimate herbaceous biomass.

\section{Statistics}

\section{Index creation}

Index construction for socioeconomic variables was composed of several steps ${ }^{49}$. For each response variable we first signed all component variables such that a higher sign is a positive outcome, i.e., in line with CBRLM's intended impacts. Then we standardized each component by subtracting its control group mean and dividing by its control group standard deviation. We computed the mean of the standardized components of the index and standardized the sum once again by the control group sum's mean and standard deviation. When the value of one component in an index was missing, we computed the index average from the remaining components. See Extended Data Tables 3-6 for index components. 


\section{Calculation of Average Treatment Effects}

The estimate of interest is the Average Treatment Effect (ATE), or the average change in an outcome generated by assignment to CBRLM. We estimated the ATE using standard Ordinary Least Squares regression and control for variables used in stratification. Regressions for rangeland outcome variables include a unique set of controls, including rainfall over the project period, rainfall in the year of data collection, grazing area cattle density, grazing area ecological zones, and a remote-sensing estimate of pre-project biomass. The core model takes the form:

$$
\widehat{Y}=\alpha+\beta_{1} T+\boldsymbol{\beta} \boldsymbol{X}
$$

where $T$ represents treatment assignment and $\boldsymbol{X}$ represents pre-treatment covariates used to test for balance during re-randomizations. The results capture the intention-to-treat (ITT) effect rather than the effect of treatment-on-treated (TOT). ITT is more appropriate than TOT in this context for two principal reasons. First, it is more relevant for policymakers - the effect of policies should account for imperfect compliance. Second, "uptake” is not well-defined, and certainly not a binary concept, for CBRLM since many communities and community members complied partially, complied with some but not all components, and complied for some but not all of the time.

\section{Standard errors and p-values}

We report two-tailed p-values for all analyses. For each outcome, we show the two-tailed p-value from a standard Ordinary Least Squares (OLS) regression with standard errors clustered at the level of the RIA, the unit of randomization ${ }^{50}$. We also calculate two-tailed p-values using Randomization Inference (RI). To calculate RI p-values, we re-run the randomization procedure (described above) 10,000 times and generate an Average Treatment Effect (ATE) under each hypothetical randomization. The p-value is the percent of re-randomizations that generate a treatment effect that is either equal to, or larger in absolute value than, the true ATE.

\section{Multiple hypotheses correction}

We calculate q-values to account for families of outcome indices with multiple hypotheses $^{51}$. The q-value represents the minimum false discovery rate at which the null hypothesis would be rejected for a given test. We pre-specified five families of indices:

1. Behavioral outcomes (all in 2014): Grazing planning, Grazing-plan adherence, Herding practices, and Herder management

2. Behavioral outcomes (all in 2016): Grazing planning, Grazing-plan adherence, Herding practices, and Herder management

3. Primary material outcomes: Cattle herd value (2016), Herd productivity (2016), Household income (2017), Household expenditures (2017), Household livestock wealth (2017)

4. Secondary material outcomes: Time use (2017), Resilience (2017), Female empowerment (2017), Diet (2017), and Herd structure (2016)

5. Mechanisms: Collective Action (2014, 2016), Community Governance (2014, 2016), Community disputes (2014, 2016), Trust (2014), Self and community efficacy (2014, 2017), and Knowledge (2016) 
672

673

674

675

676

677

678

679

680

681

682

683

684

685

686

687

688

689

690

\section{Heterogeneous treatment effects analysis}

We are interested in whether the effect of CBRLM was impacted by lower rainfall in some grazing areas during the project period. We evaluated heterogeneous treatment effects by rainfall in grazing areas using a variety of measures of rainfall, including aggregate rainfall during the project period and deviation in aggregate rainfall from the ten-year mean during the project period.

For simplicity, Extended Data Table 7 presents the results of analysis of the interaction between treatment and a binary indicator of low rainfall. To construct this indicator, for each GA we first compute the absolute difference between mean rainfall during the project and mean rainfall during the 10 years prior $(2000-2010)$. We divide the absolute difference by mean rainfall during the 10 years prior to produce a relative (\%) difference. We then determine the median relative difference over all GAs. For each GA, we assign the value 1 to the low rainfall indicator if the relative difference for the GA is less than the median relative difference over all GAs; we assign 0 otherwise. The results are consistent when we use alternative rainfall measures.

\section{Spillovers analysis}

Because CBRLM grazing areas were more likely to experience external incursions by cattle herds from outside the community, we test for spillovers. Specifically, we are interested in whether control grazing areas near treatment areas were affected by having a treatment grazing area nearby. We conducted the spillovers analysis only on control group grazing areas. For each control group grazing area, we measured the distance to the border of the nearest treatment grazing area. We created a binary measure taking the value 1 if the distance between the control group grazing area and nearest treatment group grazing area is below the median distance, and 0 otherwise. We find no evidence of spillover effects. The results are presented in Extended Data Table 8.

Ethical considerations: Approval for this study was obtained from the Institutional Review Boards at Yale University (1103008148), Innovations for Poverty Action (253.11March-001), and Northwestern University (STU00205556-CR0001). The program was conceived, designed, and implemented by the Millennium Challenge Account compact between the Millennium Challenge Corporation and the Government of Namibia. The research team did not participate in program design or implementation. Communities and individual farmers were informed that they were free to withdraw from participation in evaluation activities at any time. The random assignment of the program was appropriate given the uncertainty around the program's effect, and the Government of Namibia committed to implementing the program in control areas if the evaluation showed positive results.

The research team took a number of steps to ensure the autonomy and well-being of study participants. First, we designed the survey and data collection protocols after significant qualitative field work to ensure that questions about sensitive issues (e.g., cattle wealth, cattle losses, attitudes towards the Traditional Authority) were phrased appropriately and did not engender adverse emotional or social consequences. Second, all survey activities were reviewed and approved by the MCA compact, Regional Governors, and Traditional Authorities. Third, surveys were conducted with informed consent and in private to ensure that information remained private and respondents were as comfortable as possible during the survey. Finally, the 
research team disseminated findings on market prices and rangeland condition to communities and regional Agriculture Extension Officers.

We received no negative reports about the community reception of the survey from surveyors during the evaluation. Two cows were injured during the cattle weighing exercise, and the owner was financially compensated in line with a compensation agreement made with all farmers prior to the cattle weighing exercise.

Data availability: Hypotheses and analytical methods for this research were pre-registered prior to analysis through the American Economic Association's RCT registry and are available online (https://www.socialscienceregistry.org/trials/2723). Data used for this research are accessible at the Millennium Challenge Corporation website (https://data.mcc.gov/evaluations/index.php/catalog/138/study-description) and will be posted on the Innovations for Poverty Action dataverse. In the publicly available data, some numerical outliers have been censored in order to preserve the anonymity of the survey respondents. Access to uncensored data is available upon request from the corresponding author, subject to approval by the Millennium Challenge Corporation.

Code availability: Data analysis was conducted in R and Stata. All code needed to replicate the figures and tables in this paper and the Supplementary Information is available, with accompanying datasets, through the Millennium Challenge Corporation at (https://data.mcc.gov/evaluations/index.php/catalog/138/study-description) and will be posted on the Innovations for Poverty Action dataverse.

\section{References}

1. Hardin, G. The tragedy of the commons. Science 162, 1243-1248 (1968).

2. Climate Change and Land: an IPCC special report on climate change, desertification, land degradation, sustainable land management, food security, and greenhouse gas fluxes in terrestrial ecosystems. https://www.ipcc.ch/srccl/ (2019).

3. Ostrom, E. Governing the Commons: The Evolution of Institutions for Collective Action. (Cambridge University Press, 2015).

4. Sneath, D. State Policy and Pasture Degradation in Inner Asia. Science 281, 1147-1148 (1998).

5. Acheson, J. M. The Lobster Gangs of Maine. (UPNE, 1988). 
6. Wade, R. Village Republics: Economic Conditions for Collective Action in South India. (Cambridge University Press, 1988).

7. Netting, R. M. Balancing on an Alp: Ecological Change and Continuity in a Swiss Mountain Community. (CUP Archive, 1981).

8. McCay, B. J. The Question of the Commons: The Culture and Ecology of Communal Resources. (University of Arizona Press, 1987).

9. Ostrom, E., Burger, J., Field, C. B., Norgaard, R. B. \& Policansky, D. Revisiting the Commons: Local Lessons, Global Challenges. 284, 6 (1999).

10. McCabe, J. T. Turkana pastoralism: A case against the Tragedy of the Commons. Hum Ecol 18, 81-103 (1990).

11. Moritz, M., Scholte, P., Hamilton, I. M. \& Kari, S. Open Access, Open Systems: Pastoral Management of Common-Pool Resources in the Chad Basin. Hum Ecol 41, 351-365 (2013).

12. Slough, T. et al. Adoption of community monitoring improves common pool resource management across contexts. PNAS 118, (2021).

13. Ferraro, P. J. \& Agrawal, A. Synthesizing evidence in sustainability science through harmonized experiments: Community monitoring in common pool resources. PNAS 118, (2021).

14. Schlüter, M., Hinkel, J., Bots, P. \& Arlinghaus, R. Application of the SES Framework for Model-based Analysis of the Dynamics of Social-Ecological Systems. Ecology and Society 19, (2014).

15. Casey, K. Radical Decentralization: Does Community-Driven Development Work? Annu. Rev. Econ. 10, 139-163 (2018). 
16. Bollig, M. Shaping the African Savannah: From Capitalist Frontier to Arid Eden in Namibia. (Cambridge University Press, 2020). doi:10.1017/9781108764025.

17. Inman, E. N., Hobbs, R. J. \& Tsvuura, Z. No safety net in the face of climate change: The case of pastoralists in Kunene Region, Namibia. PLOS ONE 15, e0238982 (2020).

18. Weinzierl, T., Wehberg, J., Böhner, J. \& Conrad, O. Spatial Assessment of Land Degradation Risk for the Okavango River Catchment, Southern Africa. Land Degradation \& Development 27, 281-294 (2016).

19. Werner, W. A Brief History of Land Disposession in Namibia. Journal of Southern African Studies 19, 135-146 (1993).

20. Werner, W. No one will become rich: Economy and society in the Herero reserves in Namibia, 1915-1946. (P. Schlettwein Publishing, 1998).

21. Silvester, J. Beasts, boundaries \& buildings: the survival \& creation of pastoral economies in Southern Namibia 1915-35. in Namibia under South African Rule: Mobility \& Containment 1915-46 95-116 (Ohio University Press, 1998).

22. Werner, W. Tenure reform in Namibia's communal areas. Journal of Namibian Studies : History Politics Culture 18, 67-87 (2015).

23. Gosnell, H., Grimm, K. \& Goldstein, B. E. A half century of Holistic Management: what does the evidence reveal? Agric Hum Values 37, 849-867 (2020).

24. Huntsinger, L. Private correspondence with Lynn Huntsinger, University of California at Berkeley. (2020).

25. Briske, D. D. et al. Origin, Persistence, and Resolution of the Rotational Grazing Debate: Integrating Human Dimensions Into Rangeland Research. Rangeland Ecology \& Management 64, 325-334 (2011). 
771 26. Holechek, J., Pieper, R. D. \& Herbel, C. H. Range Management: Principles and Practices.

772 (Prentice Hall, 1989).

773 27. Gemedo-Dalle, Isselstein, J. \& Maass, B. L. Indigenous ecological knowledge of Borana

774 pastoralists in southern Ethiopia and current challenges. International Journal of Sustainable

775 Development \& World Ecology 13, 113-130 (2006).

776 28. Manzano, P. et al. Toward a holistic understanding of pastoralism. One Earth 4, 651-665

777 (2021).

778 29. Henrichsen, D. Claiming Space and Power in Pre-colonial Central Namibia: The Relevance

779 of Herero Praise Songs. (Basler Afrika Bibliographien, 1999).

780 30. Robinson, L. W. A Complex-Systems Approach to Pastoral Commons. Hum Ecol 37, 441$781 \quad 451$ (2009).

782 31. Undargaa, S. Pastoralism and Common Pool Resources: rangeland co-management, 783 property rights and access in ... Mongolia. (ROUTLEDGE, 2018).

784 32. Coppock, D. L. et al. Community Based Rangeland and Livestock Management Evaluation 785 Report. https://data.mcc.gov/evaluations/index.php/catalog/138/study-description (2020).

786 33. Banerjee, A. et al. A multifaceted program causes lasting progress for the very poor:

787 Evidence from six countries. Science 348, 1260799 (2015).

788 34. Gugissa, D. A., Ingenbleek, P. T. M. \& van Trijp, H. C. M. Market knowledge as a driver of 789 sustainable use of common-pool resources: A lab-in-the-field study among pastoralists in $790 \quad$ Ethiopia. Ecological Economics 185, 107039 (2021).

791 35. Gesellschaft für Organisation, Planung und Ausbildung. Community Based Rangeland and 792 Livestock Management Inception Report. 
https://www.yumpu.com/en/document/view/7305588/cbrlm-inception-report-millenniumchallenge-account-namibia (2013).

36. Bruhn, M. \& McKenzie, D. In pursuit of balance: Randomization in practice in development 796 field experiments. American Economic Journal: Applied Economics 1, 200-232 (2009).

37. Namibia Statistics Agency. Namibia 2011 Population and Housing Census [PUMS dataset]. (Namibia Statistics Agency [producer and distributor], 2013).

38. Mendelsohn, J. M. Atlas of Namibia a portrait of the land and its people. (2002).

800

801

39. Hartung, C. et al. Open data kit: tools to build information services for developing regions. in Proceedings of the 4th ACM/IEEE International Conference on Information and Communication Technologies and Development 1-12 (Association for Computing Machinery, 2010). doi:10.1145/2369220.2369236.

40. Groves, D. \& Tjiseua, V. The mismeasurement of cattle ownership in Namibia’s Northern Communal Areas. Nomadic Peoples 24, 255-271 (2020).

41. Machila, N., Fèvre, E. M., Maudlin, I. \& Eisler, M. C. Farmer estimation of live bodyweight of cattle: Implications for veterinary drug dosing in East Africa. Preventive Veterinary Medicine 87, 394-403 (2008).

42. Moyo, B. \& Masika, P. J. Tick control methods used by resource-limited farmers and the effect of ticks on cattle in rural areas of the Eastern Cape Province, South Africa. Trop Anim Health Prod 41, 517-523 (2009).

43. Norton, B. Rangeland Data Collection Protocol: For Evaluation of Ecological Parameters for the CBRLM Program in Northern Namibia Conducted by IPA. (2020).

44. Riginos, C., Herrick, J. \& van der Waal, C. Monitoring Rangeland health, A Manual for Namibian Rangelands. http://www.namibiarangelands.com/downloads/ (2014). 
45. Riginos, C. \& Herrick, J. Monitoring Rangeland Health: A Guide for pastoralists and Other Land Managers in Eastern Africa, Version II. (2010).

46. Klintenberg, P. \& Verlinden, A. Water points and their influence on grazing resources in central northern Namibia. Land Degradation \& Development 19, 1-20 (2008).

47. Sander, H., Bollig, M. \& Schulte, A. Himba paradise lost: Stability, degradation and pastoralist management of the Omuhonga basin (Northwestern Namibia). Die Erde 129, 301-315 (1998).

48. Yu, C. L., Li, J., Karl, M. G. \& Krueger, T. J. Obtaining a balanced area sample for the Bureau of Land Management rangeland survey. JABES 25, 250-275 (2020).

49. Kling, J. R., Liebman, J. B. \& Katz, L. F. Experimental analysis of neighborhood effects. Econometrica 75, 83-119 (2007).

50. Abadie, A., Athey, S., Imbens, G. W. \& Wooldridge, J. When should you adjust standard errors for clustering? http://www.nber.org/papers/w24003 (2017) doi:10.3386/w24003.

51. Benjamini, Y. \& Hochberg, Y. Controlling the false discovery rate: A practical and powerful approach to multiple testing. Journal of the Royal Statistical Society. Series B (Methodological) 57, 289-300 (1995).

Acknowledgements: The authors thank Nate Barker, Caton Brewster, Anais Dahmani, Pierre Durand, Alexander Fertig, Sam Hambira, Matthew Haufiku, Stephen Kulungu, Sayan Kundu, Peter Lugthart, Max Mauerman, Jared Otuke, Linda Papagallo, Amol Singh Raswan, Elvis Siyamba, Venoo Tjiseua, Delia Welsh, and Sandy Yuan for research assistance and project management; Leon Burger, Holly Dentz, and Cornelis van der Waal for their support implementing the cattle, qualitative, and rangeland data collection exercises, respectively; Helmke von Bach, Donald Green, John Huber, Indongo Indongo, Edmore Masaire, Colin Nott, Heinrich Pielok, and James Walsh for comments; and Johannes Beck, Algerlynn Gill, and Jack Molyneaux for feedback and support throughout the research process. This evaluation was made possible by funding from the Millennium Challenge Corporation. The opinions expressed herein are those of the authors and do not necessarily reflect the views of MCC or the U.S. government. 
844 Author contributions: D.L.C: Analysis, Writing, Supervision; L.C.: Conceptualization, 845 Methodology, Supervision; S.L.D.: Analysis, Methodology, Writing; D.G.: Conceptualization, 846 Analysis, Methodology, Writing, Supervision; D.K.: Conceptualization, Analysis, Methodology, 847 Writing, Supervision; J.C.J.: Conceptualization, Methodology, Writing, Supervision; B.E.N.:

848 Methodology, Writing; R.D.R.: Analysis, Methodology, Writing.

849

850

851

852

853

854

855

856

857

858

859

860

861

862

863

864

865

866

867

868

869

870

871

872

Competing interests: None of the authors declares any competing interests.

Additional information: Supplementary Information is available for this paper.

Correspondence and requests for materials should be addressed to Dean Karlan

(karlan@northwestern.edu).

\section{List of extended data tables:}

Extended Data Table 1: Treatment effect on social indices

Extended Data Table 2: Treatment effect on rangeland health, cattle productivity, and household economics

Extended Data Table 3: Treatment effect on social indices and their components (Panel A) Extended Data Table 4: Treatment effect on social indices and their components (Panels B \& C) Extended Data Table 5: Treatment effect on indices of rangeland health, cattle productivity and household economics, and their components (Panel A)

Extended Data Table 6: Treatment effect on indices of rangeland health, cattle productivity and household economics, and their components (Panel B)

Extended Data Table 7: Treatment effect heterogeneity by rainfall for rangeland health, cattle productivity and household economics

Extended Data Table 8: Geographic spillover effects, for rangeland health

Extended Data Table 9: Mechanisms

Extended Data Table 10: Audits 
Extended Data Table 1: Treatment effect on social indices

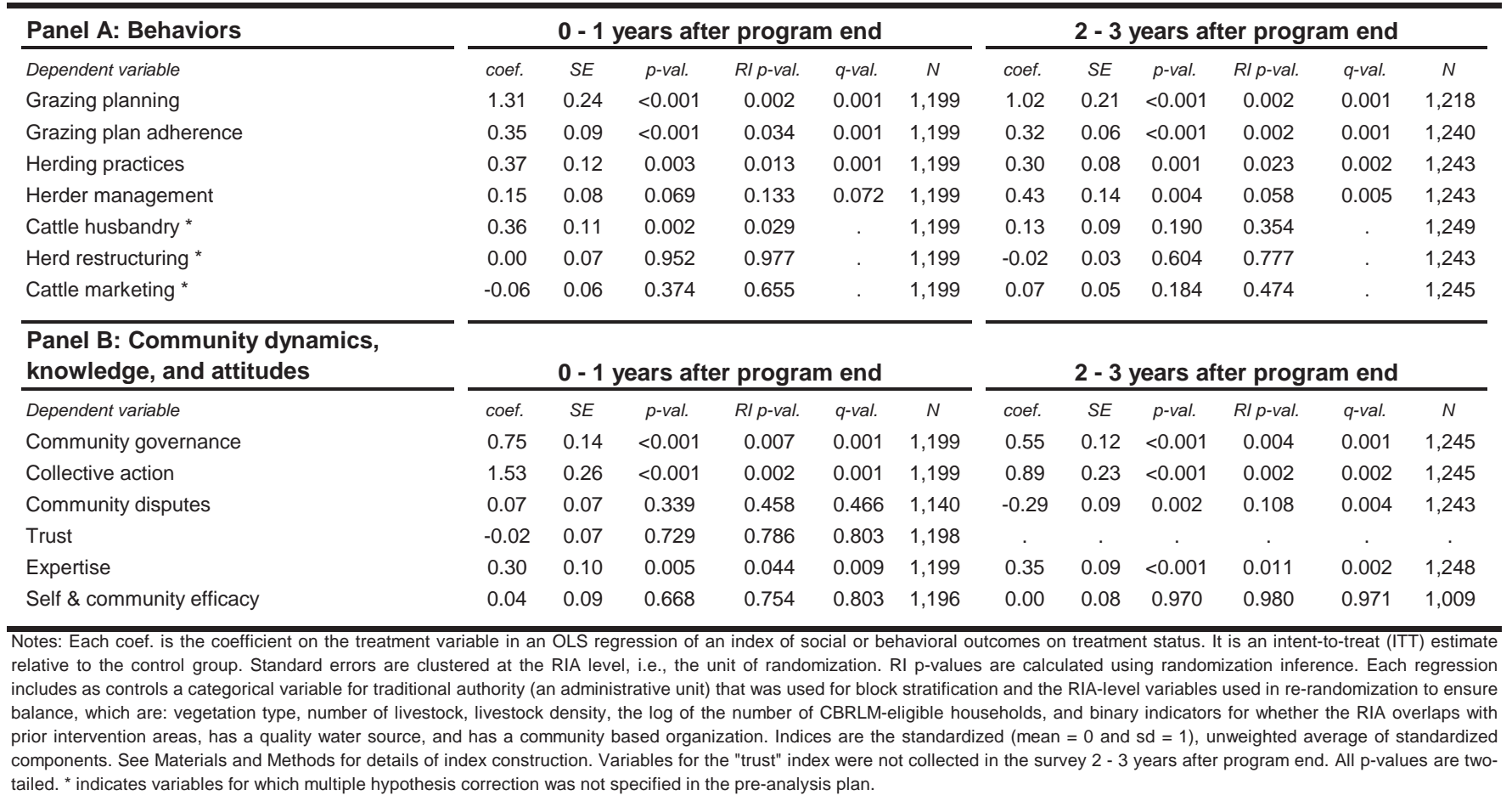




\section{Extended Data Table 2: Treatment effect on rangeland health, cattle productivity, and household economics}

\begin{tabular}{|c|c|c|c|c|c|c|}
\hline \multirow{2}{*}{$\begin{array}{l}\text { Panel A: Primary outcomes (indices) } \\
\text { Dependent variable }\end{array}$} & \multicolumn{6}{|c|}{2 - 3 years after program end } \\
\hline & coef. & SE & $p$-val. & RI p-val. & q-val. & $N$ \\
\hline Herd value & 0.00 & 0.11 & 0.988 & 0.994 & 0.982 & 653 \\
\hline Herd productivity & 0.02 & 0.09 & 0.826 & 0.904 & 0.982 & 1,285 \\
\hline Weekly household income & 0.08 & 0.07 & 0.230 & 0.418 & 0.975 & 1,210 \\
\hline Weekly household expenditure & 0.02 & 0.05 & 0.663 & 0.608 & 0.975 & 1,210 \\
\hline Household livestock wealth & -0.06 & 0.05 & 0.207 & 0.502 & 0.975 & 1,210 \\
\hline Panel B: Secondary outcomes (indices) & \multicolumn{6}{|c|}{2 - 3 years after program end } \\
\hline Dependent variable & coef. & $S E$ & $p$-val. & RI p-val. & $q$-val. & $N$ \\
\hline Herd structure & -0.02 & 0.07 & 0.746 & 0.841 & 0.984 & 653 \\
\hline Time use & 0.04 & 0.10 & 0.703 & 0.818 & 0.984 & 1,210 \\
\hline Resilience & -0.02 & 0.07 & 0.786 & 0.885 & 0.984 & 1,210 \\
\hline Female empowerment & -0.01 & 0.08 & 0.880 & 0.909 & 0.984 & 1,210 \\
\hline Meat and dairy consumption & 0.00 & 0.04 & 0.990 & 0.993 & 0.997 & 1,210 \\
\hline Panel C: Rangeland outcomes (standardized) & \multicolumn{6}{|c|}{2 - 3 years after program end } \\
\hline Dependent variable & coef. & $S E$ & $p$-val. & RI p-val. & q-val. & $N$ \\
\hline \multicolumn{7}{|l|}{ Erosion: } \\
\hline Wet season site erosion ( $1=$ no erosion, $0=$ erosion $)$ & -0.08 & 0.10 & 0.389 & 0.661 & . & 972 \\
\hline \multicolumn{7}{|l|}{ Ground cover: } \\
\hline Wet season unexposed soil surface (\%, logit-transformed) & -0.21 & 0.10 & 0.051 & 0.160 & . & 972 \\
\hline Wet season plant litter cover (\%, logit-transformed) & -0.18 & 0.08 & 0.035 & 0.201 & . & 972 \\
\hline Dry season plant litter cover (\%, logit-transformed) & -0.09 & 0.12 & 0.444 & 0.715 & . & 885 \\
\hline \multicolumn{7}{|l|}{ Herbaceous cover: } \\
\hline Wet season herbaceous canopy cover (\%, logit-transformed) & -0.26 & 0.14 & 0.072 & 0.270 & . & 972 \\
\hline Dry season herbaceous canopy cover (\%, logit-transformed) & -0.23 & 0.07 & 0.002 & 0.079 & . & 885 \\
\hline Wet season fresh plant biomass at site ( $\mathrm{kg} / \mathrm{ha}$, log-transformed) & -0.26 & 0.16 & 0.104 & 0.294 & . & 966 \\
\hline Dry season fresh plant biomass at site (kg/ha, log-transformed) & -0.21 & 0.07 & 0.004 & 0.112 & . & 792 \\
\hline \multicolumn{7}{|l|}{ Relative canopy cover of perennial and annual grasses: } \\
\hline Wet season perennial to annual canopy ratio (log-transformed) & -0.05 & 0.08 & 0.486 & 0.750 & . & 972 \\
\hline \multicolumn{7}{|l|}{ Relative canopy cover of grasses and forbs: } \\
\hline Wet season grass to forb canopy ratio (log-transformed) & -0.23 & 0.10 & 0.025 & 0.260 & . & 972 \\
\hline \multicolumn{7}{|l|}{ Weeds: } \\
\hline Wet season $\%$ of shrubs that are not stinkbush (\%, logit-transformed) & 0.02 & 0.08 & 0.770 & 0.922 & . & 870 \\
\hline Wet season grass to Aristida canopy cover ratio (log-transformed) * & -0.14 & 0.13 & 0.259 & 0.467 & . & 752 \\
\hline \multicolumn{7}{|l|}{ Woody vegetation: } \\
\hline Wet season shrub canopy cover (\%, logit-transformed) & -0.01 & 0.14 & 0.956 & 0.972 & . & 972 \\
\hline Dry season shrub canopy cover (\%, logit-transformed) & -0.09 & 0.15 & 0.569 & 0.734 & . & 885 \\
\hline
\end{tabular}

Notes: Each coef. is the coefficient on the treatment variable in an OLS regression of a physical program outcome on treatment status. It is an intent-to-treat (ITT) estimate relative to the control group. Data in Panels A and B were collected from surveys of heads of household and cattle managers, and data in Panel C were collected from randomly selected transects as described in the Methods. Standard errors are clustered at the RIA level, i.e., the unit of randomization. RI p-values are calculated using randomization inference. Each regression includes as controls a categorical variable for traditional authority (an administrative unit) that was used for block stratification and the RIA-level variables used in re-randomization to ensure balance, which are: quality of water source, an indicator for whether the RIA has a community based organization, vegetation type, number of livestock, livestock density, the log of the number of CBRLM-eligible households, and an indicator for whether the RIA overlaps with prior intervention areas. Indices are the standardized (mean $=0$ and sd $=1$ ), unweighted average of standardized components. Monetary variables have been scaled to weekly Namibian dollar (NAD) amounts. At the time of data collection (2017) the exchange rate was 13.3 NAD to 1 USD. Rangeland outcomes have been transformed as noted in parentheses to better meet assumptions of normality and homogeneity of variance. See Materials and Methods and the Supplementary Materials for details of index and variable construction. Multiple hypothesis correction was not specified for rangeland outcomes in the pre-analysis plan. All p-values are two-tailed. * Aristida is a genus of grasses that are undesirable forage plants in this context. 
Extended Data Table 3: Treatment effect on social indices and their components (Panel A)

Panel A: Behavioral outcomes

Dependent variable

Index: Grazing planning

Manager has grazing plan

Manager can show written grazing plan

Manager has grazing plan for next season

Dependent variable

Index: Grazing plan adherence

Manager followed grazing plan *

Number of months followed plan (past year)

Dependent variable

Index: Herding practices

Someone herds manager's cattle

Herder stays with cattle throughout day *

Cattle herded from water point in bunch

Cattle herded in bunch when grazing

No cattle missing from manager's herd

$(-1)^{\star}$ Ratio of cattle lost/stolen to cattle owned

Grazing plan intended to protect grass

Dependent variable
Index: Herder management
Manager communicates weekly with herders
Manager pays herders in cash
Total cash \& in-kind payment to herders (NAD)
Total spent on gear provided to herders (NAD)
Total gear provided to herders (\# of items)

Dependent variable

Index: Cattle husdandry

Cattle visit water point at least once per day

Any non-mandatory cattle vaccination

Cumulative number of cattle vaccinations

Total spent on cattle vaccines (NAD)

Cattle have been dewormed

Number of cattle dietary supplements provided

Cattle checked for ticks at least monthly

Total investment in animal treatment (NAD)

Fraction of cattle eartagged

Dependent variable

Index: Herd restructuring

Sold cattle to improve herd structure

Dependent variable

Index: Cattle marketing

Any live cattle sold (past year)

Total number of live cattle sold (past year)

Total value of live cattle sold (NAD, past year)
0 - 1 years after program end

.

\begin{tabular}{cccccc} 
coef. & $S E$ & $p$-val. & RI p-val. & Ctrl mean & $N$ \\
$\mathbf{1 . 3 1}$ & $\mathbf{0 . 2 4}$ & $<0.001$ & $\mathbf{0 . 0 0 2}$ & $\mathbf{0 . 0 0}$ & $\mathbf{1 , 1 9 9}$ \\
0.08 & 0.04 & 0.032 & 0.215 & 0.67 & 1,199 \\
0.27 & 0.05 & $<0.001$ & 0.001 & 0.01 & 1,182 \\
0.18 & 0.03 & $<0.001$ & 0.006 & 0.45 & 1,199 \\
\hline
\end{tabular}

$\begin{array}{cccccc}\text { coef. } & S E & p \text {-val. } & \text { RI p-val. } & \text { Ctrl mean } & N \\ \mathbf{0 . 3 5} & \mathbf{0 . 0 9} & <0.001 & \mathbf{0 . 0 3 4} & \mathbf{0 . 0 0} & \mathbf{1 , 1 9 9} \\ 0.17 & 0.03 & <0.001 & 0.017 & 0.40 & 1,199 \\ 0.88 & 0.39 & 0.030 & 0.178 & 5.00 & 1,186\end{array}$

$\begin{array}{cccccc}\text { coef. } & S E & p \text {-val. } & \text { RI p-val. } & \text { Ctrl mean } & N \\ \mathbf{0 . 3 7} & \mathbf{0 . 1 2} & \mathbf{0 . 0 0 3} & \mathbf{0 . 0 1 3} & \mathbf{0 . 0 0} & \mathbf{1 , 1 9 9} \\ 0.06 & 0.04 & 0.113 & 0.192 & 0.78 & 1,199 \\ 0.11 & 0.03 & <0.001 & 0.020 & 0.40 & 1,199 \\ 0.16 & 0.06 & 0.007 & 0.041 & 0.21 & 1,199 \\ 0.13 & 0.04 & 0.004 & 0.023 & 0.14 & 1,199 \\ 0.00 & 0.03 & 0.916 & 0.960 & 0.56 & 1,199 \\ -0.01 & 0.03 & 0.848 & 0.877 & -0.14 & 1,187\end{array}$

\begin{tabular}{cccccc}
. &. &. &. & -0.14 & 1,187 \\
&. &. &. &. \\
\hline
\end{tabular}

\begin{tabular}{cccccc}
\hline coef. & $S E$ & $p$-val. & Rl p-val. & Ctrl mean & $N$ \\
$\mathbf{0 . 1 5}$ & $\mathbf{0 . 0 8}$ & $\mathbf{0 . 0 6 9}$ & $\mathbf{0 . 1 3 3}$ & $\mathbf{0 . 0 0}$ & $\mathbf{1 , 1 9 9}$ \\
0.05 & 0.04 & 0.203 & 0.442 & 0.67 & 1,198 \\
0.09 & 0.04 & 0.019 & 0.106 & 0.28 & 1,198 \\
64.97 & 35.64 & 0.076 & 0.132 & 252.95 & 1,196 \\
. &. &. &. &. &. \\
-0.04 & 0.09 & 0.651 & 0.781 & 1.00 & 1,195 \\
\hline coef. & $S E$ & $p$-val. & RI p-val. & Ctrl mean & $N$
\end{tabular}

$\begin{array}{cccccc}\text { coef. } & S E & p \text {-val. } & \text { RI } p \text {-val. } & \text { Ctrl mean } & N \\ \mathbf{0 . 3 6} & \mathbf{0 . 1 1} & \mathbf{0 . 0 0 2} & \mathbf{0 . 0 2 9} & \mathbf{0 . 0 0} & \mathbf{1 , 1 9 9} \\ 0.17 & 0.05 & <0.001 & 0.020 & 0.18 & 1,199 \\ 0.07 & 0.05 & 0.158 & 0.366 & 0.54 & 1,199 \\ 0.17 & 0.09 & 0.071 & 0.257 & 0.83 & 1,199 \\ . & . & . & . & . & .\end{array}$

2 - 3 years after program end

coef. SE p-val. RIp-val. Ctrl mean N

$\begin{array}{llllll}1.02 & 0.21 & <0.001 & 0.002 & 0.00 & 1,218\end{array}$

$\begin{array}{llllll}0.13 & 0.03 & <0.001 & 0.002 & 0.62 & 1,217\end{array}$

$\begin{array}{llllll}0.20 & 0.05 & <0.001 & 0.002 & 0.03 & 1,218\end{array}$

coef. SE p-val. RIp-val. Ctrl mean $N$

$\begin{array}{llllll}0.32 & 0.06 & <0.001 & 0.002 & 0.00 & 1,240\end{array}$

$\begin{array}{llllll}0.09 & 0.03 & 0.002 & 0.024 & 0.25 & 1,218\end{array}$

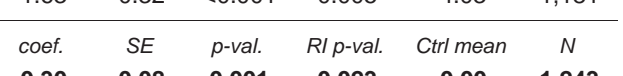

$\begin{array}{llllll}0.30 & 0.08 & 0.001 & 0.023 & 0.00 & 1,243\end{array}$

$\begin{array}{llllll}0.02 & 0.03 & 0.455 & 0.780 & 0.82 & 1,225\end{array}$

$\begin{array}{llllll}0.09 & 0.03 & 0.002 & 0.024 & 0.25 & 1,218\end{array}$

$\begin{array}{llllll}0.11 & 0.04 & 0.019 & 0.045 & 0.16 & 1,243\end{array}$

$\begin{array}{cccccc}-0.01 & 0.01 & 0.373 & 0.538 & -0.06 & 1,234\end{array}$

$\begin{array}{cccccc}0.13 & 0.05 & 0.010 & 0.045 & 0.19 & 819 \\ \text { coef. } & S E & p \text {-val. } & \text { Rl p-val. } & \text { Ctrl mean } & N\end{array}$

$\begin{array}{cccccc}\text { coef. } & S E & \text { p-val. } & \text { RI p-val. } & \text { Ctrl mean } & N \\ \mathbf{0 . 4 3} & \mathbf{0 . 1 4} & \mathbf{0 . 0 0 4} & \mathbf{0 . 0 5 8} & \mathbf{0 . 0 0} & \mathbf{1 , 2 4 3}\end{array}$

$\begin{array}{llllll}\cdot & \cdot & \cdot & \cdot & \cdot & \cdot\end{array}$

$\begin{array}{cccccc}60.45 & 69.11 & 0.387 & 0.585 & 463.78 & 1,204\end{array}$

$\begin{array}{llllll}-4.93 & 102.86 & 0.962 & 0.975 & 462.14 & 994\end{array}$

$\begin{array}{cccccc}\text { coef. } & S E & p \text {-val. } & \text { RI p-val. } & \text { Ctrl mean } & N \\ \mathbf{0 . 1 3} & \mathbf{0 . 0 9} & \mathbf{0 . 1 9 0} & \mathbf{0 . 3 5 4} & \mathbf{0 . 0 0} & \mathbf{1 , 2 4 9} \\ & . & . & . & . & \text {. }\end{array}$

$\begin{array}{llllll}0.04 & 0.05 & 0.416 & 0.603 & 0.59 & 1,242\end{array}$

$\begin{array}{cccccc}163.86 & 71.88 & 0.028 & 0.146 & 603.19 & 1,220\end{array}$

$\begin{array}{llllllllllll}0.08 & 0.04 & 0.032 & 0.124 & 0.17 & 1,199 & 0.02 & 0.04 & 0.608 & 0.652 & 0.30 & 1,243 \\ 0.11 & 0.09 & 0.236 & 0.464 & 0.93 & 1,199 & 0.18 & 0.12 & 0.165 & 0.345 & 1.39 & 1,242\end{array}$

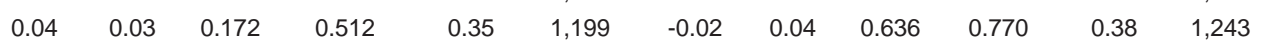

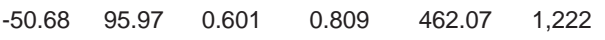

$\begin{array}{llllll}0.04 & 0.03 & 0.172 & 0.276 & 0.84 & 653\end{array}$

$\begin{array}{lccccc}\text { coef. } & S E & p \text {-val. } & \text { RI p-val. } & \text { Ctrl mean } & N \\ \mathbf{- 0 . 0 2} & \mathbf{0 . 0 3} & \mathbf{0 . 6 0 4} & \mathbf{0 . 7 7 7} & \mathbf{0 . 0 0} & \mathbf{1 , 2 4 3}\end{array}$

$\begin{array}{llllll}0.00 & 0.01 & 0.604 & 0.777 & 0.05 & 1,243\end{array}$

coef. SE p-val. Rlp-val. Ctrl mean $N$

$\begin{array}{llllll}0.07 & 0.05 & 0.184 & 0.474 & 0.00 & 1,245\end{array}$

$\begin{array}{llllll}0.04 & 0.02 & 0.067 & 0.226 & 0.36 & 1,243\end{array}$

$\begin{array}{llllll}0.18 & 0.26 & 0.506 & 0.698 & 1.67 & 1,245\end{array}$

$\begin{array}{llllll}1,246 & 1,055 & 0.245 & 0.561 & 7,108 & 1,226\end{array}$

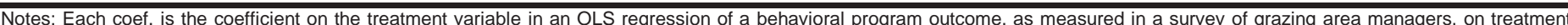

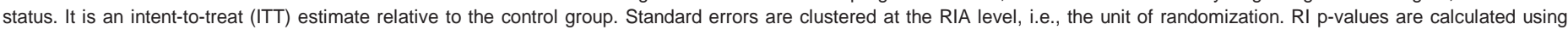

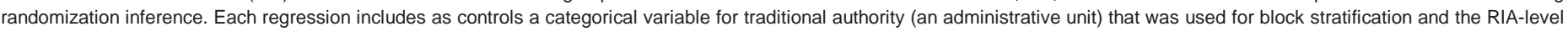

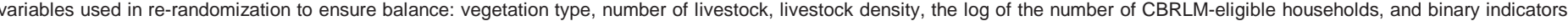

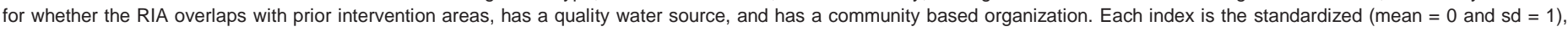

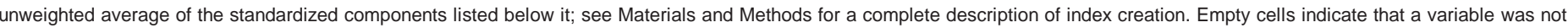

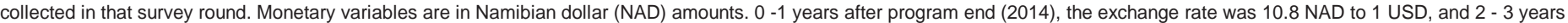

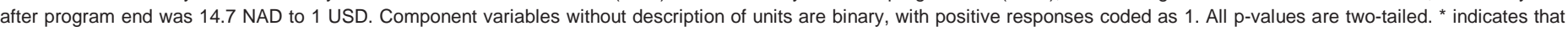

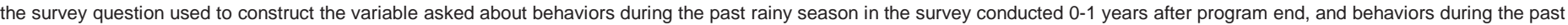
year in the survey conducted 2-3 years after program end. 
Panel B: Community dynamics, knowledge, and attitudes

Dependent variable

Index: Community governance

GA community groups, past 5 yrs (\# of groups)

GA community groups currently (\# of groups)

Manager's cumulative membership (\# of groups)

Group performance (\# of satisfying groups)

Farmers enforce water point payments

Farmers pay for water according to usage

Grazing plan formally enforced

Someone personally enforces grazing plan *

Non-community grazing not allowed

Conflict resolution is group-based

Satisfied with group conflict resolution (1 - 3 scale)

Approves of traditional authority

\section{Dependent variable}

Index: Collective action

Manager pays herders communally

Pays for vaccines communally

Pays for cattle care communally

Attended water committee $>4 x$ yearly *

Contributed money to water committee

Water committee contribution amt (NAD)

Attended development committee $>4 x$ yearly

Contributed money to development committee

Practiced rainy season combined herding *

Intentionally combined cattle with specific herd *

Ratio of GA herds to herds in combined herd *

Ratio of manager cattle to cattle in combined herd *

Grazing plan is decided on by group *

Shared grazing plan exists for rainy season *

Ratio of farmers in group grazing plan to GA herds *

Attended grazing committee $>4 x$ yearly

Contributed money to grazing committee

Grazing committee contribution amt (NAD)

Dependent variable

Index: Community disputes

Community conflicts decreased (past 3 yrs) *

Conflicts w/ farmers inside GA (-1*[\# conflicts])

Conflicts w/ farmers outside GA ( $-1^{*}$ [\# conflicts])

\section{Dependent variable}

Index: Trust

Manager believes people can be trusted

No decrease in \# of people manager trusts

\begin{tabular}{l} 
Dependent variable \\
Index: Expertise \\
Cattle expert available for disease questions \\
Cattle expert available for general questions \\
Correctly ages cow based on dental condition \\
Manager identifies ideal bull to cow ratio \\
Cattle weight guess $(-1 *[\%$ error] $)$ \\
Cattle market price guess $(-1 *[\%$ error] $)$ \\
\hline
\end{tabular}

\section{Dependent variable}

Own actions affect cattle health \& value

Community engagement affects cattle health

Community actions affect rangeland
Development committee contribution amt (NAD)

Index: Self \& community efficacy

Own actions affect rangeland quality
0 - 1 years after program end

\begin{tabular}{cccccc}
\hline coef. & $S E$ & $p$-val. & RI p-val. & Ctrl mean & $N$ \\
$\mathbf{0 . 7 5}$ & $\mathbf{0 . 1 4}$ & $<0.001$ & $\mathbf{0 . 0 0 7}$ & $\mathbf{0 . 0 0}$ & $\mathbf{1 , 1 9 9}$ \\
. &. &. &. &. &. \\
. &. &. &. &. &. \\
0.46 & 0.09 & $<0.001$ & 0.026 & 0.70 & 1,199 \\
. &. &. &. &. &. \\
. &. &. &. &. &.
\end{tabular}

$-0$

$\begin{array}{llllll}0.30 & 0.05 & <0.001 & 0.004 & 0.13 & 1,198\end{array}$

\begin{tabular}{cccccc}
-0.01 & 0.03 & 0.681 & 0.845 & 0.25 & 1,175 \\
\hline coef. & $S E$ & $p$-val. & Rl p-val. & Ctrl mean & $N$
\end{tabular}

$\begin{array}{llllll}1.53 & 0.26 & <0.001 & 0.002 & 0.00 & 1,199\end{array}$

$\begin{array}{llllll}0.08 & 0.01 & <0.001 & 0.023 & 0.02 & 1,199\end{array}$

$\begin{array}{llllll}0.15 & 0.04 & <0.001 & 0.013 & 0.03 & 1,199\end{array}$

$\begin{array}{cccccc}0.05 & 0.03 & 0.098 & 0.162 & 0.11 & 1,199\end{array}$

$\begin{array}{llllll}0.11 & 0.03 & <0.001 & 0.025 & 0.19 & 1,199\end{array}$

$\begin{array}{llllll}0.01 & 0.01 & 0.343 & 0.609 & 0.06 & 1,199\end{array}$

$\begin{array}{llllll}0.04 & 0.01 & <0.001 & 0.070 & 0.05 & 1,196\end{array}$

$\begin{array}{cccccc}0.34 & 0.04 & <0.001 & 0.004 & 0.38 & 1,188\end{array}$

$\begin{array}{llllll}0.34 & 0.06 & <0.001 & 0.004 & 0.20 & 1,199\end{array}$

$\begin{array}{llllll}0.23 & 0.05 & <0.001 & 0.003 & 0.05 & 1,089\end{array}$

$\begin{array}{llllll}0.21 & 0.06 & <0.001 & 0.007 & 0.03 & 1,039\end{array}$

$\begin{array}{llllll}0.28 & 0.05 & <0.001 & 0.004 & 0.22 & 1,189\end{array}$

$\begin{array}{llllll}0.19 & 0.04 & <0.001 & 0.012 & 0.32 & 1,199\end{array}$

$\begin{array}{llllll}0.18 & 0.04 & <0.001 & 0.020 & 0.13 & 1,171\end{array}$

$\begin{array}{llllll}0.16 & 0.03 & <0.001 & 0.009 & 0.03 & 1,199\end{array}$

$\begin{array}{llllll}0.16 & 0.04 & <0.001 & 0.007 & 0.02 & 1,197\end{array}$

$\begin{array}{cccccc} & & & & & \\ \text { coef. } & S E & p \text {-val. } & \text { RI p-val. } & \text { Ctrl mean } & N \\ \mathbf{0 . 0 7} & \mathbf{0 . 0 7} & \mathbf{0 . 3 3 9} & \mathbf{0 . 4 5 8} & \mathbf{0 . 0 0} & \mathbf{1 , 1 4 0} \\ 0.03 & 0.03 & 0.339 & 0.458 & 0.30 & \mathbf{1 , 1 4 0}\end{array}$

2 - $\mathbf{3}$ years after program end

\begin{tabular}{cccccc}
\hline coef. & $S E$ & $p$-val. & Rlp-val. & Ctrl mean & $N$ \\
$\mathbf{0 . 5 5}$ & $\mathbf{0 . 1 2}$ & $<\mathbf{0 . 0 0 1}$ & $\mathbf{0 . 0 0 4}$ & $\mathbf{0 . 0 0}$ & $\mathbf{1 , 2 4 5}$
\end{tabular}

$0.36 \quad 0.06<0.001$

$\begin{array}{llllll}0.32 & 0.08 & <0.001 & 0.049 & 1.47 & 1,243\end{array}$

$\begin{array}{llllll}0.30 & 0.08 & <0.001 & 0.060 & 0.78 & 1,244\end{array}$

$\begin{array}{llllll}0.86 & 0.21 & <0.001 & 0.041 & 3.69 & 1,243\end{array}$

$\begin{array}{llllll}0.03 & 0.05 & 0.578 & 0.742 & 0.65 & 1,243\end{array}$

$\begin{array}{llllll}0.02 & 0.06 & 0.759 & 0.821 & 0.19 & 1,239\end{array}$

$\begin{array}{llllll}0.05 & 0.02 & 0.010 & 0.083 & 0.04 & 1,243\end{array}$

$\begin{array}{llllll}0.26 & 0.05 & <0.001 & 0.003 & 0.13 & 1,217\end{array}$

$\begin{array}{llllll}0.07 & 0.02 & 0.005 & 0.070 & 0.16 & 1,230\end{array}$

$\begin{array}{llllll}0.09 & 0.02 & <0.001 & 0.041 & 0.60 & 1,243\end{array}$

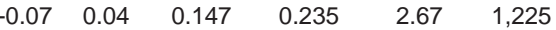

coef. SE p-val. Rlp-val. Ctrl mean $N$

$\begin{array}{llllll}0.89 & 0.23 & <0.001 & 0.002 & 0.00 & 1,245\end{array}$

$\begin{array}{llllll}0.11 & 0.03 & <0.001 & 0.036 & 0.28 & 1,240\end{array}$

$\begin{array}{llllll}0.05 & 0.07 & 0.457 & 0.646 & 0.32 & 1,243\end{array}$

$\begin{array}{llllll}0.04 & 0.02 & 0.094 & 0.156 & 0.12 & 1,239\end{array}$

$\begin{array}{llllll}0.04 & 0.04 & 0.320 & 0.503 & 0.25 & 1,243\end{array}$

$\begin{array}{llllll}43.72 & 67.97 & 0.524 & 0.609 & 138.89 & 1,230\end{array}$

$\begin{array}{llllll}0.02 & 0.01 & 0.185 & 0.498 & 0.05 & 1,238\end{array}$

$\begin{array}{llllll}-0.14 & 1.57 & 0.930 & 0.967 & 5.25 & 1,233\end{array}$

$\begin{array}{llllll}0.19 & 0.07 & 0.008 & 0.033 & 0.36 & 1,217\end{array}$

$\begin{array}{llllll}0.12 & 0.04 & 0.001 & 0.011 & 0.04 & 1,216\end{array}$

$\begin{array}{llllll}0.12 & 0.03 & <0.001 & 0.009 & 0.03 & 1,186\end{array}$

$\begin{array}{llllll}0.24 & 0.05 & <0.001 & 0.006 & 0.26 & 1,218\end{array}$

$\begin{array}{llllll}0.16 & 0.05 & 0.002 & 0.018 & 0.15 & 1,218\end{array}$

$\begin{array}{llllll}0.10 & 0.02 & <0.001 & 0.002 & 0.02 & 1,243\end{array}$

$\begin{array}{llllll}0.05 & 0.01 & <0.001 & 0.013 & 0.02 & 1,243\end{array}$

\begin{tabular}{llllll}
11.12 & 4.85 & 0.028 & 0.157 & 4.90 & 1,239 \\
\hline
\end{tabular}

$\begin{array}{cccccc}\text { coef. } & S E & p \text {-val. } & \text { RI p-val. } & \text { Ctrl mean } & N \\ \mathbf{- 0 . 2 9} & \mathbf{0 . 0 9} & \mathbf{0 . 0 0 2} & \mathbf{0 . 1 0 8} & \mathbf{0 . 0 0} & \mathbf{1 , 2 4 3}\end{array}$

$\begin{array}{cccccc}-0.12 & 0.03 & <0.001 & 0.082 & -1.15 & 1,243\end{array}$

\begin{tabular}{cccccc}
-0.08 & 0.03 & 0.012 & 0.182 & -1.08 & 1,243 \\
\hline coef. & $S E$ & $p$-val. & RI p-val. & Ctrl mean & $N$
\end{tabular}

\begin{tabular}{lccccc}
\hline coef. & $S E$ & $p$-val. & Rlp-val. & Ctrl mean & $N$ \\
$\mathbf{- 0 . 0 2}$ & $\mathbf{0 . 0 7}$ & $\mathbf{0 . 7 2 9}$ & $\mathbf{0 . 7 8 6}$ & $\mathbf{0 . 0 0}$ & $\mathbf{1 , 1 9 8}$ \\
-0.05 & 0.04 & 0.249 & 0.414 & 0.49 & 1,188 \\
0.03 & 0.03 & 0.351 & 0.603 & 0.64 & 1,177
\end{tabular}

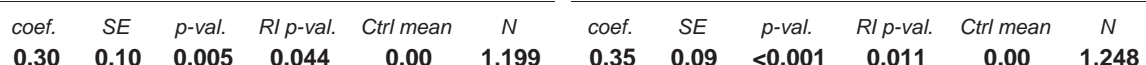

$\begin{array}{llllllllllll}0.18 & 0.05 & <0.001 & 0.025 & 0.43 & 1,199 & 0.17 & 0.06 & 0.003 & 0.020 & 0.31 & 1,234\end{array}$

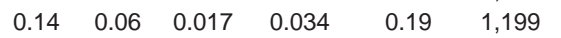

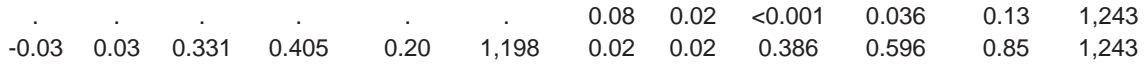

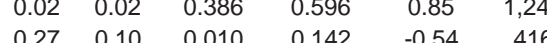

\begin{tabular}{llllll}
-0.02 & 0.02 & 0.418 & 0.587 & -0.33 & 409 \\
\hline
\end{tabular}

\begin{tabular}{ccccccccccccc}
\hline coef. & $S E$ & p-val. & RI p-val. & Ctrl mean & $N$ & & coef. & $S E$ & $p$-val. & RI p-val. & Ctrl mean & $N$ \\
$\mathbf{0 . 0 4}$ & $\mathbf{0 . 0 9}$ & $\mathbf{0 . 6 6 8}$ & $\mathbf{0 . 7 5 4}$ & $\mathbf{0 . 0 0}$ & $\mathbf{1 , 1 9 6}$ & $\mathbf{0 . 0 0}$ & $\mathbf{0 . 0 8}$ & $\mathbf{0 . 9 7 0}$ & $\mathbf{0 . 9 8 0}$ & $\mathbf{0 . 0 0}$ & $\mathbf{1 , 0 0 9}$ \\
0.00 & 0.03 & 0.903 & 0.928 & 0.78 & 1,196 & & 0.01 & 0.03 & 0.776 & 0.863 & 0.58 & 1,009 \\
0.03 & 0.05 & 0.471 & 0.642 & 0.61 & 1,195 & -0.02 & 0.03 & 0.576 & 0.637 & 0.49 & 1,009 \\
. &. &. &. &. &. & -0.02 & 0.04 & 0.683 & 0.820 & 0.64 & 1,009 \\
. &. &. &. &. &. & 0.03 & 0.04 & 0.455 & 0.682 & 0.64 & 1,009
\end{tabular}

Notes: Each coef. is the coefficient on the treatment variable in an OLS regression of a behavioral program outcome, as measured in a survey of grazing area managers, on treatment status. It is an intent-to-treat (ITT) estimate relative to the control group. Standard errors are clustered at the RIA level, i.e., the unit of randomization. RI p-values are calculated using randomization inference. Each regression includes as controls a categorical variable for traditional authority (an administrative unit) that was used for block stratification and the RIA-level variables used in re-randomization to ensure balance, which are: vegetation type, number of livestock, livestock density, the log of the number of CBRLM-eligible households, and binary indicators for whether the RIA overlaps with prior intervention areas, has a quality water source, and has a community based organization. Each index is the standardized (mean = 0 and sd = 1), unweighted average of the standardized components listed below it; see Materials and Methods for a complete description of index creation. Empty cells indicate that a variable or index was not collected in that survey round. Monetary variables are in Namibian dollar (NAD) amounts. 0 - 1 years after program end (2014), the exchange rate was 10.8 NAD to 1 USD, and 2 3 years after program end was 14.7 NAD to 1 USD. Component variables without description of units are binary, with positive responses coded as 1 . All p-values are two-tailed. * indicates that the survey question used to construct the variable asked about behaviors during the past rainy season in the survey conducted 0 - 1 years after program end, and behaviors during the past year in the survey conducted 2-3 years after program end. 
Extended Data Table 5: Treatment effect on indices of rangeland health, cattle productivity and household economics, and their components (Panel A)

\begin{tabular}{|c|c|c|c|c|c|c|}
\hline \multirow{2}{*}{$\begin{array}{l}\text { Panel A: Primary outcomes } \\
\text { Dependent variable }\end{array}$} & \multicolumn{6}{|c|}{$2-3$ years after program end } \\
\hline & coef. & SE & $p$-val. & RI p-val. & Ctrl mean & $N$ \\
\hline Index: Herd value & 0.00 & 0.11 & 0.988 & 0.994 & 0.00 & 653 \\
\hline Total number of cattle per kraal & 0.23 & 3.61 & 0.950 & 0.971 & 34.15 & 653 \\
\hline Total meat production per kraal $(\mathrm{kg})$ & -33 & 1,083 & 0.976 & 0.984 & 9,010 & 653 \\
\hline Total herd market value (NAD) & $-8,953$ & 116,241 & 0.939 & 0.960 & $1,007,571$ & 653 \\
\hline Dependent variable & coef. & $S E$ & $p$-val. & Rlp-val. & Ctrl mean & N \\
\hline Index: Herd productivity & 0.02 & 0.09 & 0.826 & 0.904 & 0.00 & 1,285 \\
\hline Calving rate among productive calves & 0.00 & 0.03 & 0.940 & 0.961 & 0.74 & 641 \\
\hline Change in herd size (\# of cattle, rainy season) & 0.47 & 1.27 & 0.715 & 0.780 & -8.23 & 1,243 \\
\hline Weekly milk products produced (kg, rainy season ) & 4.71 & 6.55 & 0.477 & 0.578 & 26.06 & 1,153 \\
\hline Sub-index: cattle weight & -0.06 & 0.09 & 0.480 & 0.622 & 0.00 & 653 \\
\hline Sub-index: cattle condition & -0.31 & 0.21 & 0.145 & 0.463 & 0.00 & 653 \\
\hline Sub-index: Cattle weight & -0.06 & 0.09 & 0.480 & 0.622 & 0.00 & 653 \\
\hline Average cow weight (kg) & 0.13 & 4.96 & 0.978 & 0.987 & 299.60 & 641 \\
\hline Average ox weight (kg) & 4.66 & 7.25 & 0.524 & 0.623 & 380.38 & 587 \\
\hline Average male calf weight $(\mathrm{kg})$ & 1.95 & 2.36 & 0.415 & 0.724 & 118.65 & 564 \\
\hline Average female calf weight $(\mathrm{kg})$ & -2.17 & 2.58 & 0.407 & 0.580 & 116.84 & 578 \\
\hline Average heifer weight $(\mathrm{kg})$ & -6.68 & 4.47 & 0.144 & 0.323 & 245.58 & 576 \\
\hline Average steer weight $(\mathrm{kg})$ & -11.15 & 6.04 & 0.073 & 0.271 & 241.01 & 363 \\
\hline Average bull weight (kg) & 16.11 & 12.59 & 0.209 & 0.343 & 386.04 & 361 \\
\hline Sub-index: Cattle body condition & -0.31 & 0.21 & 0.145 & 0.463 & 0.00 & 653 \\
\hline Average cow body condition ( 0 - 5 scale $)$ & -0.12 & 0.08 & 0.139 & 0.450 & 0.44 & 641 \\
\hline Average ox body condition ( 0 - 5 scale $)$ & -0.15 & 0.11 & 0.195 & 0.520 & 0.98 & 587 \\
\hline Average male calf body condition ( $0-5$ scale) & -0.04 & 0.05 & 0.437 & 0.711 & 0.27 & 564 \\
\hline Average female calf body condition ( $0-5$ scale $)$ & -0.10 & 0.06 & 0.072 & 0.354 & 0.26 & 577 \\
\hline Average heifer body condition ( 0 - 5 scale) & -0.19 & 0.11 & 0.090 & 0.385 & 0.65 & 576 \\
\hline Average steer body condition ( 0 - 5 scale) & -0.28 & 0.11 & 0.013 & 0.232 & 0.69 & 364 \\
\hline Average bull body condition ( 0 - 5 scale) & -0.09 & 0.15 & 0.539 & 0.705 & 1.03 & 362 \\
\hline Dependent variable & coef. & SE & $p$-val. & Rlp-val. & Ctrl mean & $N$ \\
\hline Additive index: Weekly per capita household income (NAD) & 39.81 & 32.59 & 0.230 & 0.418 & 201.09 & 1,210 \\
\hline Total crop revenue (NAD, scaled from 12 months) & 2.76 & 2.43 & 0.263 & 0.393 & 4.32 & 1,210 \\
\hline Total formal employment profits (NAD, scaled from 12 months) & 43.53 & 67.14 & 0.521 & 0.738 & 340.82 & 1,210 \\
\hline Total value of all food produced at home (NAD, weekly) & -2.80 & 33.72 & 0.934 & 0.970 & 201.48 & 1,210 \\
\hline Total value of non-sold byproducts (NAD, weekly) & -0.04 & 0.05 & 0.349 & 0.349 & 0.19 & 1,210 \\
\hline Value of own cattle used for plowing (NAD, scaled from 12 months) & -2.35 & 3.27 & 0.477 & 0.641 & 33.15 & 1,195 \\
\hline Total cattle sale revenue (NAD, scaled from 12 months) & 6.24 & 27.83 & 0.824 & 0.881 & 79.24 & 1,210 \\
\hline Total cattle byproduct sale revenue (NAD, scaled from 12 months) & 0.48 & 0.51 & 0.354 & 0.679 & 1.94 & 1,210 \\
\hline Amount of remittances received (NAD, scaled from 12 months) & 4.73 & 2.29 & 0.046 & 0.237 & 15.20 & 1,172 \\
\hline Dependent variable & coef. & SE & $p$-val. & RI p-val. & Ctrl mean & $N$ \\
\hline Additive index: Weekly per capita household expenditure (NAD) & 28.66 & 65.17 & 0.663 & 0.608 & 402.70 & 1,210 \\
\hline Total amount borrowed (NAD, scaled from 12 months) & -46.94 & 24.29 & 0.061 & 0.373 & 77.25 & 1,210 \\
\hline Total nonfood expenditure (NAD, scaled from 12 months) & -40.91 & 74.52 & 0.586 & 0.743 & 306.23 & 1,210 \\
\hline Total nonfood expenditure (NAD, scaled from 30 days) & 125.20 & 61.57 & 0.049 & 0.144 & 426.57 & 1,210 \\
\hline Total crop expenditure (NAD, scaled from 12 months) & 0.54 & 0.40 & 0.181 & 0.495 & 3.32 & 1,183 \\
\hline Expenditure hiring animals for plowing (NAD, scaled from 12 months) & 0.09 & 0.22 & 0.691 & 0.826 & 1.20 & 1,210 \\
\hline Amount sent in remittances (NAD, scaled from 12 months) & 5.06 & 3.67 & 0.176 & 0.432 & 21.89 & 1,210 \\
\hline Total expenditure on water (NAD, scaled from 12 months) & 0.08 & 0.91 & 0.927 & 0.967 & 6.60 & 1,176 \\
\hline Total value of food purchased (NAD) & 4.67 & 90.06 & 0.959 & 0.970 & 314.33 & 1,210 \\
\hline Amount spent purchasing cattle (NAD, scaled from 12 months) & 0.54 & 6.89 & 0.938 & 0.972 & 29.93 & 1,210 \\
\hline Amount spent transporting sold cattle (NAD, scaled from 12 months) & 0.07 & 0.13 & 0.620 & 0.654 & 0.13 & 1,210 \\
\hline Total cattle upkeep expenditure (NAD, scaled from 12 months) & 9.90 & 20.99 & 0.640 & 0.817 & 176.18 & 1,210 \\
\hline Dependent variable & coef. & $S E$ & $p$-val. & RI p-val. & Ctrl mean & $N$ \\
\hline Index: Household livestock wealth & -0.06 & 0.05 & 0.207 & 0.502 & 0.00 & 1,210 \\
\hline Total cattle wealth (livestock units) & -4.40 & 3.13 & 0.168 & 0.391 & 30.62 & 1,176 \\
\hline Total non-cattle wealth (livestock units) & -0.07 & 0.49 & 0.885 & 0.935 & 6.35 & 1,210 \\
\hline
\end{tabular}

Notes: Each coef. is the coefficient on the treatment variable in an OLS regression of a behavioral program outcome on treatment status. It is an intent-to-treat (ITT) estimate relative to the control group. Standard errors are clustered at the RIA level, i.e., the unit of randomization. RI p-values are calculated using randomization inference. Each regression includes as controls a categorical variable for traditional authority (an administrative unit) that was used for block stratification and the RIA-level variables used in re-randomization to ensure balance, which are: vegetation type, number of livestock, livestock density, the log of the number of CBRLM-eligible households, and binary indicators for whether the RIA overlaps with prior intervention areas, has a quality water source, and has a community based organization. Herd value, herd productivity, and household livestock wealth indices are the standardized (mean $=0$ and sd $=1$ ), unweighted average of the standardized components listed below each index. Income and expenditure indices are the sum of components, adjusted for household size. See Materials and Methods for a complete description of index creation. Monetary variables are in Namibian dollar (NAD) amounts. 0 -1 years after program end (2014), the exchange rate was 10.8 NAD to 1 USD, and 2 - 3 years after program end was 14.7 NAD to 1 USD. Cattle body condition scores are on a 0 - 5 scale used by Meat Corporation of Namibia, with 0 being low fat content and 5 being high. Component variables without description of units are binary, with positive responses coded as 1 . All p-values are two-tailed. 


\section{Extended Data Table 6: Treatment effect on indices of rangeland health, cattle productivity and}

household economics, and their components (Panel B \& C)

Panel B: Secondary outcomes

Dependent variable

Index: Herd structure

Ratio of bulls to cows is higher than 1:40

$(-1)^{\star}$ Ratio of oxen to total cattle

$(-1)^{\star}$ Ratio of unproductive cattle to total cattle

Dependent variable

Index: Time use

Days spent herding (typical week scaled to annual, adult)

Days spent working on crops (past year, adult)

Days formally employed (past year, adult)

$(-1)^{\star}$ Days spent herding (typical week scaled to annual, child)

$(-1)^{\star}$ Days spent working on crops (past year, child)

$(-1)^{\star}$ Days formally employed (past year, child)

\section{Dependent variable}

Index: Resilience

FAO food security index (-3 - 0; -3 = severely insecure)

Did not lack money for school fees (past year)

Savings available to cover emergency expense (NAD)

Savings and credit available to cover emergency expense (NAD)

Household saves money

Total household savings (NAD)

\section{Dependent variable}

Index: Female empowerment

Any female $\mathrm{HH}$ member owns cattle

Fraction of $\mathrm{HH}$ cattle owned by women

Any new female goat owner in $\mathrm{HH}$ (past 3 years)

Dependent variable

Index: Meat and dairy consumption

Per capita meat consumption (kg, past week)

Per capita dairy consumption ( $\mathrm{kg}$, past week)

\section{Panel C: Rangeland outcomes}

\section{Dependent variable}

Erosion:

Wet season site erosion ( 1 = no erosion, 0 = erosion $)$

Ground cover:

Wet season protected soil surface (\%, logit-transformed)

Wet season plant litter cover (\%, logit-transformed)

Dry season plant litter cover (\%, logit-transformed)

Herbaceous cover:

Wet season herbaceous canopy cover (\%, logit-transformed)

Dry season herbaceous canopy cover (\%, logit-transformed)

Wet season fresh plant biomass at site $(\mathrm{kg} / \mathrm{ha}$, log-transformed)

Dry season fresh plant biomass at site ( $\mathrm{kg} / \mathrm{ha}$, log-transformed)

Relative canopy cover of perennial and annual grasses:

Wet season perennial to annual canopy ratio (log-transformed)

Relative canopy cover of grasses and forbs:

Wet season grass to forb canopy ratio (log-transformed)

Weeds:

Wet season $\%$ of shrubs that are not stinkbush (\%, logit-transformed)

Wet season grass to Aristida canopy cover ratio (log-transformed) *

Woody vegetation:

Wet season shrub canopy cover (\%, logit-transformed)

Dry season shrub canopy cover (\%, logit-transformed)

2 - $\mathbf{3}$ years after program end

\begin{tabular}{|c|c|c|c|c|c|}
\hline coef. & $S E$ & p-val. & RI p-val. & Ctrl mean & $N$ \\
\hline-0.02 & 0.07 & 0.746 & 0.841 & 0.00 & 653 \\
\hline-0.10 & 0.03 & 0.001 & 0.104 & 0.61 & 646 \\
\hline 0.01 & 0.01 & 0.649 & 0.742 & -0.15 & 653 \\
\hline 0.02 & 0.01 & 0.206 & 0.586 & -0.13 & 653 \\
\hline coef. & $S E$ & p-val. & RI p-val. & Ctrl mean & $N$ \\
\hline 0.04 & 0.10 & 0.703 & 0.818 & 0.00 & 1,210 \\
\hline-8.40 & 10.49 & 0.429 & 0.558 & 81.70 & 1,210 \\
\hline 2.91 & 2.37 & 0.228 & 0.460 & 0.88 & 1,210 \\
\hline 3.62 & 4.57 & 0.433 & 0.586 & 34.74 & 1,210 \\
\hline-2.76 & 4.50 & 0.543 & 0.680 & -15.43 & 970 \\
\hline-0.27 & 0.30 & 0.381 & 0.594 & -0.17 & 970 \\
\hline-0.24 & 0.33 & 0.461 & 0.773 & -0.22 & 970 \\
\hline coef. & $S E$ & p-val. & RI p-val. & Ctrl mean & $N$ \\
\hline-0.02 & 0.07 & 0.786 & 0.885 & 0.00 & 1,210 \\
\hline-0.12 & 0.09 & 0.205 & 0.572 & -1.62 & 1,207 \\
\hline 0.02 & 0.02 & 0.343 & 0.622 & 0.89 & 1,210 \\
\hline-31.05 & 211.14 & 0.884 & 0.929 & 1,486 & 1,210 \\
\hline-341.20 & 216.17 & 0.123 & 0.407 & 2,829 & 1,210 \\
\hline 0.04 & 0.05 & 0.390 & 0.636 & 0.70 & 1,165 \\
\hline$-1,189$ & 2,279 & 0.605 & 0.731 & 6,720 & 1,034 \\
\hline coef. & $S E$ & p-val. & RI p-val. & Ctrl mean & $N$ \\
\hline-0.01 & 0.08 & 0.880 & 0.909 & 0.00 & 1,210 \\
\hline-0.03 & 0.04 & 0.382 & 0.597 & 0.48 & 1,210 \\
\hline-0.01 & 0.03 & 0.681 & 0.798 & 0.25 & 1,111 \\
\hline 0.02 & 0.02 & 0.457 & 0.616 & 0.13 & 1,210 \\
\hline coef. & $S E$ & p-val. & RI p-val. & Ctrl mean & $N$ \\
\hline 0.00 & 0.04 & 0.990 & 0.993 & 0.00 & 1,210 \\
\hline-1.12 & 2.00 & 0.579 & 0.684 & 6.77 & 1,210 \\
\hline 0.09 & 0.31 & 0.763 & 0.868 & 1.15 & 1,197 \\
\hline
\end{tabular}

\begin{tabular}{ccccccc}
\hline \multicolumn{7}{c}{$\mathbf{2}$ - $\mathbf{3}$ years after program end } \\
\hline coef. & SE & $p$-val. $\quad$ RI p-val. Ctrl mean & Treat mean $\mathrm{N}$
\end{tabular}

$\begin{array}{llllll}-0.04 & 0.05 & 0.389 & 0.661 & 0.517 & 0.434\end{array}$

$\begin{array}{lcccccc}-0.34 & 0.17 & 0.051 & 0.160 & 0.807 & 0.762 & 972 \\ -0.22 & 0.10 & 0.035 & 0.201 & 0.547 & 0.514 & 972 \\ -0.18 & 0.23 & 0.444 & 0.715 & 0.620 & 0.573 & 885 \\ & & & & & & \\ -0.53 & 0.29 & 0.072 & 0.270 & 0.446 & 0.369 & 972 \\ -0.52 & 0.16 & 0.002 & 0.079 & 0.216 & 0.171 & 885 \\ -0.45 & 0.27 & 0.104 & 0.294 & 459 & 338 & 966 \\ -0.48 & 0.16 & 0.004 & 0.112 & 233 & 227 & 792 \\ & & & & & & \\ -0.18 & 0.26 & 0.486 & 0.750 & 22.800 & 16.816 & 972 \\ -0.33 & 0.14 & 0.025 & 0.260 & 43.329 & 33.563 & 972 \\ 0.02 & 0.07 & 0.770 & 0.922 & 0.991 & 0.964 & 870 \\ -0.18 & 0.16 & 0.259 & 0.467 & 12.962 & 12.935 & 752 \\ -0.01 & 0.19 & 0.956 & 0.972 & 0.084 & 0.074 & 972 \\ -0.13 & 0.23 & 0.569 & 0.734 & 0.108 & 0.089 & 885\end{array}$

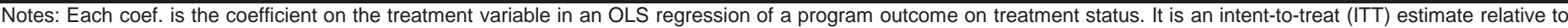

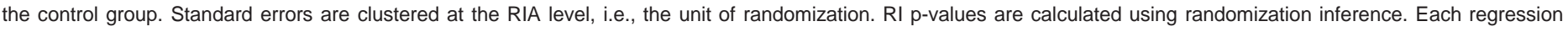

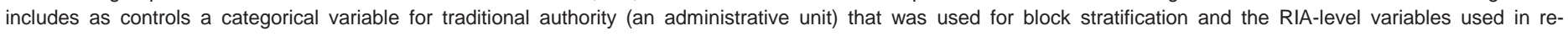

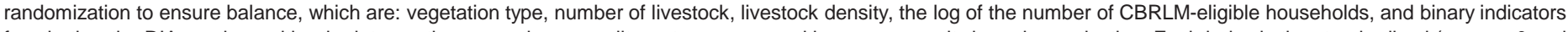

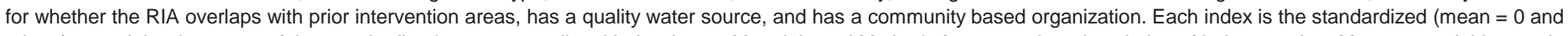

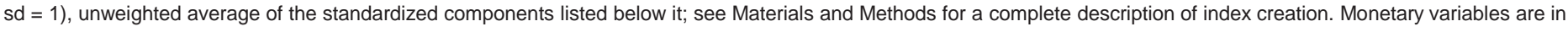

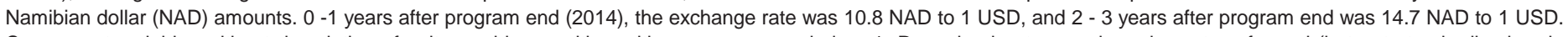

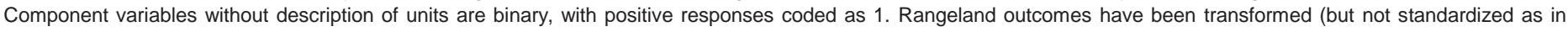

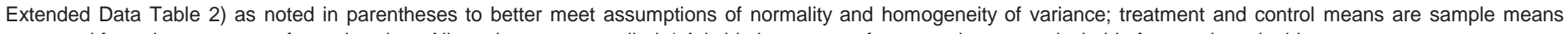
computed from data on untransformed scales. All p-values are two-tailed. * Aristida is a genus of grasses that are undesirable forage plants in this context. 


\section{Extended Data Table 7: Treatment effect heterogeneity by rainfall for rangeland health, cattle productivity and}

household economics

\begin{tabular}{|c|c|c|c|c|c|c|c|c|c|c|c|c|}
\hline \multirow{2}{*}{$\begin{array}{l}\text { Panel A: Physical outcomes ( } 2 \text { - } 3 \text { years) } \\
\text { Dependent variable }\end{array}$} & \multicolumn{3}{|c|}{ Treatment } & \multicolumn{3}{|c|}{$\begin{array}{l}\text { Low rainfall } \\
\text { indicator }\end{array}$} & \multicolumn{4}{|c|}{$\begin{array}{c}\text { Treatment } \mathrm{x} \text { low rainfall } \\
\text { indicator }\end{array}$} & \multirow[b]{2}{*}{ Ctrl mean } & \multirow[b]{2}{*}{$N$} \\
\hline & coef.1 & $S E$ & $p$-val. & coef.2 & $S E$ & $p$-val. & coef.3 & $S E$ & $p$-val. & RIp-val & & \\
\hline Herd value & 0.12 & 0.11 & 0.271 & -0.18 & 0.18 & 0.318 & -0.17 & 0.16 & 0.314 & 0.521 & 0.00 & 653 \\
\hline Herd productivity & -0.12 & 0.09 & 0.212 & -0.31 & 0.15 & 0.044 & 0.20 & 0.16 & 0.224 & 0.477 & 0.00 & 653 \\
\hline Weekly household income & 58.22 & 38.66 & 0.141 & 40.78 & 52.69 & 0.444 & -37.12 & 63.03 & 0.560 & 0.755 & 201.1 & 1,210 \\
\hline Weekly household expenditure & -33.96 & 74.49 & 0.651 & -23.77 & 113.8 & 0.836 & 118.5 & 127.5 & 0.359 & 0.549 & 402.7 & 1,210 \\
\hline Household livestock wealth & -0.03 & 0.06 & 0.624 & -0.03 & 0.16 & 0.841 & -0.05 & 0.09 & 0.565 & 0.749 & 0.00 & 1,210 \\
\hline Herd structure & -0.12 & 0.09 & 0.212 & -0.31 & 0.15 & 0.044 & 0.20 & 0.16 & 0.224 & 0.477 & 0.00 & 653 \\
\hline Time use & 0.27 & 0.16 & 0.089 & 0.62 & 0.29 & 0.037 & -0.48 & 0.26 & 0.068 & 0.168 & 0.00 & 1,210 \\
\hline Resilience & -0.17 & 0.09 & 0.076 & 0.00 & 0.13 & 0.969 & 0.28 & 0.12 & 0.028 & 0.177 & 0.00 & 1,210 \\
\hline Female empowerment & 0.06 & 0.13 & 0.666 & 0.08 & 0.14 & 0.591 & -0.14 & 0.14 & 0.347 & 0.521 & 0.00 & 1,210 \\
\hline Panel B: Rangeland outcomes (2 - years) & \multicolumn{3}{|c|}{ Treatment } & \multicolumn{3}{|c|}{$\begin{array}{l}\text { Low rainfall } \\
\text { indicator }\end{array}$} & \multicolumn{4}{|c|}{$\begin{array}{c}\text { Treatment } \mathrm{x} \text { low rainfall } \\
\text { indicator }\end{array}$} & & \\
\hline Dependent variable & coef. 1 & $S E$ & $p$-val. & coef.2 & $S E$ & p-val. & coef.3 & $S E$ & p-val. & RIp-val & Ctrl mean & $N$ \\
\hline \multicolumn{13}{|l|}{ Erosion: } \\
\hline Wet season site erosion ( $1=$ no erosion, $0=$ erosion $)$ & 0.01 & 0.08 & 0.887 & 0.01 & 0.10 & 0.877 & -0.14 & 0.09 & 0.129 & 0.319 & 0.52 & 972 \\
\hline \multicolumn{13}{|l|}{ Ground cover: } \\
\hline Wet season protected soil surface (\%, logit-trans.) & -0.53 & 0.22 & 0.019 & -0.28 & 0.17 & 0.103 & 0.43 & 0.25 & 0.099 & 0.295 & 0.81 & 972 \\
\hline Wet season plant litter cover (\%, logit-trans.) & -0.24 & 0.13 & 0.075 & 0.32 & 0.11 & 0.008 & 0.11 & 0.17 & 0.543 & 0.632 & 0.55 & 972 \\
\hline Dry season plant litter cover (\%, logit-trans.) & 0.00 & 0.42 & 0.994 & 0.02 & 0.31 & 0.950 & -0.31 & 0.49 & 0.531 & 0.687 & 0.62 & 885 \\
\hline \multicolumn{13}{|l|}{ Herbaceous cover: } \\
\hline Wet season herbaceous canopy cover (\%, logit-trans.) & -1.22 & 0.36 & 0.002 & -0.79 & 0.26 & 0.004 & 1.26 & 0.47 & 0.011 & 0.141 & 0.45 & 972 \\
\hline Dry season herbaceous canopy cover (\%, logit-trans.) & -0.84 & 0.21 & $<0.001$ & -0.84 & 0.22 & $<0.001$ & 0.58 & 0.20 & 0.007 & 0.126 & 0.22 & 885 \\
\hline Wet season fresh plant biomass at site ( $\mathrm{kg} / \mathrm{ha}$, log-trans.) & -0.67 & 0.28 & 0.024 & -0.47 & 0.29 & 0.113 & 0.41 & 0.32 & 0.209 & 0.455 & 459.37 & 966 \\
\hline Dry season fresh plant biomass at site (kg/ha, log-trans.) & -0.78 & 0.20 & $<0.001$ & -0.67 & 0.11 & $<0.001$ & 0.68 & 0.26 & 0.014 & 0.124 & 232.59 & 792 \\
\hline \multicolumn{13}{|l|}{ Relative canopy cover of perennial and annual grasses: } \\
\hline Wet season perennial to annual canopy ratio (log-trans.) & 0.44 & 0.46 & 0.347 & 0.17 & 0.50 & 0.730 & -0.87 & 0.64 & 0.184 & 0.294 & 22.80 & 972 \\
\hline \multicolumn{13}{|l|}{ Relative canopy cover of grasses and forbs: } \\
\hline Wet season grass to forb canopy ratio (log-trans.) & -0.43 & 0.23 & 0.068 & -0.09 & 0.32 & 0.783 & 0.21 & 0.33 & 0.530 & 0.640 & 43.33 & 972 \\
\hline \multicolumn{13}{|l|}{ Weeds: } \\
\hline $\begin{array}{l}\text { Wet season \% of shrubs that are not stinkbush (\%, logit- } \\
\text { trans.) } \\
\text { Wet season grass to Aristida canopy cover ratio (log- }\end{array}$ & 0.05 & 0.09 & 0.567 & 0.28 & 0.15 & 0.065 & -0.03 & 0.15 & 0.853 & 0.852 & 0.99 & 870 \\
\hline trans.) * & -0.26 & 0.19 & 0.186 & -0.49 & 0.18 & 0.011 & 0.08 & 0.19 & 0.698 & 0.873 & 12.96 & 752 \\
\hline \multicolumn{13}{|l|}{ Woody vegetation: } \\
\hline Wet season shrub canopy cover (\%, logit-trans.) & 0.01 & 0.26 & 0.967 & -0.38 & 0.18 & 0.039 & -0.10 & 0.32 & 0.747 & 0.811 & 0.08 & 972 \\
\hline Dry season shrub canopy cover (\%, logit-trans.) & -0.09 & 0.33 & 0.794 & -0.48 & 0.33 & 0.162 & -0.03 & 0.40 & 0.934 & 0.942 & 0.11 & 885 \\
\hline
\end{tabular}

Notes: Each row displays results from a separate regression in which the dependent variable is a rangeland outcome and the independent variables are treatment status and an indicator variable for low rainfall. Coef. 1 indicates the coefficient on treatment, which is an intent-to-treat (ITT) estimate relative to control. Coef. 2 indicates the coefficient on an indicator variable for low rainfall, which is equal to 1 if a grazing area was below the median of all grazing areas in terms of percent difference in the grazing area's rainfall during the project period relative to the mean of the grazing area's rainfall over the 10 years prior to the program. Coef. 3 shows the interaction of the low-rainfall indicator with treatment. Standard errors are clustered at the RIA level, i.e., the unit of randomization. RI p-values are calculated using randomization inference. Each regression includes as controls a categorical variable for traditional authority (an administrative unit) that was used for block stratification and the RIA-level variables used in re-randomization to ensure balance: vegetation type, number of livestock, livestock density, the log of the number of CBRLM-eligible households, and binary indicators for whether the RIA overlaps with prior intervention areas, has a quality water source, and has a community based organization. See Materials and Methods for additional details of this analysis. All p-values are two-tailed. 
Extended Data Table 8: Geographic spillover effects, rangeland health

Rangeland outcomes ( 2 - 3 years after program end)

Effect of control GA being located < median distance from a treatment $\mathrm{GA}$

\begin{tabular}{|c|c|c|c|c|c|c|}
\hline Dependent variable & coef. & $S E$ & $p$-val. & Distant mean & Near mean & $N$ \\
\hline \multicolumn{7}{|l|}{ Erosion: } \\
\hline Wet season site erosion ( $1=$ no erosion, $0=$ erosion $)$ & -0.03 & 0.06 & 0.627 & 0.47 & 0.56 & 553 \\
\hline \multicolumn{7}{|l|}{ Ground cover: } \\
\hline Wet season protected soil surface $(\%$, logit-transformed) & -0.52 & 0.32 & 0.126 & 0.79 & 0.82 & 553 \\
\hline Wet season plant litter cover (\%, logit-transformed) & -0.31 & 0.21 & 0.164 & 0.54 & 0.55 & 553 \\
\hline Dry season plant litter cover (\%, logit-transformed) & -0.24 & 0.42 & 0.582 & 0.60 & 0.63 & 499 \\
\hline \multicolumn{7}{|l|}{ Herbaceous cover: } \\
\hline Wet season herbaceous canopy cover (\%, logit-transformed) & -0.29 & 0.34 & 0.409 & 0.41 & 0.48 & 553 \\
\hline Dry season herbaceous canopy cover (\%, logit-transformed) & -0.32 & 0.43 & 0.475 & 0.17 & 0.25 & 499 \\
\hline Wet season fresh plant biomass ( $\mathrm{kg} / \mathrm{ha}$, log-transformed) & 0.12 & 0.22 & 0.589 & 459 & 463.82 & 550 \\
\hline Dry season fresh plant biomass (kg/ha, log-transformed) & -0.52 & 0.24 & 0.042 & 265 & 207.94 & 445 \\
\hline \multicolumn{7}{|l|}{ Relative canopy cover of perennial and annual grasses: } \\
\hline Wet season perennial to annual canopy ratio (log-transformed) & -0.33 & 0.80 & 0.683 & 27.28 & 19.07 & 553 \\
\hline \multicolumn{7}{|l|}{ Relative canopy cover of grasses and forbs: } \\
\hline Wet season grass to forb canopy ratio (log-transformed) & -0.53 & 0.23 & 0.038 & 42.97 & 44.19 & 553 \\
\hline \multicolumn{7}{|l|}{ Weeds: } \\
\hline Wet season \% of shrubs that are not stinkbush $(\%$, logit-transformed) & 0.07 & 0.14 & 0.627 & 0.98 & 1.00 & 498 \\
\hline Wet season grass to Aristida canopy cover ratio (log-transformed) * & -0.19 & 0.20 & 0.364 & 11.06 & 15.00 & 443 \\
\hline \multicolumn{7}{|l|}{ Woody vegetation: } \\
\hline Wet season shrub canopy cover (\%, logit-transformed) & 0.14 & 0.15 & 0.367 & 0.09 & 0.08 & 553 \\
\hline Dry season shrub canopy cover (\%, logit-transformed) & -0.08 & 0.27 & 0.783 & 0.13 & 0.09 & 499 \\
\hline
\end{tabular}


Extended Data Table 9: Mechanisms

\begin{tabular}{|c|c|c|c|c|c|c|}
\hline \multirow{2}{*}{$\frac{\text { Panel A: Direct evidence of grazing intensity }}{\text { Dependent variable }}$} & \multicolumn{6}{|c|}{ Treatment effect 2 years after program end } \\
\hline & coef. & SE & p-val. & $R I p$-val. & Ctrl mean & $N$ \\
\hline Evidence of heavy grazing on herbaceous plants (wet season) & 0.12 & 0.04 & 0.003 & 0.032 & 0.13 & 972 \\
\hline Evidence of heavy grazing on herbaceous plants (dry season) & 0.10 & 0.04 & 0.016 & 0.106 & 0.46 & 972 \\
\hline Evidence of any grazing on herbaceous plants (wet season) & 0.04 & 0.03 & 0.151 & 0.336 & 0.92 & 972 \\
\hline Evidence of any grazing on herbaceous plants (dry season) & 0.00 & 0.03 & 0.953 & 0.980 & 0.87 & 972 \\
\hline Panel B: Potential causes of increased grazing intensity & \multicolumn{6}{|c|}{ Treatment effect 2 - 3 years after program end } \\
\hline Dependent variable & coef. & SE & p-val. & $R I p$-val. & Ctrl mean & $N$ \\
\hline \multicolumn{7}{|l|}{ Cattle numbers } \\
\hline Number of herds currently in GA & -1.49 & 1.80 & 0.413 & 0.580 & 21.94 & 1,210 \\
\hline Number of cattle currently in GA & -178 & 130 & 0.178 & 0.433 & 1,011 & 1,245 \\
\hline \multicolumn{7}{|l|}{ Reduced farmer movement } \\
\hline Manager moved cattle outside GA in past year & -0.04 & 0.03 & 0.290 & 0.549 & 0.20 & 1,242 \\
\hline Fraction of herd that manager moved outside GA in past year & -0.04 & 0.04 & 0.295 & 0.567 & 0.19 & 1,238 \\
\hline Number of months in which manager moved cattle outside GA (past 12 months) & -0.19 & 0.17 & 0.273 & 0.535 & 0.92 & 1,243 \\
\hline Number of years in which manager moved cattle outside GA (past 6 years) & -0.08 & 0.16 & 0.636 & 0.782 & 0.76 & 1,243 \\
\hline \multicolumn{7}{|l|}{ Outside encroachment } \\
\hline Outside farmers brought cattle to GA in past year & 0.05 & 0.03 & 0.105 & 0.408 & 0.37 & 1,207 \\
\hline Outside farmers brought cattle to GA in past year without permission & 0.07 & 0.02 & 0.005 & 0.070 & 0.16 & 1,230 \\
\hline Freq. at which herders saw outside herders in GA in past wet season ( 1 - 6 scale) & 0.15 & 0.30 & 0.617 & 0.785 & 2.69 & 280 \\
\hline Freq. at which herders saw outside herders in GA in past dry season (1 - 6 scale) & 0.40 & 0.27 & 0.151 & 0.241 & 2.77 & 277 \\
\hline Herders saw outside herder in GA more than once a week in past wet season & 0.07 & 0.07 & 0.326 & 0.550 & 0.28 & 280 \\
\hline Herders saw outside herder in GA more than once a week in past dry season & 0.13 & 0.07 & 0.056 & 0.196 & 0.31 & 277 \\
\hline
\end{tabular}

Notes: Each coef. is the coefficient on the treatment variable in an OLS regression of a program outcome on treatment status. It is an intent-to-treat (ITT) estimate relative to the control group. Standard errors are clustered at the RIA level, i.e., the unit of randomization. RI p-values are calculated using randomization inference. Each regression includes as controls a categorical variable for traditional authority (an administrative unit) that was used for block stratification and the RIA-level variables used in re-randomization to ensure balance, which are: vegetation type, number of livestock, livestock density, the log of the number of CBRLM-eligible households, and binary indicators for whether the RIA overlaps with prior intervention areas, has a quality water source, and has a community based organization. The $1-6$ scale used to measure frequency at which herders saw outside herders in the GA is as follows: 0 = "never", $1=$ "less than once a month", 2 = "once a month", 3 = "multiple times per month", 4 = "once a week", 5 = "multiple times per week", 6 = "daily". Variables without description of units are binary. All p-values are two-tailed. 
Extended Data Table 10: Audits

\begin{tabular}{|c|c|c|c|c|c|c|}
\hline \multirow{2}{*}{$\begin{array}{l}\text { Panel A: } 0 \text { - } 1 \text { years after program end } \\
\text { Dependent variable }\end{array}$} & \multicolumn{6}{|c|}{ Treatment effect } \\
\hline & coef. & $S E$ & $p$-val. & RI p-val. & Ctrl mean & $N$ \\
\hline Combined herding observed in GA & 0.28 & 0.08 & $<0.001$ & 0.010 & 0.10 & 123 \\
\hline Number of herds in combined herd & 2.47 & 0.74 & 0.002 & 0.020 & 0.35 & 123 \\
\hline Number of cattle in combined herd & 52.85 & 17.10 & 0.004 & 0.020 & 14.15 & 122 \\
\hline Combined herd herded in bunched shape & 0.20 & 0.09 & 0.033 & 0.010 & 0.04 & 123 \\
\hline Combined herd is accompanied by herders & 0.37 & 0.09 & $<0.001$ & 0.000 & 0.06 & 123 \\
\hline Number of herd owners listed in grazing group meeting minutes & 2.60 & 0.70 & $<0.001$ & 0.010 & 0.96 & 123 \\
\hline Number of herd owners listed in grazing group contribution list & 1.92 & 0.54 & 0.001 & 0.020 & 0.39 & 123 \\
\hline Number of herd owners in water group meeting minutes & -1.03 & 1.54 & 0.509 & 0.770 & 3.41 & 123 \\
\hline Number of herd owners in water group contribution list & 1.31 & 0.81 & 0.112 & 0.140 & 2.93 & 123 \\
\hline Number of herd owners in development group meeting minutes & 0.86 & 0.73 & 0.247 & 0.550 & 2.10 & 123 \\
\hline Number of herd owners in development group contributions list & 0.97 & 0.46 & 0.040 & 0.180 & 0.55 & 123 \\
\hline Panel B: 3 years after program end & \multicolumn{6}{|c|}{ Treatment effect } \\
\hline Dependent variable & coef. & $S E$ & p-val. & RI p-val. & Ctrl mean & $N$ \\
\hline Herders observed combined herding & 0.12 & 0.06 & 0.047 & 0.100 & 0.16 & 358 \\
\hline Herders observed returning from grazing with cattle & 0.09 & 0.05 & 0.072 & 0.220 & 0.40 & 357 \\
\hline Herders observed actively herding cattle while grazing & 0.05 & 0.04 & 0.252 & 0.320 & 0.26 & 358 \\
\hline \# Herders observed actively herding cattle during grazing & 0.18 & 0.10 & 0.075 & 0.120 & 0.29 & 358 \\
\hline Herders report following grazing plan & 0.12 & 0.05 & 0.013 & 0.120 & 0.49 & 345 \\
\hline Herders report following written grazing plan & 0.12 & 0.04 & 0.009 & 0.130 & 0.06 & 355 \\
\hline Herders report following group grazing plan & 0.12 & 0.05 & 0.015 & 0.100 & 0.20 & 355 \\
\hline Combined cash and in-kind payments each herder receives & 123.10 & 87.79 & 0.169 & 0.430 & 631.93 & 261 \\
\hline Herd owner listed in grazing group meeting minutes & 0.10 & 0.05 & 0.029 & 0.100 & 0.04 & 1,359 \\
\hline Herd owner listed in grazing group contributions list & 0.09 & 0.05 & 0.090 & 0.220 & 0.06 & 1,359 \\
\hline Herd owner listed in water group meeting minutes & 0.07 & 0.06 & 0.250 & 0.470 & 0.17 & 1,359 \\
\hline Herd owner listed in water group contributions list & 0.09 & 0.06 & 0.150 & 0.340 & 0.26 & 1,359 \\
\hline Herd owner listen in development group meeting minutes & -0.01 & 0.02 & 0.472 & 0.750 & 0.06 & 1,359 \\
\hline Herd owner listed in development group contributions list & -0.03 & 0.02 & 0.187 & 0.430 & 0.07 & 1,359 \\
\hline
\end{tabular}

Notes: Each coef. is the coefficient on the treatment variable in an OLS regression of a program outcome on treatment status. It is an intent-to-treat (ITT) estimate relative to the control group. Standard errors are clustered at the RIA level, i.e., the unit of randomization. RI p-values are calculated using randomization inference. Each regression includes as controls a categorical variable for traditional authority (an administrative unit) that was used for block stratification and the RIA-level variables used in rerandomization to ensure balance, which are: vegetation type, number of livestock, livestock density, the log of the number of CBRLM-eligible households, and binary indicators for whether the RIA overlaps with prior intervention areas, has a quality water source, and has a community based organization. Variables without description of units are binary, with positive responses coded as 1. See Materials and Methods for additional details. All p-values are two-tailed. 


\title{
Supplementary Information for:
}

\section{Cooperation in the commons: Community-based rangeland management in Namibia}

\author{
D. Layne Coppock ${ }^{1}$, Lucas Crowley ${ }^{2}$, Susan L. Durham ${ }^{3}$, Dylan Groves ${ }^{4}$, Julian C. Jamison ${ }^{5}$, \\ Dean Karlan ${ }^{6 *}$, Brien E. Norton ${ }^{7}$, R. Douglas Ramsey ${ }^{7}$ \\ ${ }^{1}$ Department of Environment and Society, Utah State University, Logan, UT 84322-5215, USA. ${ }^{2}$ Innovations for \\ Poverty Action, Washington D.C., 20005, USA. ${ }^{3}$ Ecology Center, Utah State University, Logan, UT 84322-5205, \\ USA. ${ }^{4}$ Department of Political Science, Columbia University, New York City, NY, 10027, USA. ${ }^{5}$ Department of \\ Economics, University of Exeter, Exeter EX44LZ, U.K. ${ }^{6}$ Kellogg School of Management, Northwestern University, \\ Evanston, IL 60208, USA. ${ }^{7}$ Department of Wildland Resources, Utah State University, Logan, UT 84322-5230, \\ USA.*To whom correspondence should be addressed. E-mail: karlan@northwestern.edu
}

\section{Contents:}

1. Supplementary Methods

a. Study timelines

b. Data collection

i. Primary outcome variable definitions

ii. Cattle scoring key

2. Supplementary Text

a. Context

i. Historical context

ii. Program context

iii. Ecological context

b. Scientific rationale for planned grazing

c. Comparing CBRLM and holistic management approaches

i. Community governance

ii. Commercialization of livestock production

3. Supplementary References

4. Supplementary Tables $1-5$

a. Supplementary Table 1: Randomization balance

b. Supplementary Table 2: Program participation and attrition

c. Robustness checks

i. Supplementary Table 3: Treatment effect on social indices, with inverse probability weighting

ii. Supplementary Table 4: Treatment effect on physical outcomes, with inverse probability weighting

d. Supplementary Table 5: Treatment effect heterogeneity by rainfall for social indices 


\section{Supplementary Methods}

\section{a. Study timelines}

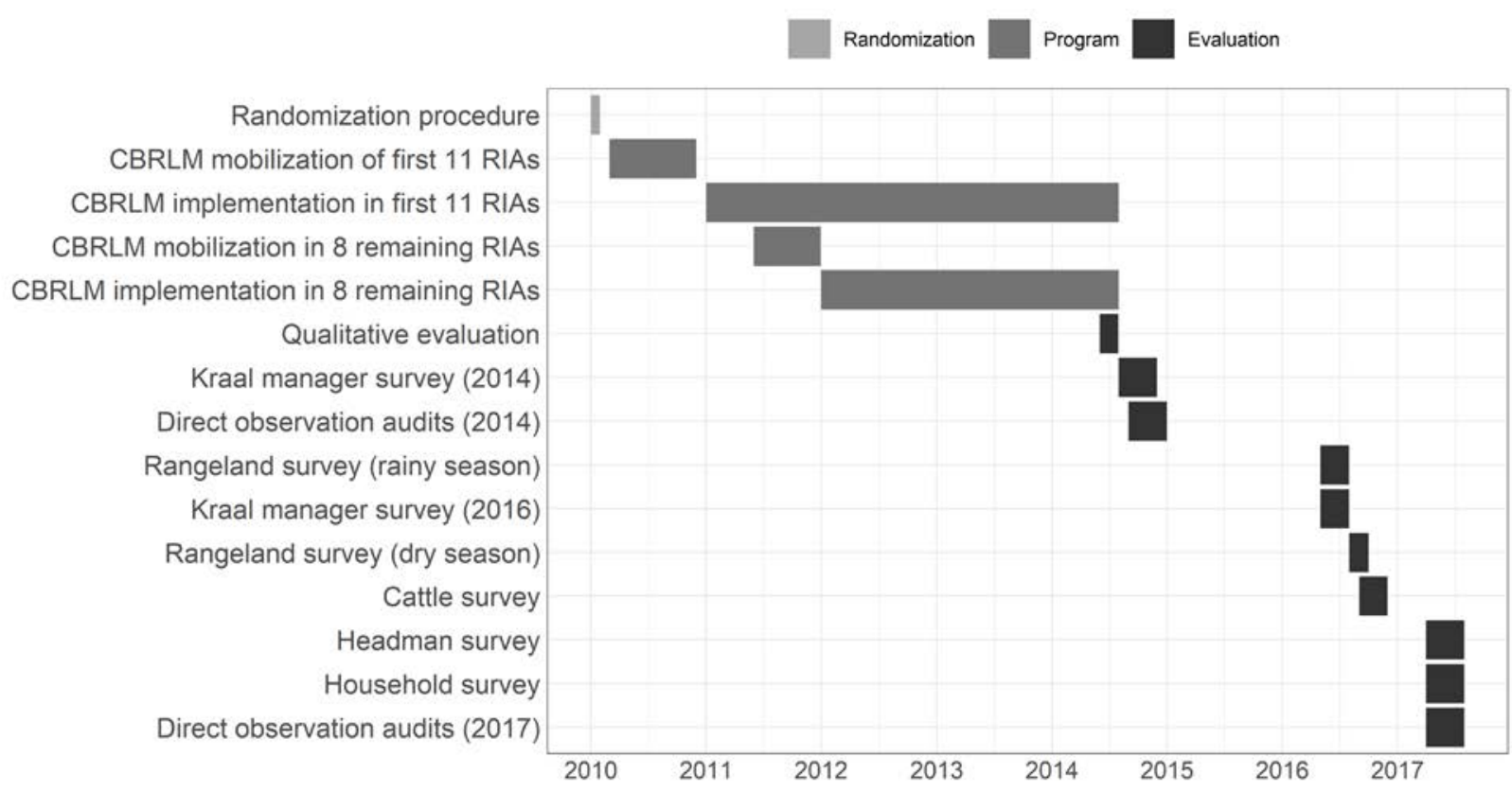

Supplementary Fig. 1. Timelines for community-based rangeland management (CBRLM) mobilization, implementation, and the research components.

$=$ Mobilized GAs = Actively enrolled GAs $=$ GA visits per month

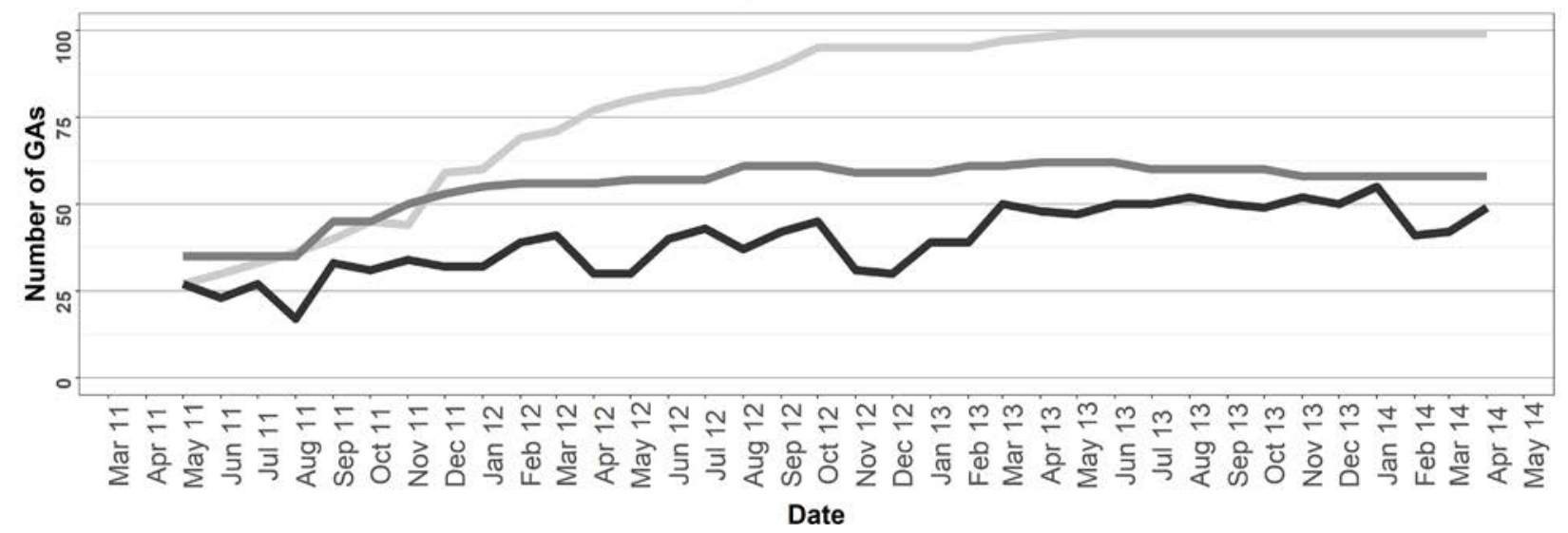

Supplementary Fig. 2. Timelines for grazing area (GA) mobilization, enrollment, and visits by implementation staff. 


\section{b. Data collection}

\section{i. Primary outcome variable definitions}

Definitions of social variables depicted in Fig. 2 (see Main Text) and Extended Data Table 1 are as follows:

(a) Grazing planning is an index of three variables measuring whether the manager has a grazing plan and whether the grazing plan is written.

(b) Grazing plan adherence is an index of two variables measuring whether and for how long the herd manager followed a pre-defined grazing plan while herding cattle.

(c) Herding practices is an index of seven variables measuring whether the herd manager follows herding practices recommended by the program, such staying with the cattle throughout the day and herding cattle in a bunch.

(d) Herder management is an index of five variables measuring the extent to which the herd owner provides oversight and material support to herders.

(e) Cattle husbandry is an index of nine variables measuring whether the herd manager follows cattle husbandry practices recommended by the program, such as vaccinating and deworming cattle.

(f) Herd restructuring is a measure of whether herd owners have made any decisions to buy or sell cattle in order to change the structure of their herd, as opposed to reasons such as immediate financial need or sick cattle.

(g) Livestock marketing is an index of three variables measuring whether the herd owners sold any cattle, the number of cattle sold, and the total value of cattle sold.

(h) Community governance is an index of 12 variables measuring whether respondent perceives their community to be governed by institutional rules.

(i) Collective action is a measure of 19 variables measuring whether respondents engaged in collective management behaviors, such as group grazing planning, combined herding, group payment for vaccines.

(j) Community disputes is an index of three variables measuring the number of unresolved community disputes with other farmers inside and outside of the grazing area.

(k) Trust is an index of two variables measuring whether the respondent trusts other individuals in the community.

(l) Expertise is an index of six variables measuring herd manager expertise and access to expertise about cattle husbandry and marketing.

(m) Self and community efficacy is an index of four variables measuring herd manager's beliefs that their actions or the actions of their community can influence cattle and rangeland outcomes.

Definitions of social variables depicted in Fig. 3 (see Main Text) and Extended Data Table 2 are as follows:

(a) Income is the total income earned by the household per week.

(b) Expenditure is the total consumption and expenditure by the household per week.

(c) Household livestock wealth is an index of cattle and non-cattle livestock units owned by the household. 
(d) Time use is an index of six variables representing time spent on economically productive activities by adults in the household (positive) and children in the household (negative).

(e) Resilience is an index of six variables measuring the household's resilience to economic hardship, including food security and savings.

(f) Female empowerment is an index of three variables measuring economic empowerment of women in the household.

(g) Meat/dairy consumption is an index of two variables measuring household consumption of meat and dairy products.

Definitions of cattle variables depicted in Fig. 3 (see Main Text) and Extended Data Table 2 are as follows:

(h) Cattle herd value is an index of three variables measuring the value of the cattle herd in total number, total weight, and total market value.

(i) Herd productivity is an index of seven variables measuring the health and productivity of the cattle herd, including calving rate, herd expansion, milk production, and average weight and body condition.

(j) Herd structure is an index of three variables measuring whether the herd has a higher ratio of bulls to cows, total cattle to oxen, and total cattle to old and unproductive cattle.

Definitions of variables depicted in Fig. 3 (see Main Text) and Extended Data Table 2 are as follows, and methods are reviewed below:

(a) No site erosion is the estimated degree of soil surface disturbance;

(b) Protected soil surface is the percentage of ground area shielded by plant material or rock;

(c) Plant litter cover is the percentage of ground area shielded by dead plant material;

(d) Herbaceous canopy cover is the percentage of ground area shaded by grass and forb foliage;

(e) Perennial to annual ratio is the ratio of respective canopy coverages for perennial and annual grasses;

(f) Grass to forb ratio is the ratio of total grass canopy cover to total forb canopy cover;

(g) No stinkbush (Pechuel-Loeschea leubnitziae) is an indicator of noxious weedy species, as measured by percent canopy coverage;

(h) Grass to Aristida ratio is the ratio of respective canopy coverages for total grasses excluding Aristida and all Aristida species-Aristida in this context are undesirable forage plants; and

(i) Shrub canopy cover is the percentage of ground surface shaded by shrub foliage. 


\section{ii. Cattle scoring key}

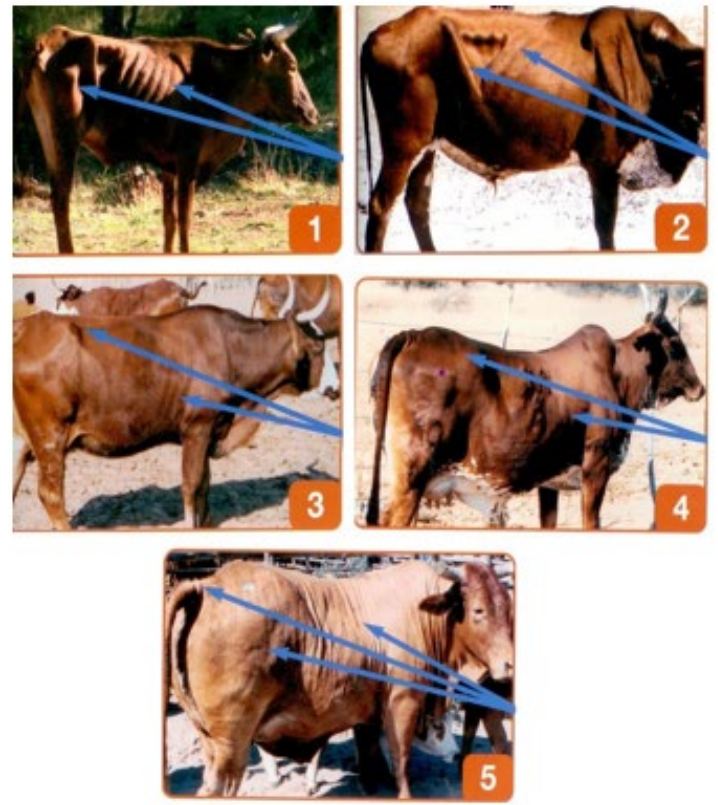

(A)

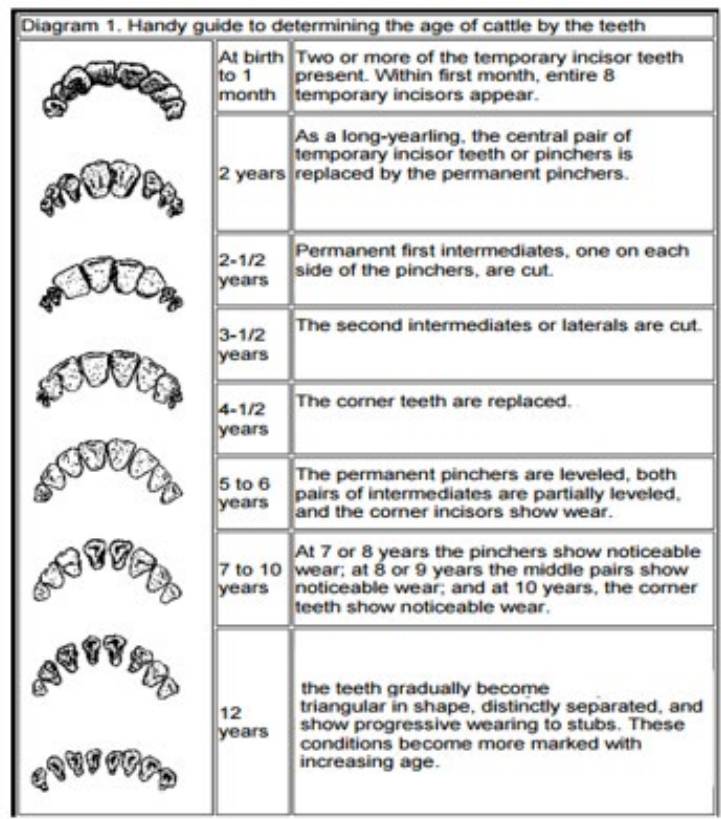

(B)

Supplementary Fig. 3. Field guides for (A) assessing cattle body condition scores (1-5) and (B) cattle age ${ }^{1}$.

\section{Supplemental Text}

\section{a. Context}

\section{i. Historical context}

The Community-Based Rangeland and Livestock Management (CBRLM) program was implemented in Namibia's Northern Communal Areas (NCAs) ${ }^{2}$. Pastoral livestock production is the predominant agricultural system in the $\mathrm{NCAs}^{3}$, although higher rainfall allows for mixed crop and livestock farming in the NCA's central and eastern regions. Today, the NCAs contain approximately $20 \%$ of Namibia's 840,000 square km of land but 45\% of Namibia's 2.6 million cattle, and $55 \%$ of Namibia's 2.1 million citizens ${ }^{4}$.

Most arable land in the NCAs is communally owned, meaning that it is the formal property of the state and fencing it is illegal, except for a limited allowance for homesteads and cultivated fields ${ }^{3}$. In recent years, population pressure, illegal fencing, and proliferation of boreholes have accelerated degradation of an already fragile ecosystem ${ }^{5}$. However, the resource governance challenges facing communal lands in Namibia should be understood in the context of Namibia's history, from pre-colonial to colonial to post-independence.

The origins of the Northern Communal Areas are traceable to two distinct systems of economic production and political authority in pre-colonial Namibia ${ }^{6}$. Southern, central, and 
northwestern Namibia was predominantly inhabited by transhumant pastoral communities with limited political centralization ${ }^{5,7}$. In contrast, populations in north-central and north-eastern Namibia, most of what we call the Northern Communal Areas today, combined settled agriculture and animal husbandry and were ruled by centralized tribal kingdoms ${ }^{7}$.

Under German colonialism, the differences between northern and southern systems of economic production were formalized into distinct systems of legal land ownership and political authority $^{8}$. German colonists arrived in Namibia in 1883 and by 1902 had seized most of Namibia's southern and central territory ${ }^{7}$. However, German colonizers did not move into northern Namibia, both because colonial authorities did not think northern Namibia contained valuable natural resources and because Ovambo tribal authorities in northern Namibia were more politically powerful than the Southern, decentralized pastoralist groups ${ }^{6}$. In 1897, Germany formally demarcated the border between southern Namibia and the Northern Communal Areas by establishing a Veterinary Cordon Fence (VCF) to contain a Rinderpest epidemic ${ }^{8}$. A decade later, Germany prohibited white land settlement in the NCAs, and Germany's political influence in the NCAs remained restricted to indirect arrangements with traditional authorities ${ }^{9}$.

When South Africa began administering Namibia after World War I, it maintained and expanded Germany's policy of land expropriation in the south and indirect rule in the north. South Africa also relocated large portions of the indigenous population living south of the VCF onto marginal communal lands called "native reserves" that were governed by indigenous authorities $^{10,11}$. Native reserves were located both north and south of the VCF. The South African government did not support, and in some cases actively hindered, agriculture and animal husbandry development on native reserves in order to ensure a reservoir of cheap indigenous migratory laborers for white-owned farms, mines, and businesses ${ }^{10,11}$. The native reserve policy has left a lasting legacy on livestock farmers in the central and eastern NCAs, who still suffer from low quality grazing land, underdeveloped livestock markets, and limited training in animal husbandry.

While communal land policy in the NCAs is traceable to colonial policy in the first half of the twentieth century, the present ecological crisis facing the NCAs is also influenced by South African policy changes initiated in the 1960s in response to the emergence of indigenous resistance to South African apartheid ${ }^{5,6}$. In 1962, the Odendaal Commission recommended that the South African government consolidate scattered native reserves into ethnic homelands and increase investment in economic development in communal areas ${ }^{7}$. In the NCA's, the Odendaal Commission led to the dramatic expansion of investments in borehole drilling and road networks, especially in north-western Namibia, and the first steps towards privatization of communal lands in Oshikoto and Kavango West ${ }^{5,9}$. These changes upended existing systems of grazing and water management by delinking grazing patterns from the availability of natural water sources and enabling growth of human and livestock populations ${ }^{5}$. However, the South African government failed to establish a framework of customary rights for regulating access to land, water, and grazing resources to manage to these dynamics ${ }^{5,9}$.

Debates around the development of livestock markets, land tenure reform, and natural resource conservation continued after Namibian independence in 1990. For example, laws restricting the movement and sale of livestock from the NCAs south of the VCF remain deeply contested because they are perceived to limit the economic potential of livestock production in communal areas ${ }^{12}$. The Communal Land Reform Act of 2002 acknowledged the authority of traditional leaders to manage customary land rights and established Communal Land Boards to register new and customary land allocations. However, progress in registration in the ensuing 
decades has been slow and current customary land rights focus narrowly on grazing access to the exclusion of other communal resources, such as water and fire $\operatorname{wood}^{9}$. In the absence of group land rights, many communities in the NCAs have developed resource government strategies using conservancies, community forests, and Water Point Associations, but the powers of these organizations are severely circumscribed ${ }^{9}$. The ecological and economic challenges facing the livestock sector in the NCAs at the time CBRLM was introduced should be understood in this historical context. Far from a static socio-economic and ecological system, the NCAs have been deeply influenced by pre-colonial, colonial, and post-independence land administration.

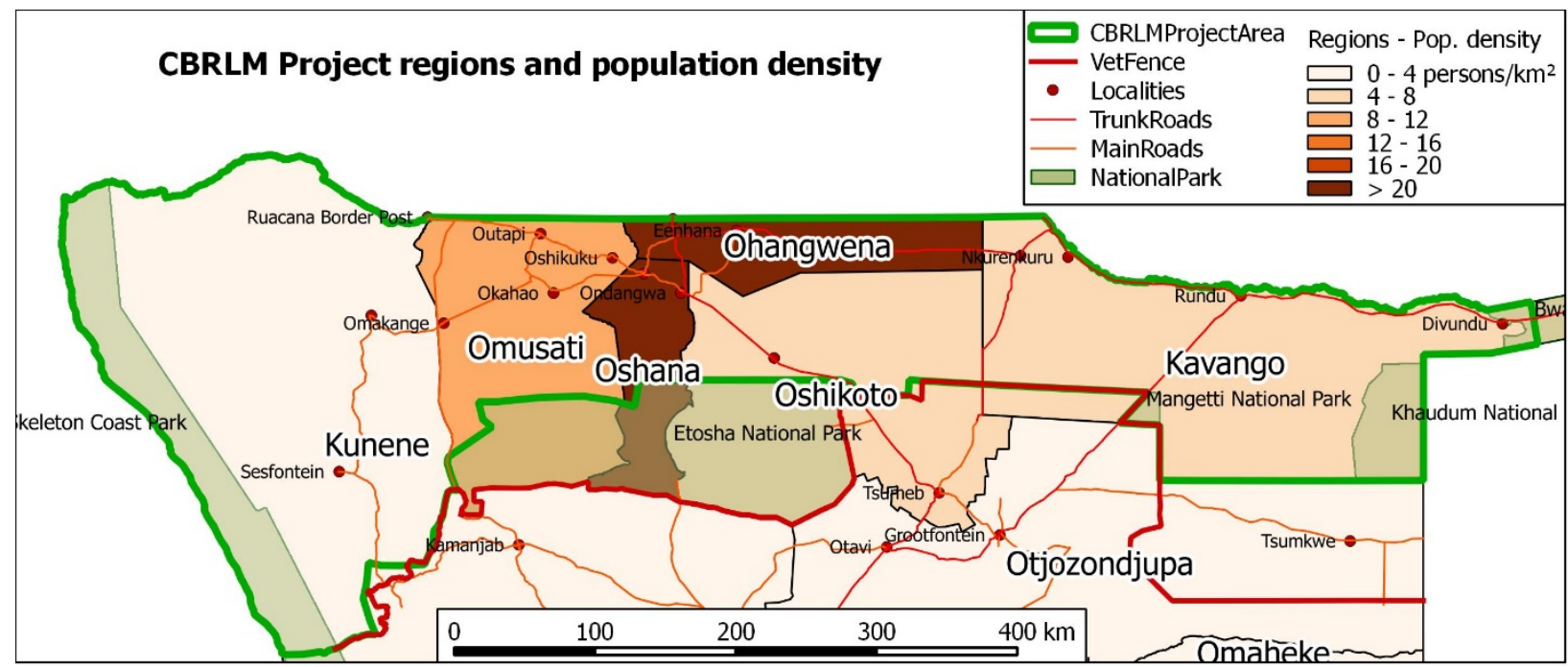

Supplementary Fig. 4. CBRLM project regions and human population density (20).

\section{ii. Program context}

The CBRLM was funded under the auspices of the Millennium Challenge AccountNamibia, and was implemented by a consulting firm called Gesellschaft für Organisation, Planung und Ausbildung (GOPA) ${ }^{2}$. The CBRLM spanned seven administrative regions including: Kunene, Omusati, Oshana, Oshikoto, Ohangwena, Kavango West and Kavango East. Together these cover an area of about $170,000 \mathrm{~km}^{2}$ (Supplementary Fig. 4). The area can be approximated by a rectangle that is $800 \mathrm{~km}$ long (East to West) and $200 \mathrm{~km}$ wide (South to North). The NCAs have a predominantly warm and dry climate with a pronounced seasonal distribution of precipitation. Ecological details are reviewed later in this section.

Within the seven administrative regions listed above, the CBRLM operated across 11 areas governed by Traditional Authorities (TAs) ${ }^{2}$. TAs allocate communal land, regulate communal land use, and formulate and enforce customary law ${ }^{4}$. Within each TA the GOPA implementation team mapped Rangeland Intervention Areas (RIAs) where CBRLM could be implemented. Wherever possible, RIAs conformed to the boundaries of pre-existing Communal Area Conservancies or Community Forests ${ }^{2}$. Where no Communal Area Conservancy or Community Forest existed, the implementation team worked with TAs to map appropriately sized intervention areas in their jurisdiction ${ }^{13}$. Each RIA contains five to 15 Grazing Areas (GAs). The GAs are communal rangeland parcels used by five to 50 cattle kraals; herd owners in each GA share forage and water resources. The cattle kraals are overnight holding pens for cattle herds owned by one to five households (usually extended family members). Households that 
share a kraal usually designate or hire a herd manager who is responsible for day-to-day management of cattle but does not generally make decisions with regards to buying, selling, or health treatments without the consent of the cattle owners. The size, makeup, and economic status of herding households varies greatly across Northern Namibia ${ }^{14}$. Most GAs have a local headman who is a member of the TA and is responsible for admission of new herd owners to the GA as well as the management of community disputes. In practice, the extent of the power of the local headman varies substantially among GAs.

CBRLM was intended to improve cattle raising by facilitating herd restructuring, animal husbandry, and cattle marketing. GOPA hoped that the intervention would improve the productivity and economic viability of cattle rearing in the NCAs ${ }^{15}$. Previous research points to low bull-to-cow ratios, low calving rates, and inadequate weaning practices as causes for poor productivity ${ }^{16,17}$. Others have argued that greater integration between small-scale communal pastoralism and livestock markets could also alleviate such problems. However, there are significant practical barriers to raising cattle for profit in northern Namibia; many cattle producers are absentee owners and marketing transaction costs can be a hindrance ${ }^{18}$.

Such challenges are reflected in the broader literature on African pastoral development. Some critics of cattle commercialization projects argue that raising cattle for the formal market on communal land is not economically viable, and that development interventions should enhance herd productivity for its own sake ${ }^{15}$. There is also debate over factors that keep communal pastoralists from selling cattle in the formal economy. One argument is that for pastoralists the primary economic value of cattle comes not from income-generating potential but rather from their use as insurance ${ }^{19}$. In this view, cattle are a reliable store of wealth and animals are primarily sold during crisis. Others argue that reluctance to sell cattle comes from their value as social capital ${ }^{20}$.

Water development is another key issue. The question of how to protect and sustainably maintain water resources is urgent in Namibia. Like many developing countries, the Namibian government has adopted a community-management approach to the maintenance of boreholes in rural areas ${ }^{21,22}$. However, water users often fail to pay their fees, especially in areas where governance is weak. Moreover, during times of drought water users often ignore externally imposed regulations in favor of traditional customs of reciprocity ${ }^{21,22}$.

As will be described, the CBRLM project was conceived not only as a check on environmental degradation, but as a means of community self-help. New GA committees were created and incentivized to pool financial resources to fund cattle production inputs like vaccines, feed supplements, and herder salaries; CBRLM also invested in the development of local marketing cooperatives. As such, the CBRLM is an example of a partnership to create processes referred to as community-driven development. This is an increasingly popular concept in international development (see Main Text), but the literature on its efficacy is mixed ${ }^{23}$. Related evidence from recent randomized evaluations suggests that community-driven development can successfully deliver infrastructure and economic returns, but has less success sustainably affecting community governance and creation of social capital ${ }^{24,25}$ and may even crowd-out pre-existing local institutions dependent on the beliefs of constituents with respect to local politics $^{26}$.

The Namibian government has previously pursued several projects meant to reduce rangeland degradation and improve livestock production in the NCAs. A project called the Northern Regions Livestock Development Project (NOLIDEP) took place from 1995-2003 and had a general focus on commercialization of livestock production, with specific attention to 
community capacity building and provision of strategic inputs such as rural veterinary clinics and water points ${ }^{27}$. Another effort, referred to as the Sustainable Animal and Rangeland Development Program (SARDEP), has existed in Namibia for over two decades with a focus on creating more sustainable linkages between rural producers and service institutions, as well as supporting dialogue to create national policies regarding sustainable use of natural resources ${ }^{28}$.

\section{iii. Ecological context}

In terms of ecological systems, the NCAs are diverse ${ }^{3}$. The topography is generally flat with only the extreme western region exhibiting topographic variation towards the Great Escarpment in Kunene (Supplementary Fig. 4). Precipitation has a distinct East to West gradient, with the West being drier than the East ${ }^{3}$. Across the entire study region, annual precipitation averages just under $400 \mathrm{~mm}$ with high variability ${ }^{3}$. The main wet season occurs from January to March with precipitation steadily dropping after April. A distinct dry period occurs from May to September. During June through August the study region typically receives only scant precipitation $^{3}$.

Soils are diverse and are dominated by sandy, silty, or clay substrates ${ }^{3}$. Vegetation community types include grasslands, shrublands, bushlands, and savannas ${ }^{3}$. Localized heavy livestock grazing over many years is associated with the sedentarization of human settlement and borehole development ${ }^{29,30}$. Woody encroachment and conversion of herbaceous perennial communities to annual plants are common ecological responses to overuse of these rangelands ${ }^{29,30}$.

As with most drylands of the world, low and highly variable precipitation is the norm in northern Namibia. Drought, defined here as one or more years of below-average precipitation that negatively affect socioeconomic attributes, is common. Resource use systems such as pastoralism have evolved to cope with drought.

Our study region in northern Namibia has experienced a significant decline in rainfall in the past eight years (e.g., 2013 to 2020) when compared to the previous 31 years beginning in 1981. This is illustrated by superimposing the monthly rainfall distributions in Supplementary Fig. 5. Precipitation data are based on the Climate Hazards Group InfraRed Precipitation with Station (CHIRPS) data set consisting of daily modeled precipitation from January 1981 to the present with a ground resolution of $5.5 \mathrm{~km}$. The overall decline in precipitation is on the order of $36 \%$, with notable decreases from the main wet season months of January, February, and March. Annual variation has been substantial over the past 39 years - and possibly increasing - as illustrated in Supplementary Fig. 6. These data suggest that CBRLM was implemented and evaluated during a particularly dynamic period. The project implementation phase of 2010 to 2014 may have been wetter than average, while the evaluation phase of 2014 to 2017 may have been drier than average. The implications of such dynamism for pastoral development outcomes from CBLRM are explored in subsequent sections. 


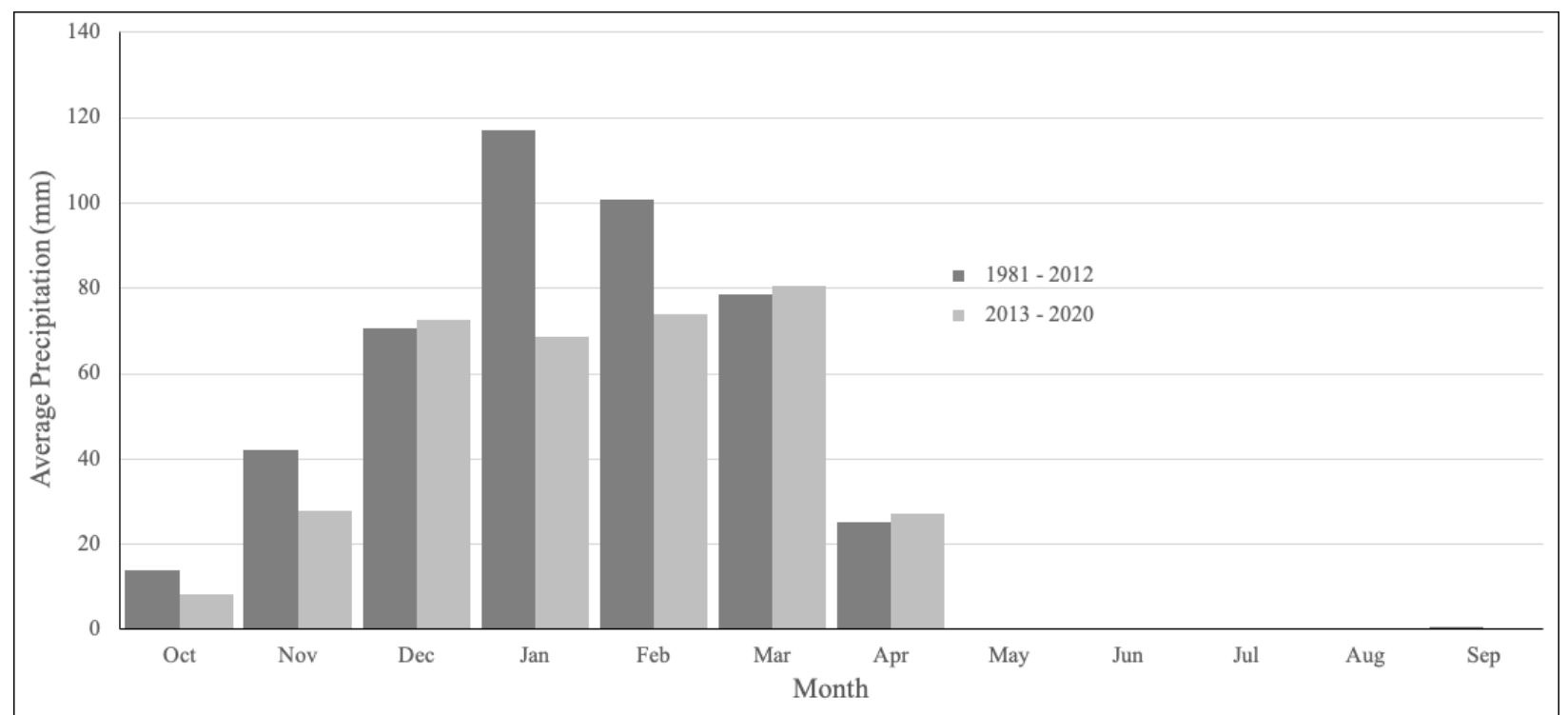

Supplementary Fig. 5. Average monthly precipitation in northern Namibia for two periods, 1981 to 2012 and 2013 to 2020. Data are organized according to water year that commences October $1^{31}$.

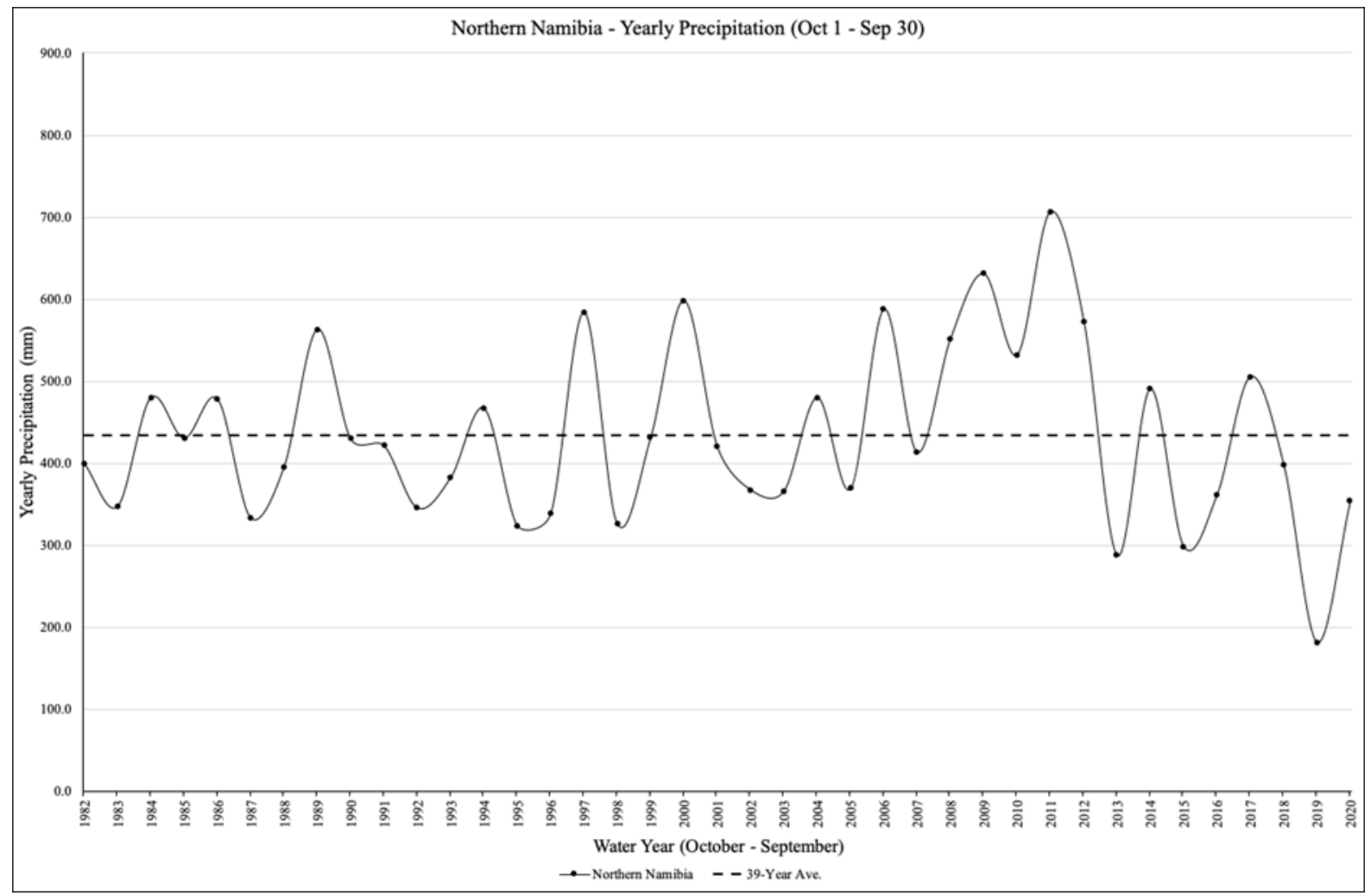

Supplementary Fig. 6. Annual precipitation patterns from 1981 to 2020 for northern Namibia ${ }^{31}$. 


\section{b. Scientific rationale for planned grazing}

Rotational grazing (often lumped into the category of 'planned grazing' or 'prescribed grazing') has become a popular resource management strategy for averting environmental degradation and increasing sustainable levels of forage and livestock production. The essential practice of rotational grazing consists of combining herds that would otherwise graze independently into one or more large herds. Herders then move these large herds around the landscape, spending a short period in one location before moving to a new location. Allan Savory $^{32,33}$ espoused the idea that this form of intensively managed grazing replicates coevolved, sustainable relationships between grasses and large grazing animals, and that such interactions can be used to restore damaged rangelands.

The core idea is that grasses have evolved to withstand frequent herbivory and will be most productive when defoliated at a judicious frequency. Therefore, grasses in any given area should be subjected to intensive, short bursts of heavy defoliation and then allowed time to recover before subsequent waves of grazing. In a planned grazing rotation, livestock may occupy a grazing location for just a few days to a week or so-in some forms of rotational grazing the grazing period is just one day - and are herded together at high stocking density. This highdensity grazing creates a 'herd effect' imposing concentrated disturbance to the soil that Savory believes is an important factor contributing to rangeland rehabilitation ${ }^{32}$. Savory has been one of the more high-profile advocates of rotational grazing since 1978 when he first presented his ideas, most of which were based on a book by French agronomist André Voisin ${ }^{34}$ at the First International Rangeland Congress. Voisin pointed out that the concept of rotational grazing has been around since at least the late $18^{\text {th }}$ century, but it has become common practice for ranchers and pastoralists on a global scale during only the last few decades.

Practitioners of rotational grazing see the benefits occurring more in terms of extended rest periods that allow the vegetation to recover from defoliation, rather than the impact of animal hooves disturbing the soil and breaking up dead plant material on the surface. They also observe changes in plant composition of the pasture or rangeland in which palatable species tend to increase at the expense of less palatable and weedy plants. In his review of relevant literature, Norton $^{35}$ noted that the rest periods protecting plants from grazing allow greater total forage production, and that increased above-ground photosynthetic biomass builds a larger root system penetrating deeper into the soil profile. However, Briske et al. ${ }^{36}$ reported that while there has long been widespread concurrence among range scientists, federal land managers, and commercial ranchers regarding the efficacy of rotational grazing on US rangelands relative to continuous grazing, this distinction has not been supported by hard scientific evidence from grazing trials on research stations.

Many research trials comparing rotational grazing to continuous grazing have failed to find a consistent and significant benefit to either forage yield or livestock production ${ }^{36,37}$. Trials were conducted on research stations where the experimental paddocks were small and research herds likewise small, sometimes only 3-4 head of cattle. Another feature of research grazing trials is that the number of paddocks in the rotation was often as low as 3 (in deferred rotations) and rarely more than 14 . Following the guidelines in Voisin ${ }^{34}$, grazing periods should be limited to around seven days followed by a rest period of 30 days, which defines a rotation around just five paddocks. As the grazing period is reduced and the rest period increased, the number of paddocks required by the rotation rises. A grazing period of two days in a rotation of 60 paddocks means that livestock spend on average only six days grazing per year in each paddock, 
and the paddock is rested for almost 360 days per year, which can lead the biological mechanics of rotational grazing to cause a doubling of sustainable stocking rate and greater tolerance of low rainfall seasons or years ${ }^{38}$. Voisin ${ }^{34}$ worked on dairy farms in temperate France; in a rangeland setting, on the other hand, for most of the year rest periods need to be much longer than 30 days to allow adequate time for recovery under the irregular and sparse rainfall patterns of a semi-arid environment. Similarly, herds need to consist of dozens of animals or more to achieve a grazing herd's natural cohesive social behavior.

A key factor of livestock management is missing from grazing research in small experimental units, namely, the spatial dimension: scientists could assume that both available forage and forage utilization by grazing animals were spatially homogeneous, which is untrue in a landscape context. When the distribution of grazing livestock across a spatially heterogenous landscape is entered into the discussion, rotational grazing is clearly superior to continuous grazing $^{39,40}$. Even Briske et al. have admitted that research station results could not apply to a commercial-scale operation ${ }^{41}$. Livestock in a small paddock can explore the entire area of available pasture on a daily basis, and forage utilization is spatially more even than across a landscape where patch-grazing is usually the norm if animal movement is unconstrained. One would expect the simple factor of small paddocks to enhance livestock production, and it does. Norton $^{35}$ reported examples where he compared the experimental stocking rates to the stocking rates for livestock on commercial ranches near the station: rates approaching twice the recommended commercial rate could be sustained on the research station for many years without adverse ecological consequences to either the continuous or the rotation treatment. Alternatively, in a much larger paddock the livestock concentrate their grazing activity in preferred patches and much of the pasture is neglected. The stocking rate calculated for the entire paddock is much lower than the de facto stocking rate imposed on the preferred patches or zones where most of the grazing is taking place. A critical aspect of rotational grazing is to prevent patch grazing that opens up pastures to patch degradation (i.e., localized overgrazing), weed invasion, and erosion.

In a nutshell, the theory of rotational grazing has three elements: 1) Controlled defoliation frequency achieved by short grazing periods followed by long rest periods; 2) high-density grazing forcing even utilization by using combined herds for short grazing periods, with stocking rate calculated for the entire rotation area; and 3) even spatial distribution of grazing animals in a rotational sequence around landscape units. The outcomes comprise: 1) Greater forage production; 2) higher livestock productivity from bigger animals or higher fecundity or both; and 3) increased ecological health of the pasture in terms of biodiversity and drought tolerance. A good illustration of the benefits of rotational grazing that incorporates a number of dimensions of the livestock management/pasture interaction was published by Odadi et al. from work in Kenya.

Odadi et al. ${ }^{42}$ describe an ecological assessment of rotational grazing conducted within a communal pastoral area in northern Kenya divided into unfenced 'paddocks'. The assessment followed five years of planned rotational grazing and employed an experimental approach with three pairs of sites. One of each site pair was subjected to rotational "planned grazing," while the other consisted of unplanned grazing (i.e., control). The planned system included bunched grazing of livestock, multiple unfenced paddocks, and a 50\% recommended level of forage utilization prior to moving animals among paddocks. Overall, they concluded that the planned grazing system had positive effects on all plant and animal indicators ${ }^{42}$.

In a later paper, Odadi et. al. ${ }^{43}$ focused specifically on the effectiveness of bunched herds in a low-level rotation. Odadi and his colleagues compared herds that grazed in loose bunches managed by one herder with herds that grazed in tight bunches enforced by three herders. All 
other aspects of the grazing system were similar for both types of herding. The results were noteworthy. Cattle herded in tight bunches traveled shorter distances, had higher nutrient intake per unit of distance traveled, grazed less selectively consuming less of the preferred species with intake spread over a wider array of species, but had higher weight gain. The higher cattle live weights generated more income greater than the extra cost of herding. The benefits of herding in tight bunches were financial as well as ecological.

Herding for rotational grazing as practiced in the CBRLM GAs was much looser and often abandoned once the herd had been shepherded to a designated grazing site. In general, rotational grazing in the GAs was implemented less rigorously by communities than by the trained staff implementing the program described in Odadi et al. The CBRLM program should be understood as an evaluation of a program designed to mobilize best practices in rotational grazing through external support, rather than an evaluation of rotational grazing when applied rigorously.

\section{c. Comparing CBRLM and holistic management approaches}

The approach to grazing management in the CBRLM proposal for the NCAs ${ }^{15}$ was inspired by the Holistic Management (HM) model of Allan Savory ${ }^{32,33}$. In his 1988 textbook $^{33}$, Savory emphasizes the need to first identify community or household goals and then make detailed plans to achieve those goals, which should include financial and life-style goals as well as resource productivity, socio-economic sustainability, and household welfare. Furthermore, Savory stresses that resource managers should be flexible, monitoring performance and revising plans and activities on a regular basis. This flexibility and process of revising plans and actions is an essential component of the HM strategy.

In the case of CBRLM, although it adopted rotational grazing and socio-economic integration and household prosperity in project design ${ }^{15}$, the overarching goals were largely determined by external development agents instead of being generated by recipient communities, and full-scale revision of plans and activities was not possible within the short time-frame of project implementation, even if it had been accommodated in CBRLM design. Therefore, CBRLM did not employ the full HM template, although it followed some aspects of HM. It also transpired that communities were unable to strictly enforce grazing management protocols of combined herds and planned grazing; independent herder actions and trespassing by external herds that poached conserved forage compromised the recommended rotational grazing practice (see Main Text). Insofar as CBRLM is a test of well-executed rotational grazing at community and landscape scales, testing the efficacy of planned grazing management was frustrated and anticipated outcomes thwarted. CBRLM also failed as an example of HM because key features of HM were omitted, but even if CBRLM had faithfully followed HM, there was insufficient project time for adequate execution and evaluation of the full HM approach. This evaluation should be considered a test of external inducements to engage in rotational grazing at community and landscape scales, rather than a direct test of rigorously implemented HM.

In general, CBRLM, however, can be lauded for pursuing a development effort that connected many elements of a complex social-ecological system (SES) in a core theory of change (TOC) (see previous section). The study of outcomes - very unusual in development programs - was thus a means to assess lessons learned. Our research has indicated that while persistent changes in many social features of this pastoral community occurred with respect to commons management planning, changes in the household economy, cattle production system, 
and rangeland condition were not observed. This is not surprising, however, given the relatively short time frame for assessment and bio-physical time lags in a setting strongly affected by variable rainfall and other perturbations (see Main Text).

How a complex SES responds to externally generated intervention has received little detailed study, particularly in the context of dryland settings. Rangeland management scholars note anecdotally that while practitioners (e.g., ranchers) adopting HM paradigms in the western US often perceive positive outcomes with regards to social or psychological aspects of their increased investments in resource planning, hard evidence of associated improvements in the natural environment as a result of treatment is often lacking ${ }^{44}$. A similar perspective is voiced by Gosnell et al. in their recent meta-analysis of global studies on $\mathrm{HM}^{45}$. Although they note the dearth of truly integrated SES research, their review points to a distinct dichotomy between the ecological and social domains of HM; namely, that while many controversies prevail over the pros and cons of ecological impacts arising from HM, far more consensus exists concerning the positive benefits in the social sphere including attention to goal setting, human capacity building, enhanced social networking, and creating social resilience. Our research findings generally conform to this perspective.

\section{i. Community governance}

One of the key assumptions of CBRLM was that community governance needed to be fortified to help combat environmental degradation as related to poor grazing management. There is a growing agreement among researchers and development practitioners that a weakening of traditional community governance is a major problem in the world's dry lands. Traditional governance in pastoral areas includes efforts to mitigate social disputes, allocate natural resources, and organize labor to address community challenges ${ }^{20}$. When these attributes are lost social cohesion can suffer and resource degradation occurs. Population growth, shifts in cultural norms, increases in resource-based conflicts, emergence of local, ultra-wealthy elites (who do as they please), expansion of absentee herd-ownership, and an undermining of local traditional authorities by regional or national governments are some of the major internal and external factors involved ${ }^{46-49}$. The problem is recognized by development agencies, who have increasingly focused on restoring aspects of traditional governance in local situations to improve natural resource management. Such processes include efforts to strengthen governance via participatory combinations of traditional and contemporary leadership that reflects differing knowledge bases and access to resources ${ }^{48}$.

\section{ii. Commercialization of livestock production}

Another key assumption of CBRLM was that the communities would be responsive to efforts to boost cattle productivity via changes in animal husbandry, with an eye towards more marketed offtake and increased producer incomes. While this presumed process makes perfect sense to an outside expert trained in livestock development, there are false assumptions concerning cultural values and differing economic goals for traditional producers that undermine such plans in places like the NCAs of Namibia.

The struggles of pushing for more commercialized animal offtake from pastoral areas have been well known for decades, but largely ignored by project donors who follow top-down models of project design and implementation from a western perspective ${ }^{48}$. Cattle marketing is 
often pursued by governments seeking exports to boost foreign exchange coffers ${ }^{48}$. New projects based on false assumptions thus keep coming down the pipeline. The fundamental, inimical nature of subsistence pastoralism versus commercial livestock production is best depicted by Behnke $^{50}$. Major differences occur in terms of inputs, outputs, goals, and even human demographics. While indeed pastoral systems are changing ${ }^{46,51}$, it continues to be a truism that traditional herdowners (e.g., men) typically aspire to accumulate large stock such as cattle. More cattle may allow for a higher likelihood of surviving droughts or other crises, and there is little doubt that large herds can convey high social status to herd owners in many cultures ${ }^{48}$. The flip side is that large herds can dominate local resource consumption, thus exacerbating household wealth stratification ${ }^{46}$. Large herds can also suffer enormous death losses during droughts ${ }^{20,46}$.

In contrast to cattle, however, small stock such as goats or sheep are more routinely sold by pastoralists to meet modest cash needs. Small stock are also more readily produced in more ecologically degraded environments ${ }^{20}$. Commercialization will thus tend to be more successful for small stock when compared to that for cattle, and this can have a gender dimension as women are then more likely to market these animals and use the proceeds to improve the livelihoods of themselves and their children ${ }^{52}$. Such processes are more aligned with the rural-development ambitions of project donors and development experts. Traditional pastoral systems are low-input, high-risk enterprises. For cattle, they are not "cow-calf” operations as seen in modern commercialized ranching. In pastoral systems, immature animals are typically retained and matures are sold at advanced ages when they have attained a maximum body size. And when mature cattle are sold the objective is often to use the proceeds to buy more immatures to meet herd-building goals ${ }^{20}$.

Veterinary interventions for cattle are often embraced by producers because they facilitate herd-building goals, not commercialization or cash-generation goals. Alternative investments to large stock such as cattle are needed to diversify assets in support of household resilience and improvement in rangeland management, and this can include bank accounts, urban investments such as real estate or small businesses, and support for children who leave the traditional system and become formally educated. Such options become more attractive when "boom and bust" cycles for cattle productivity tilt the portfolio choices against more reinvestment in livestock versus the relative stability of investments in non-pastoral options less connected to stocking rates or the weather ${ }^{46}$. A robust mix of different investments is the key for managing risk.

Besides socioeconomic barriers, the cattle producers of northern Namibia also face significant operational or structural barriers for marketing. These may include weak trading networks and low farm-gate prices ${ }^{15}$. The Veterinary Cordon Fence, imposed by colonial authorities and still enforced to manage the risks of epidemic diseases, limits access of producers in the NCAs to more lucrative markets in the southern parts of Namibia ${ }^{12}$.

\section{Supplementary References}

1. Ensminger, M. E. The Stockman’s Handbook. (The Interstate, 1959).

2. Anon. Community Based Rangeland and Livestock Management Final Report. (2014). 
3. Mendelsohn, J. M. Atlas of Namibia a portrait of the land and its people. (David Philip, 2002).

4. Mendelsohn, J. Farming Systems in Namibia. (Research \& Information Services of Namibia, 2006).

5. Bollig, M. Shaping the African Savannah: From Capitalist Frontier to Arid Eden in Namibia. (Cambridge University Press, 2020). doi:10.1017/9781108764025.

6. Werner, W. A Brief History of Land Disposession in Namibia. J. South. Afr. Stud. 19, 135146 (1993).

7. Wallace, M. \& Kinahan, J. A history of Namibia: from the beginning to 1990. (2011).

8. Lechler, M. \& McNamee, L. Indirect Colonial Rule Undermines Support for Democracy: Evidence From a Natural Experiment in Namibia. Comp. Polit. Stud. 51, 1858-1898 (2018).

9. Werner, W. Tenure reform in Namibia's communal areas. J. Namib. Stud. Hist. Polit. Cult. 18, 67-87 (2015).

10. Werner, W. No one will become rich: Economy and society in the Herero reserves in Namibia, 1915-1946. (P. Schlettwein Publishing, 1998).

11. Silvester, J. Beasts, boundaries \& buildings: the survival \& creation of pastoral economies in Southern Namibia 1915-35. in Namibia under South African Rule: Mobility \& Containment 1915-46 95-116 (Ohio University Press, 1998).

12. Miescher, G. Namibia's Red Line: The History of a Veterinary and Settlement Border. (Palgrave Macmillan, New York, 2012).

13. Coppock, D. L. et al. Community Based Rangeland and Livestock Management Evaluation Report. https://data.mcc.gov/evaluations/index.php/catalog/138/study-description (2020). 
14. Namibia Statistics Agency. Namibia 2011 Population and Housing Census [PUMS dataset]. (Namibia Statistics Agency [producer and distributor], 2013).

15. Gesellschaft für Organisation, Planung und Ausbildung. Community Based Rangeland and Livestock Management Inception Report. https://www.yumpu.com/en/document/view/7305588/cbrlm-inception-report-millenniumchallenge-account-namibia (2013).

16. Hangara, G. N., Teweldemedhin, M. Y. \& Groenewald, I. B. Major constraints for cattle productivity and managerial efficiency in communal areas of Omaheke Region, Namibia. Int. J. Agric. Sustain. 9, 495-507 (2011).

17. Frayne, B. Rural productivity and urban survival in Namibia: Eating away from home. $J$. Contemp. Afr. Stud. 23, 51-76 (2005).

18. Shiimi, T., Taljaard, P. R. \& Jordaan, H. Transaction costs and cattle farmers' choice of marketing channel in North-Central Namibia. Agrekon 51, 42-58 (2012).

19. Kazianga, H. \& Udry, C. Consumption smoothing? Livestock, insurance and drought in rural Burkina Faso. J. Dev. Econ. 79, 413-446 (2006).

20. Coppock, D. The Borana Plateau of Southern Ethiopia: Synthesis of Pastoral Research, Development and Change. Int. Livest. Cent. Afr. Addis Ababa 374 (1994).

21. Schnegg, M. \& Linke, T. Living Institutions: Sharing and Sanctioning Water among Pastoralists in Namibia. World Dev. 68, 205-214 (2015).

22. Schnegg, M. \& Bollig, M. Institutions put to the test: Community-based water management in Namibia during a drought. J. Arid Environ. 124, 62-71 (2016).

23. Casey, K. Radical Decentralization: Does Community-Driven Development Work? Annu. Rev. Econ. 10, 139-163 (2018). 
24. Casey, K., Glennerster, R. \& Miguel, E. Reshaping Institutions: Evidence on Aid Impacts Using a Preanalysis Plan*. Q. J. Econ. 127, 1755-1812 (2012).

25. Humphreys, M., Sánchez de la Sierra, R. \& Van der Windt, P. Exporting democratic practices: Evidence from a village governance intervention in Eastern Congo. J. Dev. Econ. 140, 279-301 (2019).

26. Baldwin, K., Karlan, D., Udry, C. R. \& Appiah, E. How Political Insiders Lose Out When International Aid Underperforms: Evidence from a Participatory Development Experiment in Ghana. http://www.nber.org/papers/w26930 (2020) doi:10.3386/w26930.

27. Northern Regions Livestock Development Project Interim Evaluation Report. https://www.ifad.org/es/web/ioe/evaluation/asset/39835302 (2002).

28. Programme (Namibia), S. A. and R. D. Coping in a Fragile Environment: The SARDEP Experience : the Sustainable Animal and Range Development Programme (SARDEP) in the Communal Areas of Namibia. (SARDEP, Ministry of Agriculture, Water and Rural Development, 2001).

29. Sander, H., Bollig, M. \& Schulte, A. Himba paradise lost: Stability, degradation and pastoralist management of the Omuhonga basin (Northwestern Namibia). Erde 129, 301-315 (1998).

30. Klintenberg, P. \& Verlinden, A. Water points and their influence on grazing resources in central northern Namibia. Land Degrad. Dev. 19, 1-20 (2008).

31. Funk, C. et al. The climate hazards infrared precipitation with stations - a new environmental record for monitoring extremes. Sci. Data 2, 150066 (2015).

32. Savory, A. A Holistic Approach to Ranch Management Using Short Duration Grazing. in Proceedings of First International Rangeland Congress 555-557 (1978). 
33. Savory, A. Holistic Resource Management. (Island Press, 1988).

34. Voisin, A. Grass Productivity. (Island Press, 1988).

35. Norton, B. E. The application of grazing management to increase sustainable livestock production : the McClymont lecture. http://www.asap.asn.au/livestocklibrary/1998/MCCMONT.PDF (1998).

36. Briske, D. D. et al. Rotational Grazing on Rangelands: Reconciliation of Perception and Experimental Evidence. Rangel. Ecol. Manag. 61, 3-17 (2008).

37. Hawkins, H.-J. A global assessment of Holistic Planned Grazing ${ }^{\mathrm{TM}}$ compared with seasonlong, continuous grazing: meta-analysis findings. Afr. J. Range Forage Sci. 34, 65-75 (2017).

38. Norton, B. Personal Observation.

39. Norton, B. E., Barnes, M. \& Teague, R. Grazing Management Can Improve Livestock Distribution. Rangelands 35, 45-51 (2013).

40. Teague, R. \& Barnes, M. Grazing management that regenerates ecosystem function and grazingland livelihoods. Afr. J. Range Forage Sci. 34, 77-86 (2017).

41. Briske, D. D. et al. Origin, Persistence, and Resolution of the Rotational Grazing Debate: Integrating Human Dimensions Into Rangeland Research. Rangel. Ecol. Manag. 64, 325334 (2011).

42. Odadi, W. O., Fargione, J. \& Rubenstein, D. I. Vegetation, Wildlife, and Livestock Responses to Planned Grazing Management in an African Pastoral Landscape. Land Degrad. Dev. 28, 2030-2038 (2017).

43. Odadi, W. O., Riginos, C. \& Rubenstein, D. I. Tightly Bunched Herding Improves Cattle Performance in African Savanna Rangeland. Rangel. Ecol. Manag. 71, 481-491 (2018). 
44. Huntsinger, L. Private correspondence with Lynn Huntsinger, University of California at Berkeley. (2020).

45. Gosnell, H., Grimm, K. \& Goldstein, B. E. A half century of Holistic Management: what does the evidence reveal? Agric. Hum. Values 37, 849-867 (2020).

46. Coppock, D. L., Bailey, D., Ibrahim, M. \& Tezera, S. Diversified Investments of Wealthy Ethiopian Pastoralists Include Livestock and Urban Assets That Better Manage Risk 2 .

Rangel. Ecol. Manag. 71, 138-148 (2018).

47. Fernandez-Gimenez, M. E. Reconsidering the Role of Absentee Herd Owners: A View from Mongolia. Hum. Ecol. 27, 1-27 (1999).

48. Davies, J. et al. Improving governance of pastoral lands. Gov. Tenure Tech. Guide FAO Eng No 6 (2016).

49. Coppock, D. L. et al. Rangeland Systems in Developing Nations: Conceptual Advances and Societal Implications. in Rangeland Systems: Processes, Management and Challenges (ed. Briske, D. D.) 569-641 (Springer International Publishing, 2017). doi:10.1007/978-3-31946709-2_17.

50. Behnke, R. H. Production rationales: The commercialization of subsistence pastoralism. Nomadic Peoples 3-33 (1983).

51. Galvin, K. A. Transitions: Pastoralists Living with Change. Annu. Rev. Anthropol. 38, 185198 (2009).

52. Coppock, D. L., Desta, S., Tezera, S. \& Gebru, G. Capacity building helps pastoral women transform impoverished communities in Ethiopia. Science 334, 1394-1398 (2011).

\section{Supplementary Tables 1 - 5 (following pages)}




\begin{tabular}{|c|c|c|c|c|c|c|}
\hline \multirow{2}{*}{$\begin{array}{l}\text { Panel A: Data collected at RIA level } \\
\text { RIA characteristic }\end{array}$} & \multicolumn{6}{|c|}{ RIA-level statistics (pre-program) } \\
\hline & Ctrl mean & Treat mean & $p$-val. & RI p-val. & $\%$ missing & N \\
\hline Log of the number of CBRLM-eligible households * & 4.47 & 4.61 & 0.445 & 0.307 & 0.00 & 38 \\
\hline RIA has good water source * & 0.79 & 0.74 & 0.674 & 0.658 & 0.00 & 38 \\
\hline RIA has community-based organizations * & 0.74 & 0.79 & 0.568 & 0.545 & 0.00 & 38 \\
\hline Forest present in RIA & 0.42 & 0.42 & 1.000 & 0.870 & 0.00 & 38 \\
\hline Grassland present in RIA & 0.11 & 0.11 & 1.000 & 0.980 & 0.00 & 38 \\
\hline Livestock density $(\mathrm{kg} / \mathrm{ha}) *$ & 16.79 & 16.88 & 0.939 & 0.953 & 0.00 & 38 \\
\hline Number of livestock * & 17,380 & 16,497 & 0.903 & 0.824 & 0.00 & 38 \\
\hline \multirow[t]{2}{*}{ RIA overlaps geographically with prior interventions * } & 0.37 & 0.42 & 0.530 & 0.456 & 0.00 & 38 \\
\hline & \multicolumn{3}{|c|}{ p-value, joint F-test: 0.998} & \multicolumn{2}{|c|}{$\mathrm{p}$-value, joint $\mathrm{F}$-test, $\mathrm{RI}$ : } & $>0.999$ \\
\hline Panel B: Data collected at GA level & \multicolumn{6}{|c|}{ RIA-level statistics (pre-program) } \\
\hline GA characteristic & Ctrl mean & Treat mean & $p$-val. & RI p-val. & $\%$ missing & N \\
\hline Community is willing to change & 0.76 & 0.88 & 0.186 & 0.193 & 2.63 & 38 \\
\hline Traditional authority is ready for change & 0.54 & 0.67 & 0.995 & 0.995 & 13.16 & 38 \\
\hline Community has social cohesion & 0.63 & 0.67 & 0.756 & 0.721 & 0.00 & 38 \\
\hline Community is worried about spillover/grass poaching & 0.49 & 0.65 & 0.166 & 0.094 & 2.63 & 38 \\
\hline Community perceives herder turnover as high & 0.25 & 0.40 & 0.389 & 0.342 & 7.89 & 38 \\
\hline GA has cell phone reception & 0.20 & 0.13 & 0.331 & 0.315 & 5.26 & 38 \\
\hline Community believes herders perform well & 0.42 & 0.21 & 0.159 & 0.090 & 0.00 & 38 \\
\hline Cattle carrying capacity at or above regional norm & 0.84 & 0.88 & 0.356 & 0.430 & 0.00 & 38 \\
\hline Proportion of HHs near water point made of mud/clay/brick & 0.06 & 0.03 & 0.206 & 0.116 & 5.26 & 38 \\
\hline Full water point installed & 0.72 & 0.66 & 0.754 & 0.771 & 7.89 & 38 \\
\hline Himba people live in community & 0.25 & 0.36 & 0.454 & 0.381 & 5.26 & 38 \\
\hline Vegetation biomass production ( $1-9 ; 9=$ extremely high production) & 6.88 & 6.89 & 0.854 & 0.840 & 0.00 & 38 \\
\hline Non-cattle livestock density (mean \#/square km) & 1.12 & 1.27 & 0.874 & 0.834 & 0.00 & 38 \\
\hline Cattle density (mean \#/square km) & 7.63 & 8.01 & 0.925 & 0.904 & 0.00 & 38 \\
\hline Annual rainfall deficit (evaporation minus rainfall, in $\mathrm{mm}$ ) & 9.18 & 9.32 & 0.323 & 0.264 & 0.00 & 38 \\
\hline GA area (square $\mathrm{km}$ ) & $7,540.76$ & $6,321.75$ & 0.185 & 0.184 & 0.00 & 38 \\
\hline Ethnolinguistic fractionalization (inverted Herfindahl index) & 0.00 & 0.01 & 0.380 & 0.247 & 0.00 & 38 \\
\hline Number of kraals per grazing area & 25.25 & 22.84 & 0.452 & 0.326 & 0.00 & 38 \\
\hline Proportion plant cover of any kind & 0.84 & 0.85 & 0.750 & 0.636 & 0.00 & 38 \\
\hline \multirow[t]{2}{*}{ Rainfall $(\mathrm{mm})$ in year ending in August 2016} & 353.30 & 355.33 & 0.753 & 0.698 & 0.00 & 38 \\
\hline & \multicolumn{3}{|c|}{$\mathrm{p}$-value, joint $\mathrm{F}$-test: 0.662} & \multicolumn{2}{|c|}{$\mathrm{p}$-value, joint $\mathrm{F}$-test, RI: } & $>0.999$ \\
\hline Panel C: Data collected from herd managers & \multicolumn{6}{|c|}{ Individual-level statistics ( 0 - 1 years after program end) } \\
\hline Herd owner characteristic & Ctrl mean & Treat mean & $p$-val. & RI p-val. & $\%$ missing & N \\
\hline Herd owner age (years) & 54.46 & 54.32 & 0.178 & 0.125 & 1.92 & 1,176 \\
\hline \multirow[t]{2}{*}{ Herd owner completed primary education } & 0.39 & 0.44 & 0.804 & 0.773 & 0.00 & 1,199 \\
\hline & \multicolumn{3}{|c|}{$\mathrm{p}$-value, joint $\mathrm{F}$-test: 0.396} & \multicolumn{2}{|c|}{$\mathrm{p}$-value, joint F-test, RI: } & 0.557 \\
\hline Panel D: Data collected from heads of household & \multicolumn{6}{|c|}{ Individual-level statistics (3 years after program end) } \\
\hline Household characteristic & Ctrl mean & Treat mean & $p$-val. & RI p-val. & $\%$ missing & N \\
\hline Household head is male & 0.80 & 0.79 & 0.783 & 0.784 & 11.04 & 1,209 \\
\hline Household head age (years) & 55.94 & 57.47 & 0.927 & 0.917 & 11.63 & 1,201 \\
\hline Household head education level ( 0 - 9 scale; $0=$ none) & 2.13 & 2.42 & 0.555 & 0.549 & 11.04 & 1,209 \\
\hline Household speaks Rukwangli & 0.17 & 0.19 & 0.120 & 0.125 & 11.04 & 1,209 \\
\hline \multirow[t]{2}{*}{ Household speaks Herero } & 0.30 & 0.27 & 0.920 & 0.910 & 11.04 & 1,209 \\
\hline & \multicolumn{3}{|c|}{$\mathrm{p}$-value, joint F-test: 0.551} & \multicolumn{2}{|c|}{$\mathrm{p}$-value, joint $\mathrm{F}$-test, $\mathrm{RI}$ : } & 0.837 \\
\hline
\end{tabular}

Notes: Treatment and control means are sample means for each subgroup. Each $p$-value is two-tailed and comes from an OLS regression of treatment on the associated balance variable, and indicates the probability of observing a test statistic as extreme or more extreme than the observed test statistic given a true null hypothesis of no treatment effect. In each joint F-test, treatment status is regressed on all the variables in the associated panel of the table. RI p-values are calculated using randomization inference. Standard errors are not clustered in Panels A and B because RIAs are the unit of observation and the unit of randomization, but in Panels $C$ and D are clustered at the RIA level. Each regression in Panels A and B controls for a categorical variable for traditional authority (an administrative unit) that was used for block stratification. Panels $C$ and $D$ include as controls this categorical variable for traditional authority and the RIA-level variables used in re-randomization to ensure balance: vegetation type, number of livestock, livestock density, the log of the number of CBRLM-eligible households, and binary indicators for whether the RIA overlaps with prior intervention areas, has a quality water source, and has a community based organization. RIA-level regressions in Panels $A$ and B do not include this full set of randomization controls to avoid having more predictors than observations. In Panel B, missing values are coded as 0 . In $P$ anels $C$ and $D$, missing values are coded as zeros and regressions include a binary variable equal to 1 for observations in which the balance variable was missing and zero otherwise. Variables without description of units are binary. * indicates that a variable was used for re-randomization to ensure balance. 
Supplementary Table 2: Program participation and attrition

\begin{tabular}{|c|c|c|c|c|c|}
\hline \multicolumn{6}{|l|}{ Panel A: GA-level participation } \\
\hline Dependent variable & Ctrl mean & Treat mean & $p$-val & RI p-val. & N \\
\hline GA formally enrolled in CBRLM & 0.00 & 0.71 & $<0.001$ & $<0.001$ & 123 \\
\hline \multicolumn{6}{|l|}{ Panel B: GA manager-level participation } \\
\hline Dependent variable & Ctrl mean & Treat mean & $p$-val. & RI p-val. & N \\
\hline Manager has heard of CBRLM program & 0.63 & 0.91 & $<0.001$ & 0.002 & 1,234 \\
\hline Manager was offered chance to participate in CBRLM & 0.13 & 0.67 & $<0.001$ & $<0.001$ & 1,208 \\
\hline Manager participated in CBRLM & 0.05 & 0.56 & $<0.001$ & $<0.001$ & 1,222 \\
\hline \multicolumn{6}{|l|}{ Panel C: Attrition } \\
\hline Dependent variable & Ctrl mean & Treat mean & $p$-val. & RI p-val. & N \\
\hline Attrited 0 - 1 years after end (behavioral survey 1 ) & 0.03 & 0.04 & 0.336 & 0.407 & 1,241 \\
\hline Attrited 2 - 3 years after end (behavioral survey 2 ) & 0.08 & 0.07 & 0.476 & 0.608 & 1,348 \\
\hline Attrited 2 - 3 years after end (cattle survey) & 0.12 & 0.09 & 0.193 & 0.294 & 730 \\
\hline Attrited 3 years after end (household survey) & 0.10 & 0.10 & 0.465 & 0.627 & 1,345 \\
\hline \multicolumn{6}{|c|}{$\begin{array}{l}\text { Notes: Each p-value is two-tailed and comes from an OLS regression of a variable measuring participation in the CBRLM program on } \\
\text { treatment status, and indicates the probability of observing a test statistic as extreme or more extreme than the observed test statistic } \\
\text { given a true null hypothesis of no treatment effect. RI p-values are calculated using randomization inference. Standard errors are } \\
\text { clustered at the RIA level, i.e., the unit of randomization. Each regression includes as controls a categorical variable for traditional } \\
\text { authority (an administrative unit) that was used for block stratification and the RIA-level variables used in re-randomization to ensure } \\
\text { balance, which are: vegetation type, number of livestock, livestock density, the log of the number of CBRLM-eligible households, and } \\
\text { binary indicators for whether the RIA overlaps with prior intervention areas, has a quality water source, and has a community based } \\
\text { organization. Variables without description of units are binary. }\end{array}$} \\
\hline
\end{tabular}




\section{Supplementary Table 3: Treatment effect on social and behavioral indices, with inverse probability}

weighting

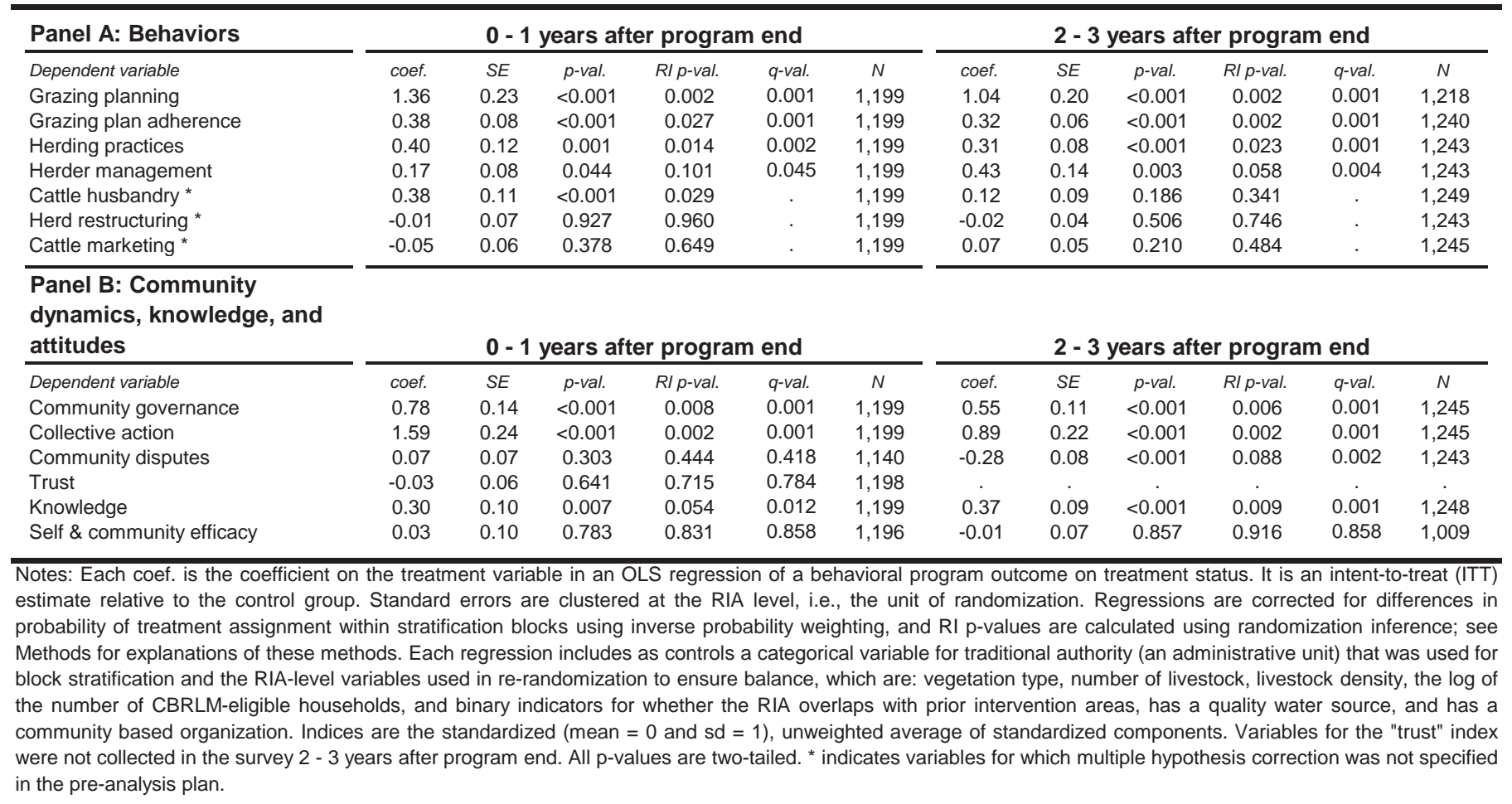


Supplementary Table 4: Treatment effect on rangeland health, cattle productivity and household economics, with inverse probability weighting

\begin{tabular}{|c|c|c|c|c|c|c|}
\hline \multirow{2}{*}{$\begin{array}{l}\text { Panel A: Primary outcomes (indices) } \\
\text { Dependent variable }\end{array}$} & \multicolumn{6}{|c|}{2 - 3 years after program end } \\
\hline & coef. & $S E$ & $p$-val. & RI p-val. & $q$-val. & N \\
\hline Herd value & 0.01 & 0.11 & 0.955 & 0.969 & 0.955 & 653 \\
\hline Herd productivity & 0.03 & 0.08 & 0.748 & 0.874 & 0.935 & 1,285 \\
\hline Weekly household income & 0.10 & 0.07 & 0.163 & 0.353 & 0.408 & 1,210 \\
\hline W eekly household expenditure & 0.03 & 0.05 & 0.567 & 0.506 & 0.935 & 1,210 \\
\hline Household livestock wealth & -0.07 & 0.05 & 0.121 & 0.423 & 0.408 & 1,210 \\
\hline Panel B: Secondary outcomes (indices) & \multicolumn{6}{|c|}{2 - 3 years after program end } \\
\hline Dependent variable & coef. & $S E$ & $p$-val. & RI p-val. & $q$-val. & N \\
\hline Herd structure & -0.01 & 0.07 & 0.875 & 0.932 & 0.945 & 653 \\
\hline Time use & 0.04 & 0.10 & 0.699 & 0.832 & 0.945 & 1,210 \\
\hline Resilience & -0.03 & 0.07 & 0.642 & 0.806 & 0.945 & 1,210 \\
\hline Female empowerment & -0.02 & 0.08 & 0.804 & 0.849 & 0.945 & 1,210 \\
\hline Meat and dairy consumption & 0.00 & 0.04 & 0.945 & 0.965 & 0.945 & 1,210 \\
\hline Panel C: Rangeland outcomes (standardized) & \multicolumn{6}{|c|}{2 years after program end } \\
\hline Dependent variable & coef. & SE & p-val. & RI p-val. & $q$-val. & $N$ \\
\hline \multicolumn{7}{|l|}{ Erosion: } \\
\hline Wet season site erosion ( $1=$ no erosion, $0=$ erosion $)$ & -0.09 & 0.10 & 0.360 & 0.646 & . & 972 \\
\hline \multicolumn{7}{|l|}{ Ground cover: } \\
\hline Wet season protected soil surface (\%, logit-transformed) & -0.21 & 0.11 & 0.061 & 0.184 & . & 972 \\
\hline Wet season plant litter cover (\%, logit-transformed) & -0.18 & 0.08 & 0.029 & 0.191 & . & 972 \\
\hline Dry season plant litter cover (\%, logit-transformed) & -0.08 & 0.11 & 0.466 & 0.729 & . & 885 \\
\hline \multicolumn{7}{|l|}{ Herbaceous cover: } \\
\hline Wet season herbaceous canopy cover $(\%$, logit-transformed $)$ & -0.23 & 0.13 & 0.092 & 0.303 & . & 972 \\
\hline Dry season herbaceous canopy cover (\%, logit-transformed) & -0.23 & 0.07 & 0.002 & 0.076 & . & 885 \\
\hline Wet season fresh plant biomass (kg/ha, log-transformed) & -0.23 & 0.15 & 0.142 & 0.326 & . & 966 \\
\hline Dry season fresh plant biomass (kg/ha, log-transformed) & -0.21 & 0.07 & 0.004 & 0.116 & . & 792 \\
\hline \multicolumn{7}{|l|}{ Relative canopy cover of perennial and annual grasses: } \\
\hline Wet season perennial to annual canopy ratio (log-transformed) & -0.06 & 0.07 & 0.389 & 0.710 & . & 972 \\
\hline \multicolumn{7}{|l|}{ Relative canopy cover of grasses and forbs: } \\
\hline Wet season grass to forb canopy ratio (log-transformed) & -0.21 & 0.10 & 0.037 & 0.289 & . & 972 \\
\hline \multicolumn{7}{|l|}{ Weeds: } \\
\hline Wet season $\%$ of shrubs that are not stinkbush $(\%$, logit-transformed) & 0.00 & 0.08 & 0.980 & 0.993 & . & 870 \\
\hline Wet season grass to Aristida canopy cover ratio (log-transformed) * & -0.12 & 0.13 & 0.358 & 0.554 & . & 752 \\
\hline \multicolumn{7}{|l|}{ Woody vegetation: } \\
\hline Wet season shrub canopy cover (\%, logit-transformed) & 0.02 & 0.15 & 0.866 & 0.917 & . & 972 \\
\hline Dry season shrub canopy cover (\%, logit-transformed) & -0.06 & 0.15 & 0.704 & 0.822 & . & 885 \\
\hline \multicolumn{7}{|c|}{$\begin{array}{l}\text { Notes: Each coef. is the coefficient on the treatment variable in an OLS regression of a program outcome on treatment status. It is an intent-to-treat (ITT) estimate relative to } \\
\text { the control group. Data in Panels A and B were collected using surveys of heads of household and cattle managers, and data in Panel C were collected as described in the } \\
\text { Methods. Standard errors are clustered at the RIA level, i.e., the unit of randomization. Regressions include corrections for differences in probability of treatment assignment } \\
\text { within stratification blocks using inverse probability weighting, and RI p-values were calculated using randomization inference; see Materials and Methods for explanations of } \\
\text { these methods. Each regression includes as controls a categorical variable for traditional authority (an administrative unit) that was used for block stratification and the RIA- }\end{array}$} \\
\hline
\end{tabular}


Supplementary Table 5: Treatment effect heterogeneity by rainfall, social outcomes and cattle productivity

Panel A: Social and Behavioral

Outcomes (0 - 1 years)

\begin{tabular}{ccc}
\multicolumn{3}{c}{ Treatment } \\
\hline coef.1 & $S E$ & $p$-val. \\
1.70 & 0.32 & $<0.001$ \\
0.42 & 0.08 & $<0.001$ \\
0.36 & 0.12 & 0.004 \\
0.17 & 0.09 & 0.067 \\
0.51 & 0.12 & $<0.001$ \\
0.07 & 0.11 & 0.503 \\
-0.01 & 0.08 & 0.920 \\
0.92 & 0.19 & $<0.001$ \\
1.65 & 0.27 & $<0.001$ \\
0.13 & 0.07 & 0.065 \\
0.04 & 0.07 & 0.595 \\
0.51 & 0.13 & $<0.001$ \\
0.04 & 0.12 & 0.725 \\
& &
\end{tabular}

\begin{tabular}{ccc}
\multicolumn{3}{c}{ Low rainfall indicator } \\
\hline coef.2 & SE & $p$-val. \\
0.07 & 0.32 & 0.826 \\
0.18 & 0.13 & 0.174 \\
0.12 & 0.23 & 0.596 \\
-0.01 & 0.19 & 0.944 \\
0.14 & 0.16 & 0.396 \\
0.03 & 0.12 & 0.795 \\
0.15 & 0.14 & 0.301 \\
-0.02 & 0.24 & 0.943 \\
0.41 & 0.31 & 0.190 \\
0.01 & 0.12 & 0.912 \\
-0.01 & 0.14 & 0.927 \\
0.42 & 0.18 & 0.029 \\
0.02 & 0.19 & 0.930
\end{tabular}

\begin{tabular}{llll}
\multicolumn{4}{l}{ Treatment x low rainfall indicator } \\
\hline coef.3 SE & $p$-val. & RI $p$-val.
\end{tabular}

Dependent variable

a)

Grazing planning

Grazing plan adherence

Herding practices

Herder management

Cattle husbandry

Herd restructuring

Cattle marketing

Community governance

Collective action

Community disputes

Trust

Knowledge

Self \& community efficacy

\begin{tabular}{ccl}
\hline \multicolumn{3}{c}{ Treatment } \\
\hline coef.1 & SE & $p$-val. \\
1.53 & 0.26 & $<0.001$ \\
0.53 & 0.09 & $<0.001$ \\
0.46 & 0.12 & $<0.001$ \\
0.47 & 0.14 & 0.002 \\
0.06 & 0.10 & 0.536 \\
-0.01 & 0.06 & 0.822 \\
0.01 & 0.08 & 0.861 \\
0.63 & 0.14 & $<0.001$ \\
1.07 & 0.20 & $<0.001$ \\
-0.39 & 0.11 & 0.001 \\
0.43 & 0.10 & $<0.001$ \\
0.09 & 0.11 & 0.430
\end{tabular}

Outcomes ( 2 - 3 years)

Dependent variable
Grazing planning
Grazing plan adherence
Herding practices
Herder management
Cattle husbandry
Herd restructuring
Cattle marketing
Community governance
Collective action
Community disputes
Knowledge
Self \& community efficacy

Panel C: Physical outcomes

(2 - 3 years)

\begin{tabular}{ccc}
\hline \multicolumn{3}{c}{ Treatment } \\
\hline coef.1 & SE & $p$-val. \\
0.12 & 0.11 & 0.271 \\
-0.15 & 0.13 & 0.274 \\
58.22 & 38.66 & 0.141 \\
-33.96 & 74.49 & 0.651 \\
-0.03 & 0.06 & 0.624 \\
-0.12 & 0.09 & 0.212 \\
0.27 & 0.16 & 0.089 \\
-0.17 & 0.09 & 0.076 \\
0.06 & 0.13 & 0.666 \\
0.03 & 0.07 & 0.662
\end{tabular}

Low rainfall indicator

coef.2 SE $p$-val.

$\begin{array}{lll}0.80 & 0.27 & 0.006\end{array}$

$\begin{array}{lll}0.21 & 0.15 & 0.173\end{array}$

$\begin{array}{lll}0.32 & 0.13 & 0.017\end{array}$

$\begin{array}{lll}0.33 & 0.15 & 0.035\end{array}$

$\begin{array}{lll}0.04 & 0.11 & 0.745\end{array}$

$\begin{array}{lll}0.21 & 0.08 & 0.014\end{array}$

$\begin{array}{lll}-0.17 & 0.10 & 0.096\end{array}$

$\begin{array}{lll}0.16 & 0.18 & 0.385\end{array}$

$\begin{array}{lll}0.37 & 0.29 & 0.198\end{array}$

$\begin{array}{lll}0.18 & 0.24 & 0.462\end{array}$

$\begin{array}{lll}-0.09 & 0.14 & 0.548\end{array}$

$\begin{array}{lll}0.23 & 0.21 & 0.272\end{array}$

Low rainfall indicator

coef.2 SE $p$-val.

$\begin{array}{lll}-0.18 & 0.18 & 0.318\end{array}$

$\begin{array}{lll}-0.22 & 0.21 & 0.308\end{array}$

$\begin{array}{lll}40.78 & 52.69 & 0.444\end{array}$

$\begin{array}{lll}-23.77 & 113.83 & 0.836\end{array}$

$\begin{array}{lll}-0.03 & 0.16 & 0.841\end{array}$

$\begin{array}{lll}-0.31 & 0.15 & 0.044\end{array}$

$\begin{array}{lll}0.62 & 0.29 & 0.037\end{array}$

$\begin{array}{lll}0.00 & 0.13 & 0.969\end{array}$

$\begin{array}{lll}0.08 & 0.14 & 0.591\end{array}$

$\begin{array}{lll}-0.17 & 0.12 & 0.144\end{array}$ $\begin{array}{lllll}0.75 & 0.42 & 0.086 & 0.409 & 1,199\end{array}$

$\begin{array}{lllll}-0.14 & 0.15 & 0.331 & 0.560 & 1,199\end{array}$

$\begin{array}{lllll}0.02 & 0.18 & 0.928 & 0.954 & 1,199\end{array}$

$\begin{array}{lllll}-0.04 & 0.13 & 0.772 & 0.869 & 1,199\end{array}$

$\begin{array}{lllll}-0.27 & 0.17 & 0.113 & 0.470 & 1,199\end{array}$

$\begin{array}{lllll}-0.11 & 0.13 & 0.401 & 0.579 & 1,199\end{array}$

$\begin{array}{lllll}-0.09 & 0.11 & 0.439 & 0.551 & 1,199\end{array}$

$\begin{array}{lllll}-0.32 & 0.25 & 0.207 & 0.536 & 1,199\end{array}$

$\begin{array}{lllll}-0.25 & 0.45 & 0.585 & 0.771 & 1,199\end{array}$

$\begin{array}{lllll}-0.10 & 0.12 & 0.406 & 0.656 & 1,140\end{array}$

$\begin{array}{lllll}-0.11 & 0.11 & 0.337 & 0.548 & 1,198\end{array}$

$\begin{array}{lllll}-0.39 & 0.17 & 0.026 & 0.226 & 1,199\end{array}$

$\begin{array}{lllll}-0.01 & 0.15 & 0.960 & 0.981 & 1,196\end{array}$

Time use

Resilience
Female empowerment

Food consumption

\section{Treatment $\mathrm{x}$ low rainfall indicator}

coef.3 SE p-val. RI p-val.

$\begin{array}{ccccc}-1.02 & \text { SE } & p \text {-val. } & \text { Rl p-val. } & N \\ & 0.30 & 0.002 & 0.181 & 1,218\end{array}$

$<0.001-0.156$

$\begin{array}{lllll}-0.40 & 0.10 & <0.001 & 0.156 & 1,240\end{array}$

$\begin{array}{lllll}-0.32 & 0.16 & 0.057 & 0.214 & 1,243\end{array}$

$\begin{array}{lllll}-0.10 & 0.20 & 0.641 & 0.834 & 1,243\end{array}$

$\begin{array}{lllll}0.11 & 0.15 & 0.461 & 0.695 & 1,249\end{array}$

$\begin{array}{lllll}-0.02 & 0.08 & 0.847 & 0.915 & 1,243\end{array}$

$\begin{array}{lllll}0.12 & 0.12 & 0.343 & 0.606 & 1,245\end{array}$

$\begin{array}{lllll}-0.17 & 0.20 & 0.407 & 0.683 & 1,245\end{array}$

$\begin{array}{lllll}-0.37 & 0.40 & 0.353 & 0.602 & 1,245\end{array}$

$\begin{array}{lllll}0.19 & 0.13 & 0.149 & 0.437 & 1,243\end{array}$

$\begin{array}{lllll}-0.16 & 0.15 & 0.297 & 0.538 & 1,248\end{array}$

$\begin{array}{lllll}-0.20 & 0.18 & 0.298 & 0.473 & 1,009\end{array}$

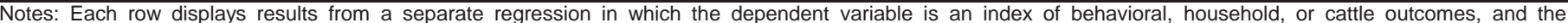

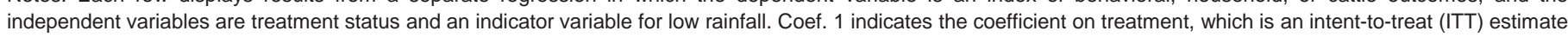

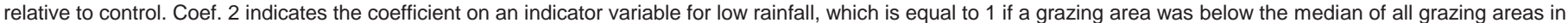

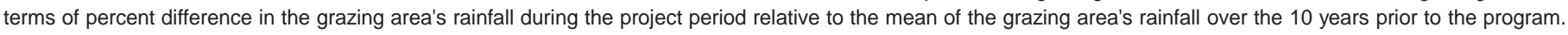

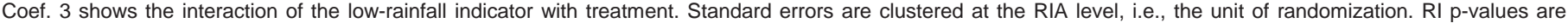

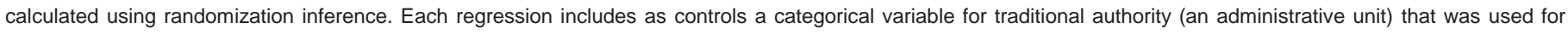

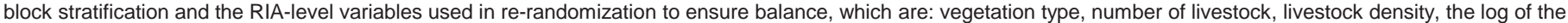

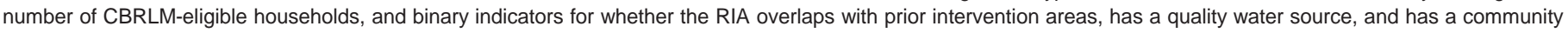

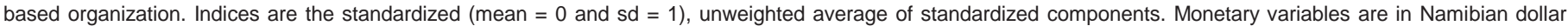

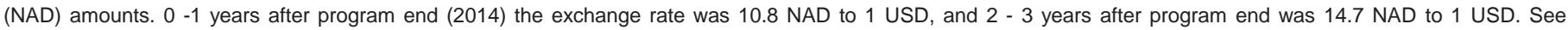
Materials and Methods and the Supplementary Materials for additional details. All p-values are two-tailed. 